\title{
Lower Ocean Crust beneath Slow-Spreading Ridges: a Combined Oxygen Isotopic and Elemental in-situ Study on Hole 735B Gabbros
}

\author{
Dissertation \\ zur Erlangung des Doktorgrades \\ der Mathematisch-Naturwissenschaftlichen Fakultäten \\ der Georg-August-Universität zu Göttingen
}

\author{
vorgelegt von \\ Yongjun Gao \\ aus HeBei, VR China
}

Göttingen 2004 
D7

Referent:

Prof. Dr. Jochen Hoefs

Korreferent:

Prof. Dr. Gerhard Wörner

PD Dr. Jonathan E. Snow 


\section{ACKNOWLEDGEMENTS}

First of all I would like to express my sincere thanks to Prof. Dr. Jochen Hoefs, not only for his excellent supervising and full support on my Ph.D academic work but also for his father like care on my living here during the last 3 and half years. This work could not have been accomplished in this form without the scientific freedom he allowed me throughout the work. I will always remember that and be grateful for it. I would like to give my thanks to PD Dr. Jonathan E. Snow for his great help on my work. I will never forget his encouragement and fully support which help me to pass through the hardest time of this period. I also like to thank Prof. Dr. Albrecht W. Hofmann for the support he has given me to work in the geochemistry department of Max-Planck Institute für Chemie and the financial support to take part in several fruitful international conferences. I would like to thank Prof. Dr. Gerhard Wörner for his interest in my work and for taking on the function as a co-advisor.

Special thanks go to Dr. Eric Hellebrand. He has given me a great help on ion probe and has been always patient during our discussions.

Dr. Klaus Simon is thanked for invaluable helps concerning the use of ICP-MS and computer programs.

Mr. R. Przybilla is greatly appreciated for their help with the UV-laser ablation method of the in-situ oxygen isotope analysis. I kindly acknowledge Dr. A. Kronz and Ms. A. von de Handt for their help during electron microprobe measurements.

Dr. Yilin Xiao is specially thanked for his great help both on academic work and on my life in Goettingen.

Dr. X. Chen is thanked for the help and discussion on the mathematics related to diffusion modeling.

I would also like to thank all my colleagues from the Geochemisches Institut for their contribution to having a pleasant and productive time during my stay.

Last, but never least, I would like to thank my parents, who enabled me the education in China, and my wife Hua who has accompanied and supported me during my stay in Germany. 
Chapter 1 INTRODUCTION .................................................... 1

Chapter 2 GEOLOGICAL SETTING AND SAMPLING ............... 7

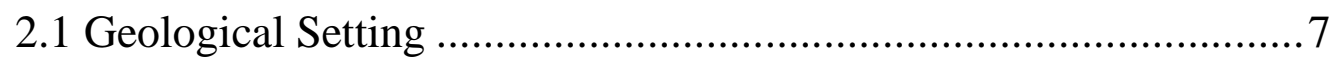

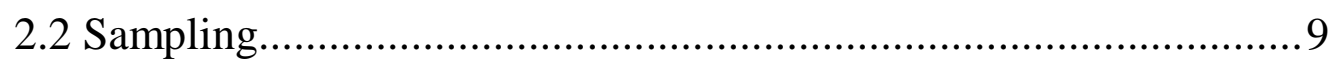

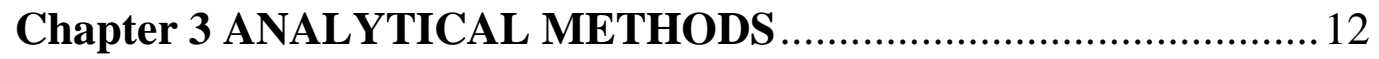

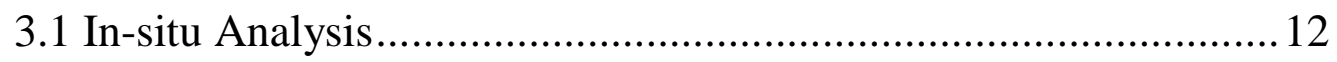

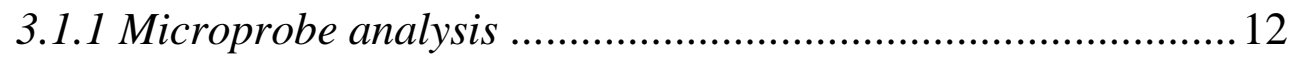

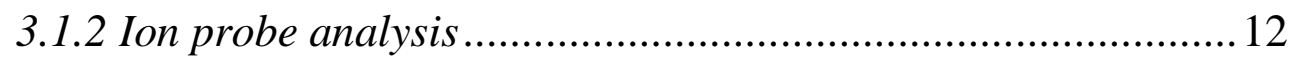

3.1.3 UV laser in-situ oxygen isotope analysis ............................... 14

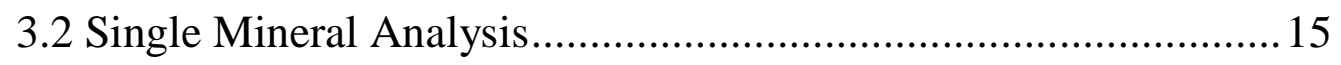

3.3 Whole Rock Analysis ............................................................. 15

Chapter 4 MINERAL GEOCHEMISTRY …….............................. 16

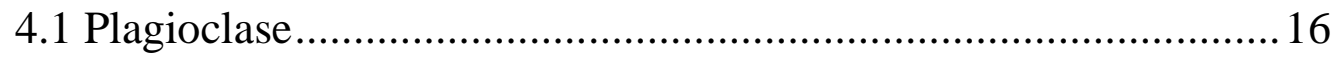

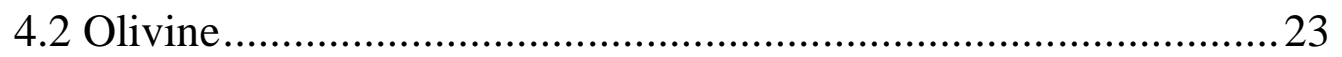

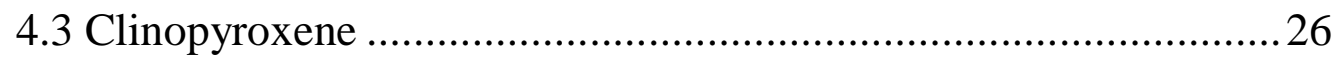

Chapter 5 OXYGEN ISOTOPE GEOCHEMISTRY …...................40

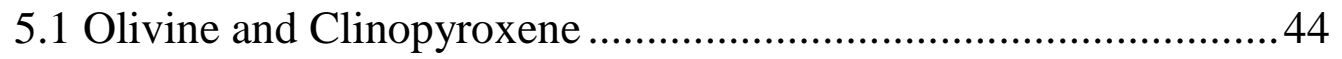

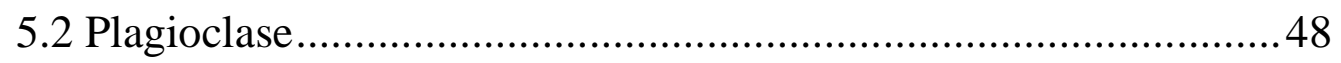

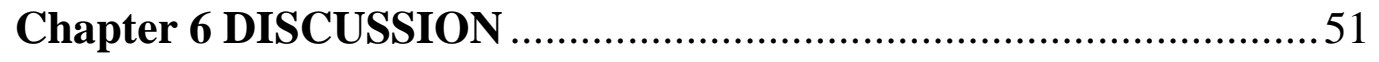

6.1 Chemical Evolution of Hole 735B Gabbros .................................51

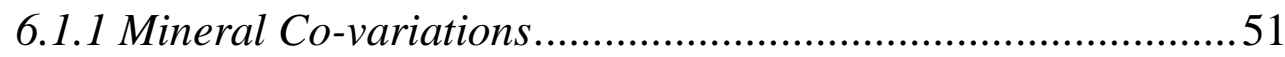


6.1.2 Down-Hole Chemical Variations ...........................................52

6.2 Evidence on Late-Stage Melt Migrations .....................................54

6.2.1 Bulk versus Mineral Composition ..........................................54

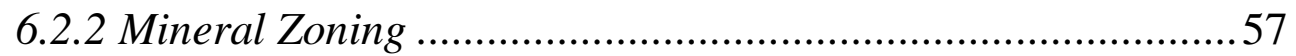

6.3 Oxygen Isotope Composition of Hole 735B Gabbros ....................77

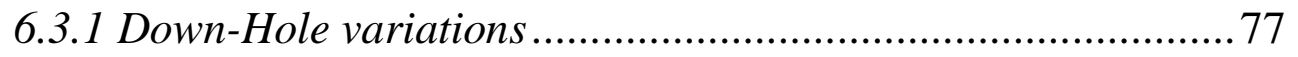

6.3.2 Mechanism of Oxygen Isotope Exchange …….......................79

6.3.3 Oxygen Isotope Composition of the Lower Oceanic Crust-The

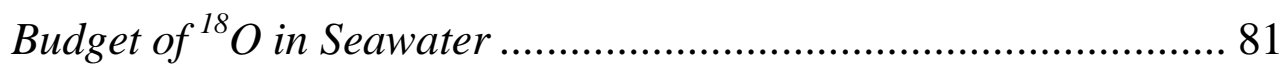

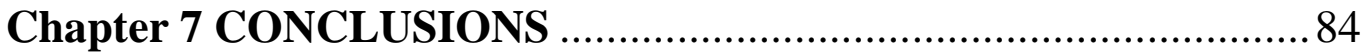

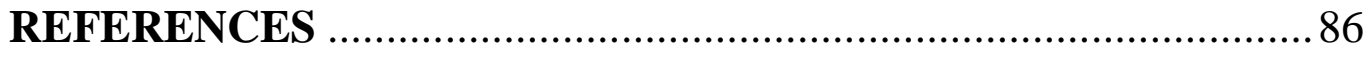

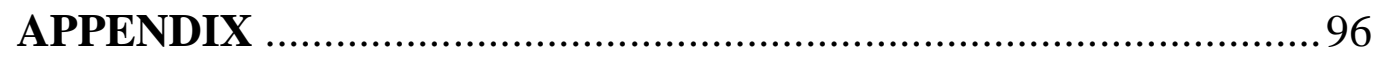




\section{Chapter 1 INTRODUCTION}

The oceanic crust, which covers about $70 \%$ of the Earth's surface, is the net product of magmatic, tectonic, and hydrothermal processes taking place along MidOcean-Ridges. Although this concept is well conceived, important details of these processes and the structure and composition of bulk ocean crust remains poorly understood because of the inaccessibility of lower ocean crust.

Although "Hess crust" of which ocean crust is mainly composed by serpentinite represents a very important structure of ocean crust (Snow, 1995), in general 'layercake' model the lower ocean crust is believed to consist of gabbros overlying mantle peridotites while underlying pillow basalts and sheeted dykes (Cann, 1970; Vine and Moores, 1972). Knowledge of the actual composition of lower ocean crust is not only important to understand the process of oceanic crust formation but also important to constrain fundamental geochemical models. For instance, the mechanism of igneous differentiation, the interactions between rocks and circulating fluids that supply hightemperature hydrothermal vents, and the mechanism of melt aggregation within the crust.

Before 1987, 17 DSDP (Deep Sea Drilling Project) and ODP (Ocean Drilling Program) legs had been conducted to drill ocean crust at spreading ridges starting at the top in basalts (Natland et al., 2002). However, due to the technical difficulties of drilling, none of them had reached the lower crust, even Hole 504B near the Costa Rica Rift only penetrated about 1800 meters of pillow basalts and dikes.

Fortunately, the opportunity to study an in-situ section of lower ocean crust formed at slow-spreading ridges was provided by ODP Hole 735B on the Southwest Indian Ridge, where lower ocean crust is exposed on the sea floor (Dick et al., 1991a). 
Hole 735B, was first drilled during Leg 118 in 1987 (Dick et al., 1991b) and continued during Leg 176 ten years later in 1997 (Dick et al., 1999; Dick et al., 2000) to a depth of 1508 mbsf (meters below the sea floor). Crust formed at the ultra-slowspreading Southwest Indian Ridge (SWIR) is only about $4 \mathrm{~km}$ (Bown and White, 1994), so given the assumption that the upper $1.5-2 \mathrm{~km}$ of this crust is composed of pillow lavas and dikes it is believed that the top of this $1.5 \mathrm{~km}$ core is near the dikegabbro transition and its bottom is close to the crust-mantle boundary (Dick et al., 2000). This is in consistent with the fact that basaltic dykes were found at the top 200 meters of this Hole (Dick et al., 1991a).

The composition and structure of the lower oceanic crust at Site 735B seem to be different in many respects from what has been learned from ophiolites for the crust formed at fast-spreading ocean ridges (Dick et al., 2000; Natland and Dick, 2001; Natland and Dick, 2002). Available data on downhole variation of both whole rock and mineral compositions for Hole 735B gabbro have shown that the formation of this gabbroic crust requires processes of multiple melt injection on highly localized scales and a widespread permeable flow of late stage melts through these intrusions (Dick et al., 2000; Coogan et al., 2000a; Coogan et al., 2001; Natland and Dick, 2001; Niu et al., 2002; Natland and Dick, 2002; Dick et al., 2002). However, so far, evidence for this process has come mainly from whole rock and bulk mineral data for gabbros, so nearly no constraint on the thermodynamics of melt transportation (such as time scale of multiple melt intrusions) and the mechanism of interaction between crystals and late stage melt (diffusive or dissolution-precipitation) can be derived from these studies.

Seawater circulation at or near the axis of Mid-Ocean-Ridges plays an important role on the modification of isotopic and chemical composition of the oceanic crust 
which is finally recycled into the mantle at subduction zones. At the same time, the interaction between seawater and oceanic crust is also critical for the evolution of the isotopic and chemical composition of seawater itself. Although it has been shown that basalt-seawater reactions in the upper $200-300 \mathrm{~m}$ of ocean crust have the largest effects on the net chemical and isotopic fluxes between seawater and crust, crustseawater reactions in the lower ocean crust are also critical for global geochemical budgets (Eiler et al., 2000; Bach et al., 2001).

In the past years, much effort has been made to characterize the effects of seawater interaction with the lower crust. This includes studies of dredged samples, depth profile studies of fossil oceanic crust (ophiolite complexes), and modern oceanic crust exposed on ocean floor (Stakes and O'Neil, 1982; Ito and Clayton, 1983; Kempton et al., 1991; Bach and Humphris, 1999; Hart et al., 1999; Bach et al., 2001). It has been shown that the alteration styles in metagabbros are much more complex and variable than observed in pillow basalts, and all grades of alteration may be superimposed in a single hand specimen. The patterns of alteration tend to be localized around individual mineral grains and strongly controlled by the original mineralogy (Stakes and O'Neil, 1982). Compared with other elemental and isotopic indexes (such as ${ }^{87} \mathrm{Sr} /{ }^{86} \mathrm{Sr}$ ), oxygen isotopic composition is very sensitive to both high- and low-temperature alteration even before other geochemical effects have been registered.

The ${ }^{18} \mathrm{O}$ balance of enrichment and depletion between upper and lower oceanic crust is critical for the history of seawater (Gregory and Taylor, 1981a) and the uniformity of the oxygen isotopic values of MORB (Eiler et al., 1996; Eiler et al., 1997; Eiler et al., 1998; Eiler et al., 2000; Eiler, 2001). However there is still debate about the depth of seawater penetration into the oceanic crust and the net balance 
between the upper and lower oceanic crust for its elemental and oxygen isotopic composition.

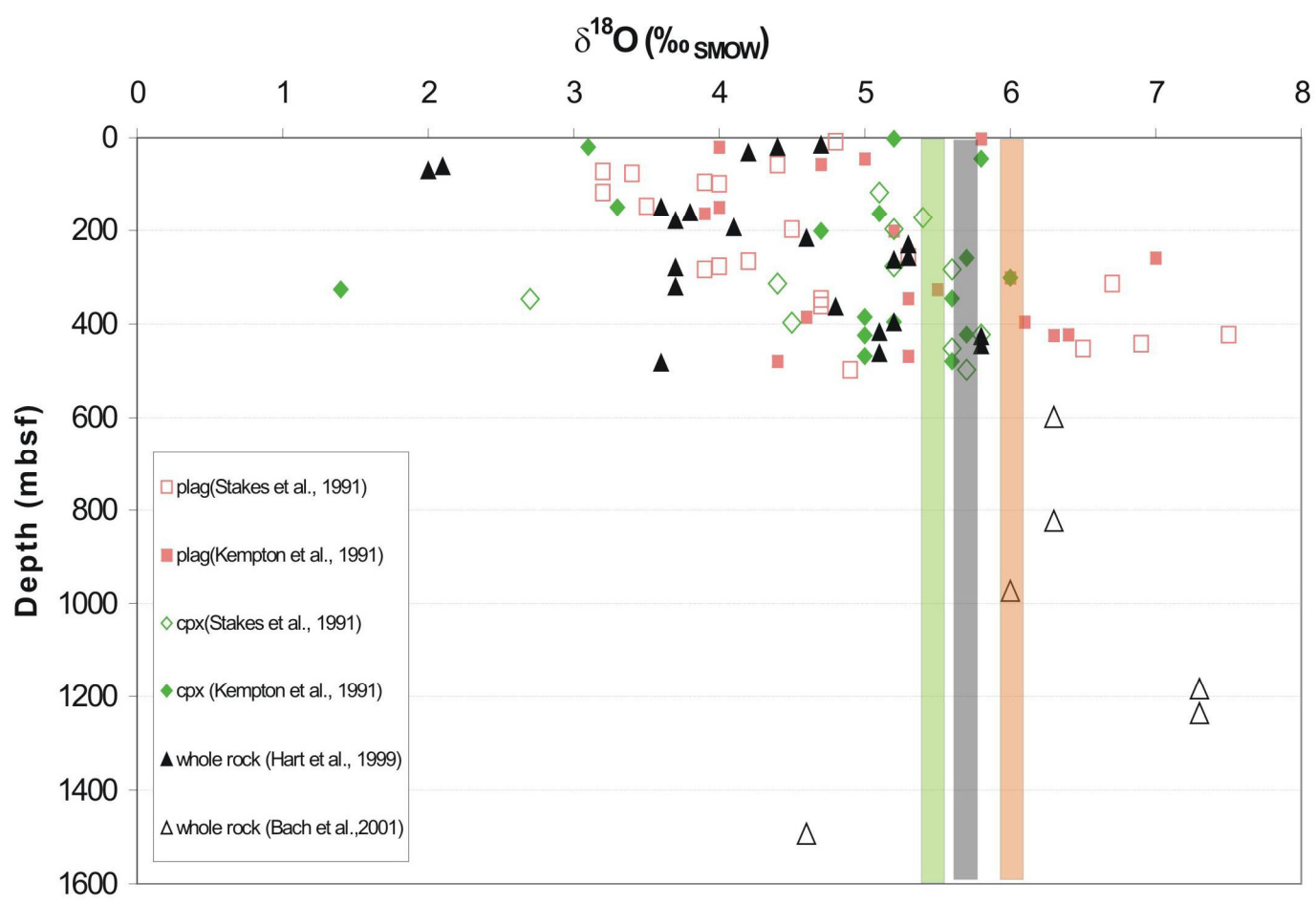

Fig. 1.1 Summary of available data on mineral and whole-rock $\delta^{18} \mathrm{O}$ values in Hole 735B gabbro. Shadowed rectangulars with green, grey, and dark orange colors represent the mantle reference value of clinopyrocene, bulk composition, and plagioclase respectively.

Several studies on the plutonic section of Hole 735B have shown that seawater had interacted with much of the gabbro section at both high and low temperature (Kempton et al., 1991; Hart et al., 1999; Bach et al., 2001). In contrast to the "normal" oceanic crust, where permeability and integrated water-to-rock ratios decrease and peak alteration temperature increase with depth, the gabbroic section of Hole 735B has a reversed profile for its oxygen isotopic composition (Bach et al., 2001). However, so far most of the oxygen isotope data are from the upper 500 meters of this gabbroic section, only a few bulk composition data points are from the lower 1000 
meters (Figure 1.1). Obviously, more data are necessary to draw any definite conclusion.

Compared with whole rock analysis, in-situ oxygen isotope investigation of coexisting minerals in submarine gabbro can reveal more information on its igneous petrology, cooling and alteration history, such as the cooling rate and water-rock ratio at which the alteration occurred (Ito and Clayton, 1983). Whole-rock composition data have inherent problems in distinguishing primary source variation from secondary hydrothermal processes. These data integrate the influence of mineral mode and mineral chemistry as well as the effects of alteration. It has been shown that events in the crystallization of plutonic rocks such as the addition of a major new injection or a major fault discontinuity are only visible in cryptic variations of mineral chemistry (Dick et al., 2002). Due to the complexity of growth patterns of minerals, such as intergrowth and exsolution lamellae on sub-millimeter scale, even analysis of separated minerals will not give the same information as in-situ analysis to investigate the grain scale heterogeneity of alteration. Thus studies of mineral chemistry are the best way to investigate the melt evolution during crystallization of plutonic rocks. Zoning in compositional minerals of lower crustal rocks provides important evidence on postcumulus processes, late-stage melt migration and melt-crystal reaction (Coogan et al., 2000a; Coogan et al., 2000b; Dick et al., 2002; Van Orman et al., 2002a). Investigation on zoned compositional profiles in minerals controlled by diffusion processes will also be able to give important constraints on the thermodynamics of melt transportation and the mechanism of interaction between crystals and late stage melt (Tracy, 1982; Loomis, 1983; Van Orman et al., 2002a; Hawkesworth et al., 2004). 
As observed in Hole 735B gabbro, all grades of alteration usually are superimposed in a single specimen and the patterns of alteration tend to be localized on a grain scale. For this reason I have made a combined in-situ study of Leg176 gabbros from Hole 735B by UV-laser oxygen isotope microprobe and ion probe (SIMS) together with electron microprobe for the oxygen isotopic and elemental compositions of their constituent minerals.

The main scientific goals are:

(1) To characterize the emplacement and crystallization of Hole 735B (Leg 176 gabbros).

(2) To understand the evolution of intercumulus liquids (trapped or migrating upward) and its role in the formation of lower ocean crust and MORB.

(3) To constrain an oxygen isotope depth profile of lower ocean crust.

(4) To determine the nature and extent of sea water penetration and circulation in the lower crust under slow-spreading ridges and its significance to the buffering of sea water oxygen isotope composition. 


\section{Chapter 2 GEOLOGICAL SETTING AND SAMPLING}

\subsection{Geological Setting}

The SW Indian Ridge is a highly segmented ridge representing nearly the ultraslow-spreading end-member for crustal accretion in the oceans (Dick et al., 2000). North of the Atlantis Bank, the SW Indian Ridge is spreading asymmetrically 0.6 $\mathrm{cm} / \mathrm{yr}$ northward and $1 \mathrm{~cm} / \mathrm{yr}$ southward (Dick et al., 1991b). Site 735 is located on a shallow platform in about $700 \mathrm{~m}$ water depth on the east rim of the Atlantis II Transform. This platform, about $9 \mathrm{~km}$ long in a north-south direction and $4 \mathrm{~km}$ wide, is one of a series of uplifted blocks that are connected by saddles to form a long, linear ridge parallel to the Atlantis II Transform (Figure 2.1).

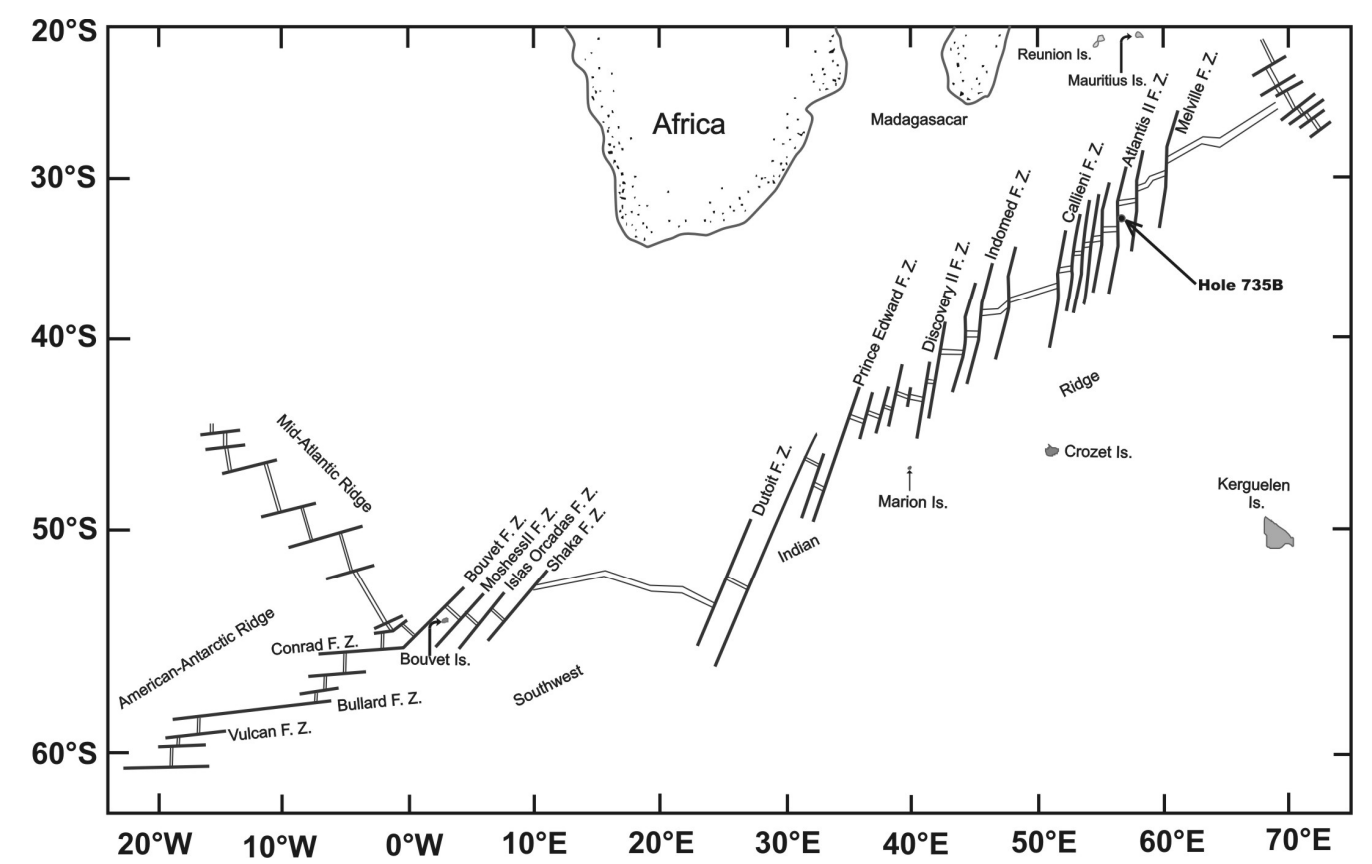

Fig. 2.1 Site location of ODP (Ocean Drilling Program) Hole 735B.

The site is located approximately $93 \mathrm{~km}$ south of the present-day axis of the SW Indian Ridge and $18.4 \mathrm{~km}$ from the inferred axis of transform faulting on the floor of 
the Atlantis II Fracture zone. Given its position, the relatively constant spreading direction over the last 11 m.y. and the strike of the local foliation, the Atlantis Bank gabbros must have formed beneath the median valley of the Southwest Indian Ridge, 15-19 km from the ridge-transform intersection about 11 million years ago. These gabbros were then subsequently uplifted 5 to $6 \mathrm{~km}$ as a giant horst block into the transverse ridge. Unroofing of this crustal section occurred on detachment faults when the upper crust section was periodically welded to the cold lithospheric plate at the ridge-transform intersection. The unroofed section was uplifted into the rift mountains along normal faults, reaching sea level within a few million years. Thus, unlike some rocks dredged from fracture-zone walls, those drilled in Hole 735B formed well away from the transform plate boundary beneath the rift-valley floor and can be regarded as representing what some have called "normal igneous ocean crust", even if subsequent uplift processes were extreme (Dick et al., 1991a).

A variety of igneous and meta-igneous rocks were recovered at site 735 . These include olivine bearing and olivine gabbros, two pyroxene gabbros, iron-titanium oxide rich gabbros, troctolites, microgabbros and rare basalts and trondjhemites. However as shown in Figure 2.2, the olivine gabbro suite, including olivine gabbros, troctolitic gabbros and troctolites, comprise about $76 \%$ of this section, and more differentiated gabbros, oxide gabbros, together with felsic veins comprise the remaining $24 \%$ of Hole $735 \mathrm{~B}$ gabbro (Natland and Dick, 2002). As an important nature, both high temperature deformation and low-temperature fault are common in Hole 735B, however most of them are located at the upper part of this hole (Figure 2.2). 


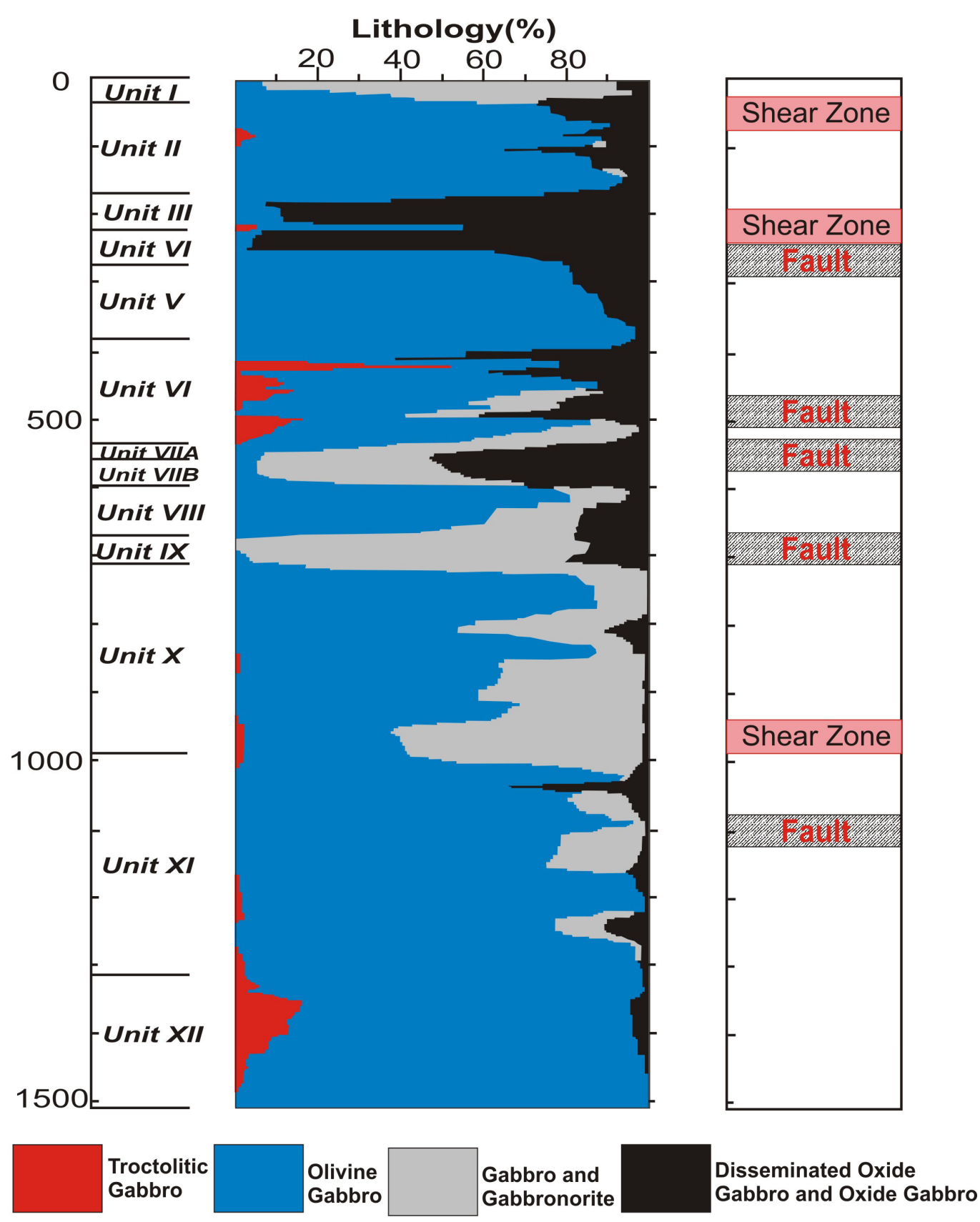

Fig. 2.2 Summary of lithostratigraphy and deformation of Hole 735B.

\subsection{Sampling}

Table 2.1 lists in detail the samples investigated by various methods at the University of Goettingen and the Max- Planck Institute for Chemistry in Mainz. A total of 24 samples were selected through the whole section of Leg 176 gabbro with the purpose to get an evenly distributed depth profile and to incorporate all of the 
major lithologies. Among them 21 samples were prepared in the form of polished thick-sections for in-situ oxygen isotope microprobe and electron microprobe analysis for their compositional minerals and five of them were further investigated by in-situ ion probe for mineral trace elements compositions, bulk trace element compositions of these five samples were also investigated with ELAN DRC II ICP-MS at University of Goettingen. Oxygen isotope compositions of picked plagioclase crystals from 13 samples out of 24 gabbros were analyzed with the conventional method according to the technique of (Clayton and Mayeda, 1963). Bulk compositions for major element and oxygen isotopes of these gabbros and 3 saw-mud were obtained by Snow (2002), while the bulk trace element composition of these 3 saw-mud were analyzed with ELAN DRC II ICP-MS.

Saw-mud was used as an integrator of the bulk composition of the hole, which was subsampled from the homogenized sediment trap of the saw table. On board the JOIDES Resolution, cores were cut in half using rock saw. The mud produced by sawing was trapped in a settling basin with a volume of about 96 liters. Each time the trap became full (3 times), it was homogenized. Approximately 4 liters of this mud were suspended repeatedly in deionized water to remove the clay fraction and any water soluble contaminants. Larger lithic and sand-sized fragments were removed by decanting the still suspended silt fraction into a fresh container. By rinsing away the clay fraction, it was hoped that the bentonite from driller in the samples would also be removed. 


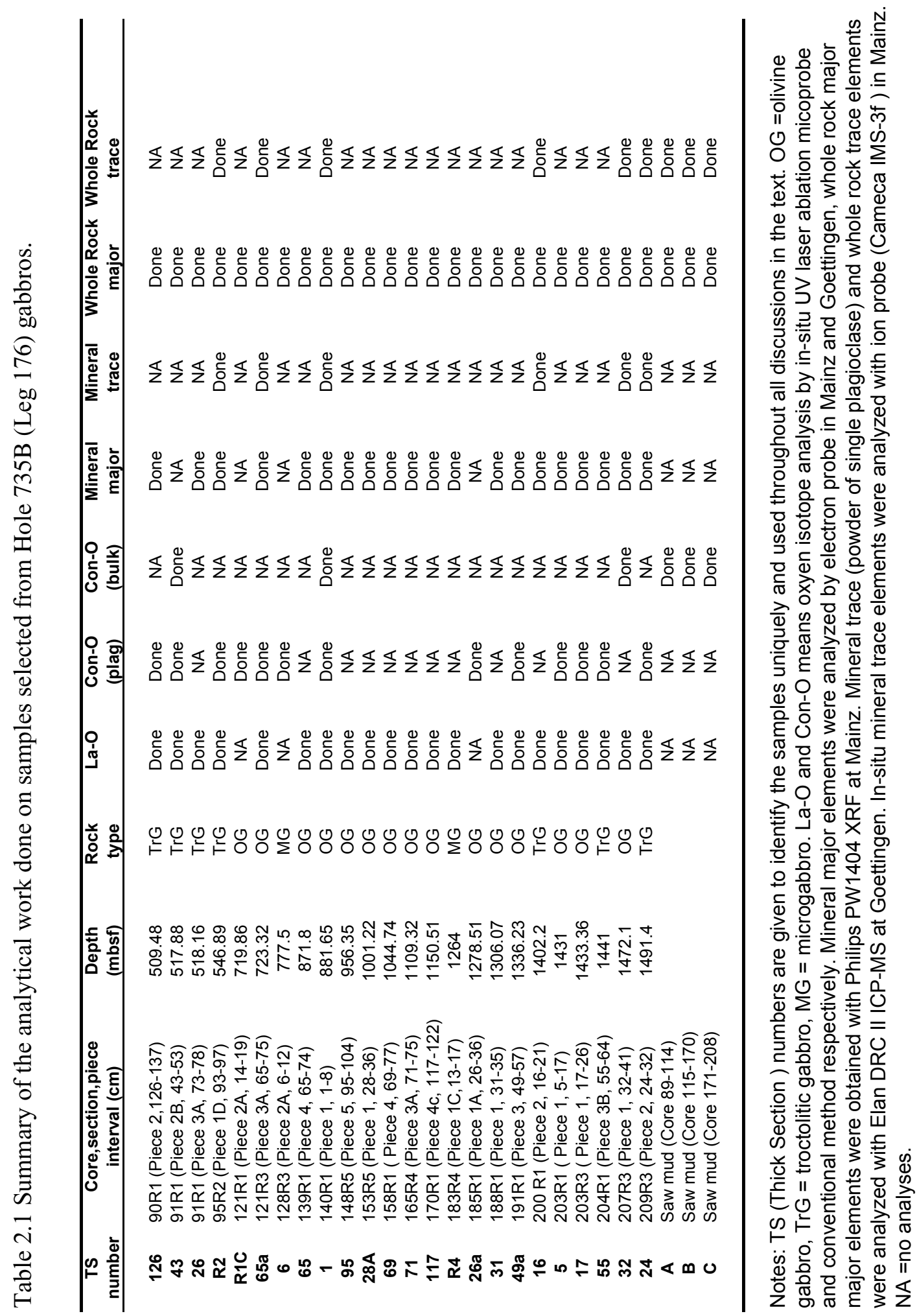




\section{Chapter 3 ANALYTICAL METHODS}

\subsection{In-situ Analysis}

With the purpose to get a combined in-situ investigation, thick-sections (about $10 \times 10 \times 4 \mathrm{~mm}$ ) were used for all geochemical analysis including oxygen isotope compositions, major element compositions and trace element compositions of compositional minerals in gabbro. Polished thick-sections were first cleaned by an ultrasonic bath with distilled water and acetone (plus $3 \% \mathrm{HCl}$ when carbonate is present in the sample) and then vacuum dried over night at $300^{\circ} \mathrm{C}$. Prepared thicksections were first put into the sample chamber for oxygen isotope analysis, and then after the procedure of cleaning and vacuum drying described above they were mounted in epoxy and repolished for microprobe and ion probe analysis. This is a necessary analytical order, as no organic material such as epoxy should be present for oxygen isotope analysis, while major element information will be needed for trace element determination. The details of each analytical technique are described below.

\subsubsection{Microprobe analysis}

Major element compositions of minerals in gabbro (olivine, pyroxene, and plagioclase) were analyzed in-situ on a five-spectrometer JEOL JXA 8900RL electron probe at the University of Mainz. All analyses were performed at the same conditions using an acceleration potential of $20 \mathrm{kV}$, a beam current of $20 \mathrm{nA}$ and a spot size of 2 $\mu \mathrm{m}$.

\subsubsection{Ion probe analysis}

Trace element compositions (selected REE and $\mathrm{Ti}, \mathrm{V}, \mathrm{Cr}, \mathrm{Sr}, \mathrm{Y}, \mathrm{Zr}$ ) for representative clinopyroxenes and plagioclase were analyzed by secondary ion mass 
spectrometry (SIMS) on a recently upgraded Cameca IMS-3f in Mainz. Spots were selected for ion microprobe analysis after detailed petrographic and electron microprobe study. Only optically clear domains that show no signs of alteration or exsolution were analyzed. Negative oxygen ions were used as primary ions (accelerating potential of $12.5 \mathrm{kV}$ and $20 \mathrm{nA}$ beam current). The spot size for these operating conditions was $15-20 \mu \mathrm{m}$. Positive secondary ions were extracted using an accelerating potential of $4.5 \mathrm{kV}$ with a $25 \mathrm{eV}$ energy window, a high-energy offset of $-80 \mathrm{~V}$, and fully open entrance and exit slits (see Hellebrand et al., 2002 for detailed analytical conditions).

Each measurement consisted of a six-cycle routine. ${ }^{30} \mathrm{Si}(3.1 \%$ isotopic abundance) is used as a reference mass, as the $\mathrm{SiO}_{2}$ concentration of standards and samples is known from electron microprobe analysis. For each cycle, mass to ${ }^{30} \mathrm{Si}$ ratios were determined after correction for time-dependence of count rates, detector deadtime $(20 \mathrm{~ms})$ and background [ $10-3$ c.p.s. (counts per second)]. The average of these ratios was used to calculate the element concentration, multiplying the measured ratios by a constant factor. Six oxides were found to produce significant interferences on REEs: ${ }^{137} \mathrm{BaO}^{+}$interferes with ${ }^{153} \mathrm{Eu}^{+},{ }^{141} \mathrm{PrO}^{+}$with ${ }^{157} \mathrm{Gd}^{+},{ }^{147} \mathrm{SmO}^{+}$with ${ }^{163} \mathrm{Dy}^{+}$, ${ }^{151} \mathrm{EuO}^{+}$with ${ }^{167} \mathrm{Er}^{+}$, and both ${ }^{158} \mathrm{GdO}^{+}$and ${ }^{158} \mathrm{DyO}^{+}$with ${ }^{174} \mathrm{Yb}^{+}$. As all elements of these oxides are free of interferences, they were measured directly. Thus the oxide interferences were corrected by appropriate $\mathrm{MO}^{+}$to $\mathrm{M}^{+}$ratios, which have been decided with long routine run. For clinopyroxene, the corrections on Eu, Gd, Dy, Er, and $\mathrm{Yb}$ are $0.1 \%, 11.7 \%, 2.1 \%, 3.3 \%$, and $13.6 \%$ of the measured element/Si ratio respectively. However, the corrections were required to be higher for plagioclase with more than $50 \%$ for Gd, Er, and $\mathrm{Yb}$. 
The well-studied glass GOR132-G (Jochum et al., 2000) was used as an external standard. The accuracy is better than 10\% RSD (relative standard deviation) for all REEs and other elements, except for Eu (18.8\% RSD) and Nd (16.1\% RSD).

\subsubsection{UV laser in-situ oxygen isotope analysis}

Oxygen isotope compositions were determined using isotope-ratio-monitoring gas chromatography-mass spectrometry (irmGCMS) with ArF laser fluorination. The analytical method in general remains the same as described by Fiebig et al. (1999) and Wiechert et al. (1995, 2002). Here we will describe some details of the actual analysis. Before ablation, the sample chamber is filled with 5 mbar $F_{2}$ to remove remnants of absorbed water. When necessary, repeated fluorination was used to reduce the blank. The oxygen was extracted by an ArF excimer laser (Compex 205, Lambda Physik Inc.), which radiates at $193 \mathrm{~nm}$ with maximum pulse energy of 400 $\mathrm{mJ}$ and a repetition rate ranging from 1 to $50 \mathrm{~Hz}$. The spatial resolution of the laser ablation for this study is $350 \mu \mathrm{m}$. After laser ablation and plasma fluorination by pure $\mathrm{F}_{2}$, the produced oxygen and other gases are guided to pass through a $\mathrm{NaCl}$ trap, where surplus $\mathrm{F}_{2}$ is reacted at $150^{\circ} \mathrm{C}$ to $\mathrm{Cl}_{2}$ and $\mathrm{NaF} . \mathrm{Cl}_{2}$ and other condensable gases such as $\mathrm{SiF}_{4}$ are frozen out in liquid nitrogen cold traps. The purified oxygen is then transferred into the GCMS for analysis. In order to guarantee a viscous flow, a continuous He flow is used for the transfer of oxygen.

During daily analysis, standards (San Carlos olivine or UWG-2 garnet or MORB glass) were run along with the samples, not only at the beginning and the end of a daily run, but also regularly during the day. This was done both to monitor the status of the system and to provide a means of drift correction after the measurement. The average internal analytical precision is $0.2 \%$. The isotopic results are reported in the conventional $\delta$ notation relative to SMOW. 


\subsection{Single Mineral Analysis}

Feldspar can react with fluorine at room temperature, and it has been found to have an effect on the precision of oxygen isotope UV laser based in-situ analysis performed on thick sections (Elsenheimer and Valley, 1993). Although theoretically this effect can be overcome by repeated fluorination before UV laser ablation on a thick section, additional analysis on single plagioclase grains was performed to check the accuracy of in-situ UV laser analysis. Plagioclase single grains were carefully picked from those sample pieces that have been used to prepare thick-section for insitu analysis. Oxygen was extracted from powdered plagioclase grains by reaction with $\mathrm{ClF}_{3}$ and converted to $\mathrm{CO}_{2}$ with the procedure described by Clayton and Mayeda (1963). Isotope ratios were measured with a Finnigan MAT 251 mass spectrometer.

Trace element compositions of these hand-picked single plagioclase grains were also measured with ICP-MS (ELAN DRC II) in Goettingen to verify the accuracy of in-situ ion probe analysis.

\subsection{Whole Rock Analysis}

Whole rock compositions for both major elements and oxygen isotopes for these samples were obtained by Snow (2002). Major elements were measured on a Philips PW1404 XRF at the University of Mainz and oxygen isotope was measured at the University of Goettingen with the same technique used for single plagioclase grains described above. Trace element compositions for these whole rock powders were analyzed with ICP-MS (ELAN DRC II) at Goettingen. 


\section{Chapter 4 MINERAL GEOCHEMISTRY}

Within the 15 years since Hole 735B was first drilled in 1987, a large number of mineral data have been collected. These data have been used to construct a mineral stratigraphy for this $1.5-\mathrm{km}$-long gabbroic hole, which represents the most complete section of lower ocean crust drilled in situ in oceans so far (Dick et al., 2002). Given the variety of scientific goals for those studies, few data are available to make systematic investigations for major and trace elements, as well as isotope compositions, especially on sub-millimeter scales. I present here a new systematically collected data set for both major and trace element compositions of the Leg 176 gabbros (the lower $1008 \mathrm{~m}$ of Hole $735 \mathrm{~B}$ ) with a focus on grain scale variations (i.e. mineral zonations).

\subsection{Plagioclase}

Plagioclase is present in every sample examined, typically in near cotectic proportions with clinopyroxene and olivine (Bloomer et al., 1991) with abundances in the range of $50 \%-65 \%$ for most gabbros.

As shown in Figure 4.1, in the feldspar ternary plot, the compositions define a very tight trend close to the anorthite-albite join far from saturation with respect to orthoclase. Although there are a few gaps in between, the anorthite content ranges from $\mathrm{An}_{40}$ to $\mathrm{An}_{80}$. While in the plot for plagioclase in Hole $735 \mathrm{~B}$ gabbros with all available data (Dick et al., 2002) there are some plagioclases with anorthite contents lower than $\mathrm{An}_{30}$, although the majority ranges from $\mathrm{An}_{30}$ to $\mathrm{An}_{80}$. The absence of plagioclase with lower anorthite content in Leg 176 gabbros studied here reflects the fact that no felsic veins were sampled for this study. And it also reflects the fact that felsic veins are relatively scarce in the lower section (Dick et al., 1999). 


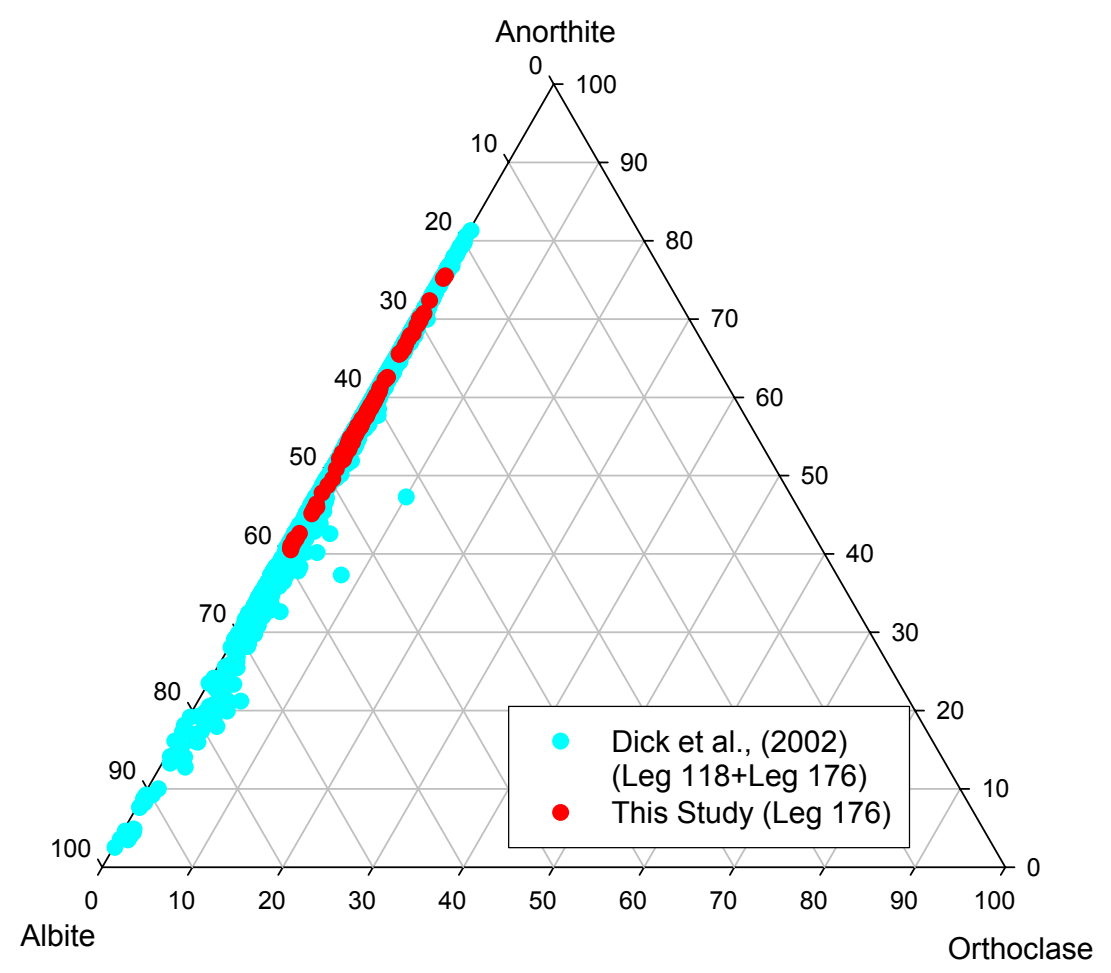

Fig. 4.1 Feldspar ternary plot of plagioclase from Hole 735B gabbros. All compositions define a very tight trend close to the anorthite-albite join, with anorthite contents ranging from $\mathrm{An}_{40}$ to $\mathrm{An}_{80}$. Compared with the whole data set, plagioclase with anorthite content lower than $\mathrm{An}_{40}$ is absent in this study, which is believed to reflect the scarcity of felsic veins in the lower part of this gabbro block.

Table 4.1 gives the major element composition for plagioclases analyzed by electron probe, which have also been analyzed with ion probe for trace elements compositions. The results for all microprobe analysis on plagioclase are given in appendix (Table AT1). In general, plagioclase has a very uniform composition, the average standard deviations for anorthite content of individual grains is generally lower than $2 \%$. However, locally large core to rim variations were observed, with up to $10 \mathrm{~mol} \%$ anorthite variations. In most cases, anorthite contents decrease from core to rim for zoned plagioclase (i.e. normal zoning), few reversed zonings are present. An-rich plagioclase + orthopyroxene + pargasite veins in these rocks, so called high 
temperature veins (Maeda et al., 2002), which has been experimentally explained to be the product of hydrous partial melting (Koepke et al., 2003) are not found in this study. This may be due to the fact that I only focused on the large grains for combined in-situ investigation, while partial melting is preferred to occur on fine grains, which have larger surface area.

Trace elements compositions of plagioclase in 4 thick sections out of 24 selected samples were further investigated by ion probe. These 4 samples represent typical gabbros from the top, middle and bottom of Leg 176 gabbro (Table 2.1).

Sample R2, located in between two fault belts, shows both high- and lowtemperature alteration indicated by oxygen isotope compositions of its compositional minerals (for details see following section). Therefore, a detailed investigation for core-rim variation of trace elements in sample R2 was not performed. It is believed the zoning profiles obtained at a high temperature stage are easily disturbed by alteration due to the very low content of most trace elements in plagioclase.

Sample 1 and sample 32 are relatively fresh olivine gabbros located in the middle and bottom of the core, while sample 24 is a relatively fresh troctolitic gabbro at the bottom of this core. The zoning patterns of plagioclase for these 3 samples were investigated by electron probe and ion probe. The results are listed in Table 4.1. 


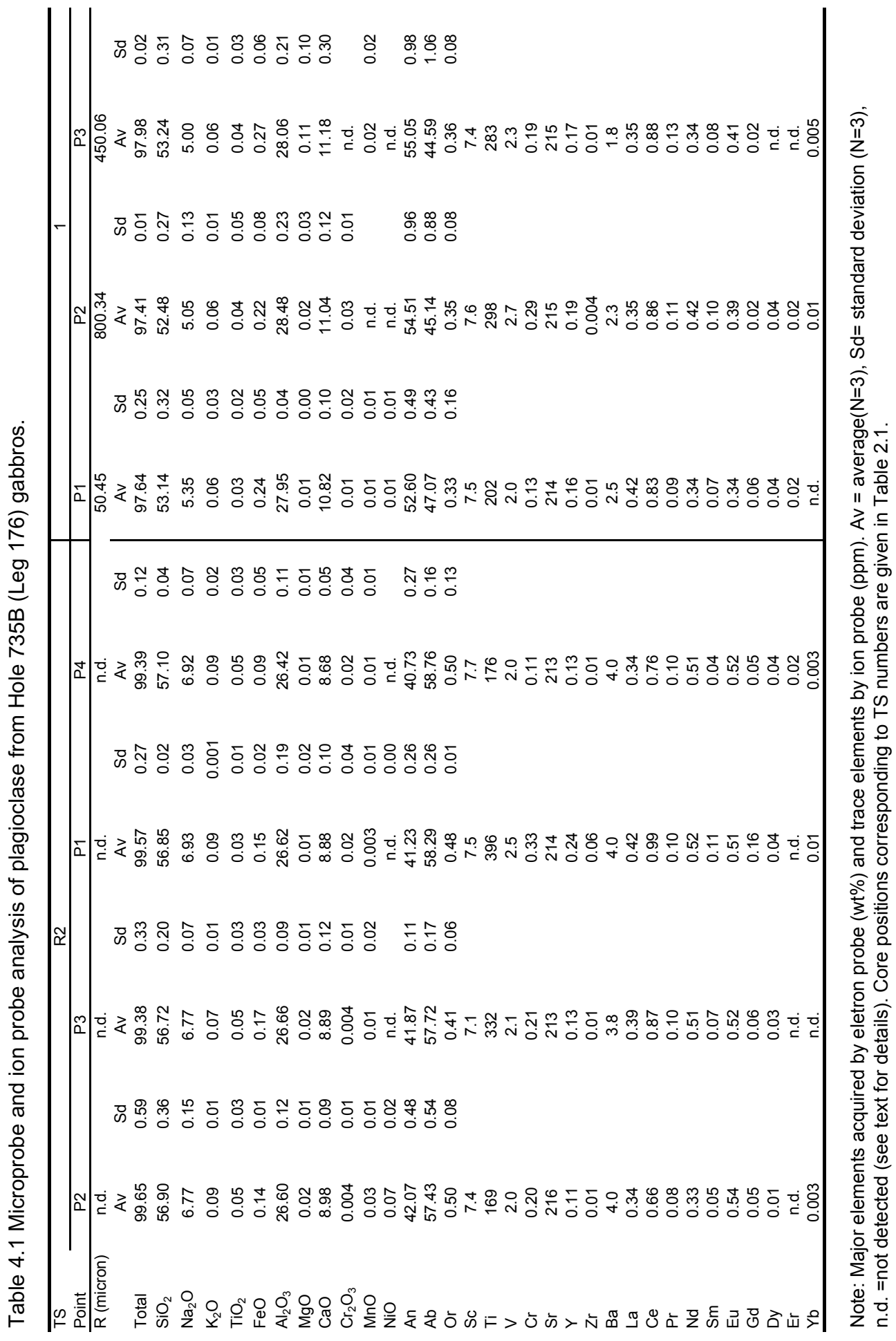




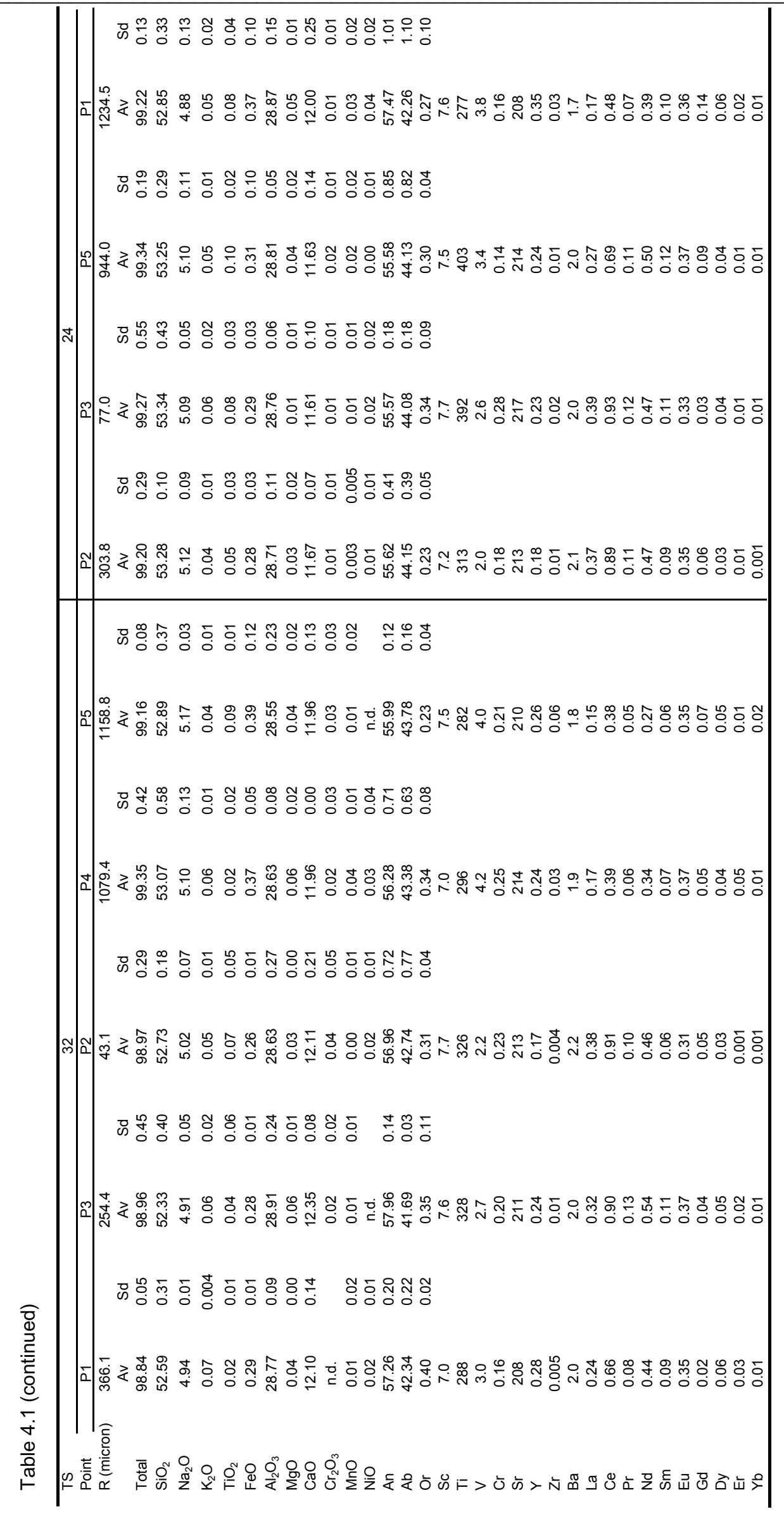


In general, incompatible trace elements (for example REE) tend to be enriched outward to the rim for zoned plagioclase, although in most cases this trend can only be observed for La, and Ce (Figure 4.2). It seems that zoning patterns for other REEs are not detectable with the current analytical method, i.e. the actual variations of concentration are in the range of analytical error. As a test for the precision of the ion probe measurements, hand picked single plagioclase crystals from the same sample of which a thick section (TS24) has been made for ion probe analysis was analyzed with Elan DRC II ICP-MS. As shown in Figure 4.2, the precision of ion probe used for insitu analysis is in general good enough for light REE, such as La, and Ce, but is problematic for other middle and heavy REEs whose concentrations are usually lower than $0.1 \mathrm{ppm}$. The excellent accuracy of in-situ ion probe analysis is also suggested by the fact that the bulk composition of the picked plagioclase just lies in between the concentrations of rim and core, which is believed to represent the average concentration throughout the whole crystal. In contrast to the general enrichment trend of incompatible elements from core to rim, Sr has a nearly constant content throughout the plagioclase crystals (Figure 4.3). 

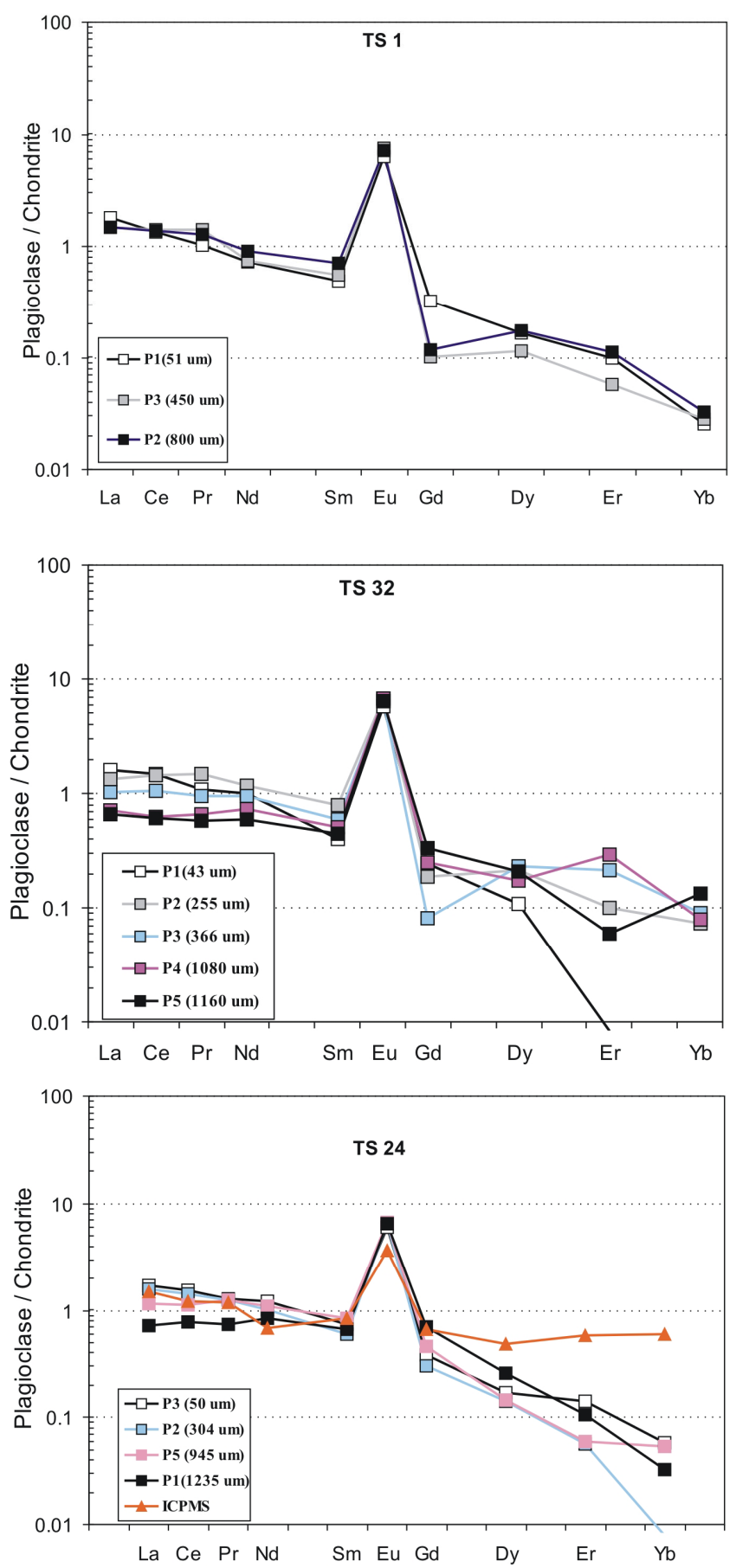

Fig. 4.2 Spatial variation for chondrite normalized REE patterns of plagioclase in TS1, TS32, and TS24 from Hole 735B gabbro. Notice that REE tend to be enriched to the rim, although it is not systematic. Analyses with ICPMS of picked single plagioclase from the same sample for TS24 is shown here to illustrate that the precision of SIMS used for this in-situ analysis is in general good enough for light REE but seems to be poor for heavy REEs where concentrations are usually lower than $0.1 \mathrm{ppm}$. 


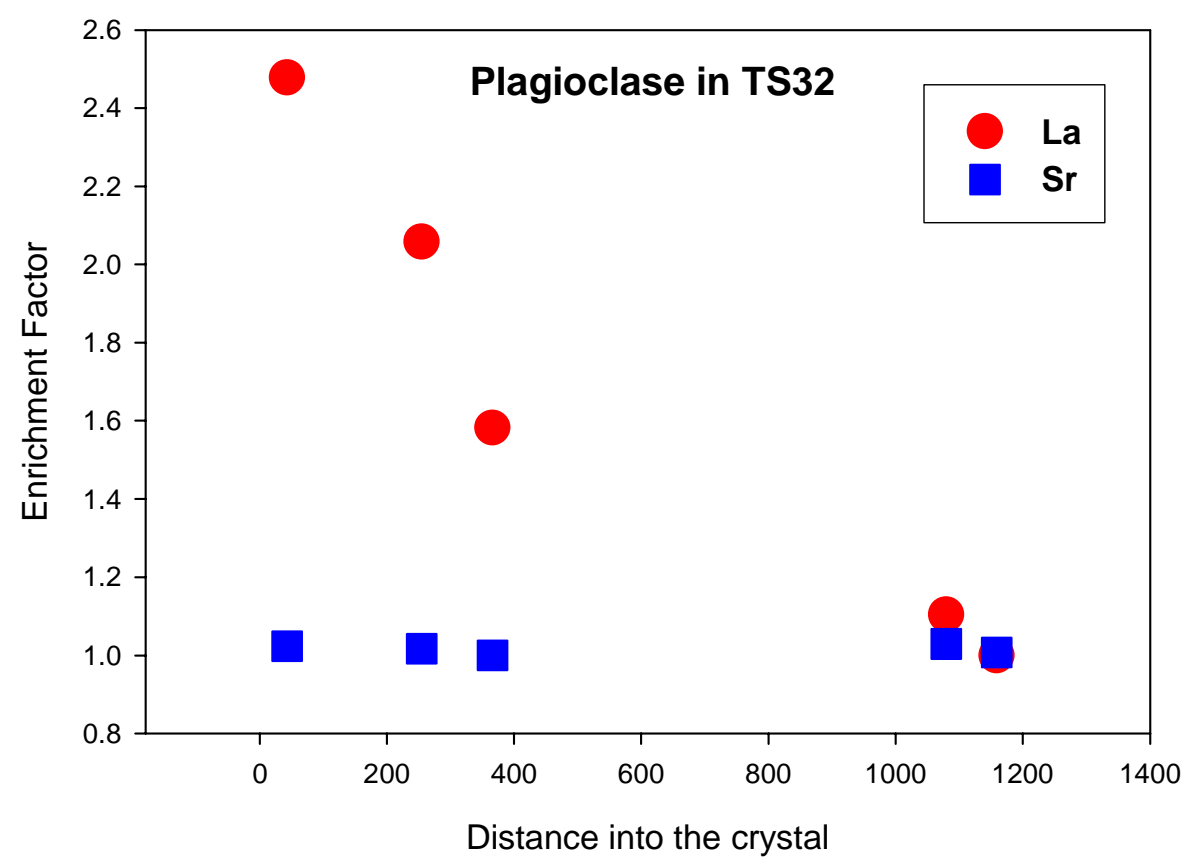

Fig. 4.3 Compositional variation of plagioclase in TS32 (TS-Thick Section) from Hole $735 \mathrm{~B}$ gabbros. Enrichment factor $=\mathrm{C} / \mathrm{C}_{0}$, where $\mathrm{C}$ is the measured concentration at any position, $\mathrm{C}_{0}$ is the concentration at core position. Compared with the significant enrichment of La to the rim, Sr has a nearly constant content throughout the crystal.

\subsection{Olivine}

Olivine is typically present as rounded anhedral grains and locally may enclose plagioclase in an oikocrystic or poikilitic pattern. The typical abundance is between $5 \%$ and $15 \%$ for most olivine gabbros, a few troctolitic gabbros can have up to $50 \%$ olivine.

Fo contents of studied olivine range from 60 to 82 (Table 4.2). Overall they overlap with the data set of Leg 176 gabbros summarized by Dick et al. (2002). Compared with Leg 118 gabbros on the upper 500 meters of Hole 735B, Fo contents of olivine in Leg 176 gabbros, including our new data, are more clustered in a narrow range of $\mathrm{Fo}_{60}$ to $\mathrm{Fo}_{80}$ (Figure 4.4). Although the most primitive olivine was found in 
the upper part, more evolved olivines $\left(<\mathrm{Fo}_{60}\right)$ are generally more abundant above 600 mbsf. This reflects the fact that more evolved gabbros (gabbronorite and oxide gabbros) are relatively scarce in the lower part of this section. Given the fact that most high-temperature shear zones and faults are located in the upper part of the hole, it is likely that late stage evolved melts are squeezed out of the olivine gabbros at depth and migrated upward to form oxide gabbros. The final emplacement location of these melts is controlled by both high- and low-temperature deformation, which may act as impermeable barriers.
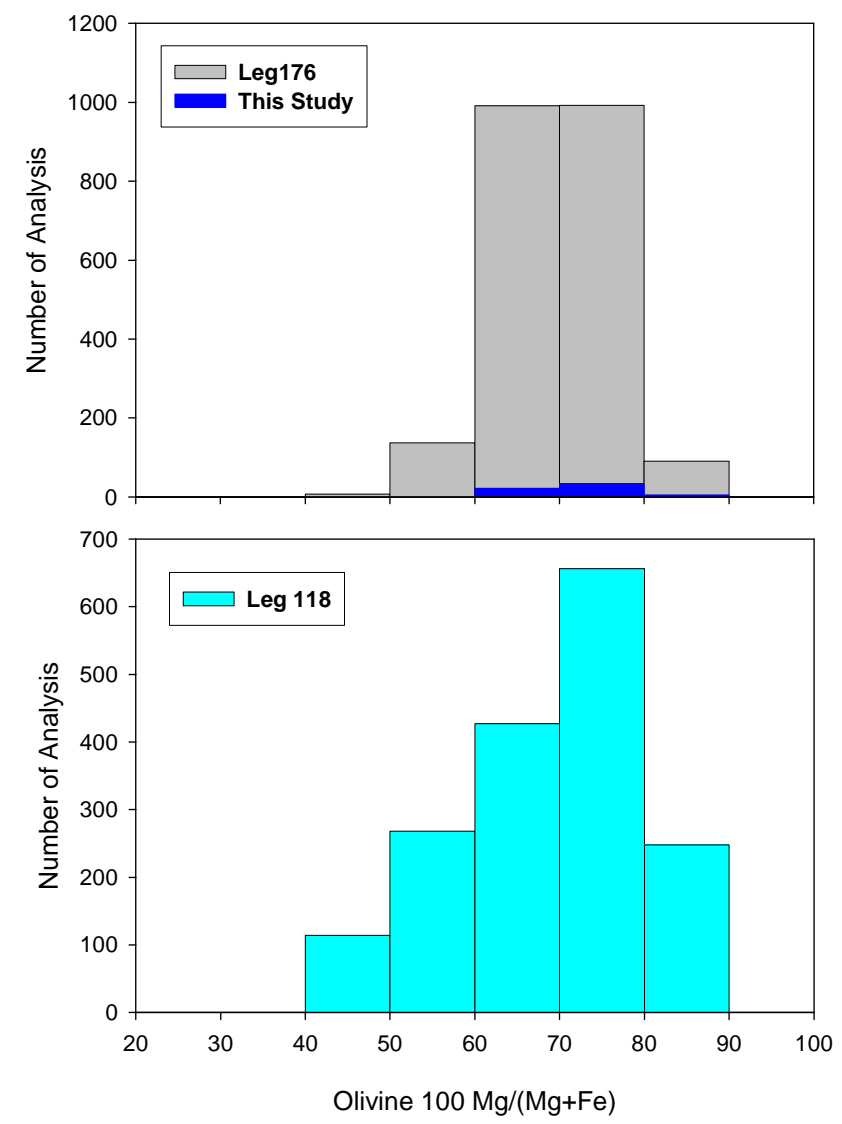

Fig. 4.4 Summary of olivine compositions in Hole 735B gabbros, data are from Dick et al., (2002). 
Table 4.2 Microprobe analysis results of olivine in Hole 735B (Leg 176) gabbros.

\begin{tabular}{|c|c|c|c|c|c|c|c|c|c|c|c|c|c|}
\hline Comment & Depth & $\mathrm{SiO}_{2}$ & $\mathrm{Na}_{2} \mathrm{O}$ & $\mathrm{K}_{2} \mathrm{O}$ & $\mathrm{TiO}_{2}$ & $\mathrm{FeO}$ & $\mathrm{Al}_{2} \mathrm{O}_{3}$ & $\mathrm{MgO}$ & $\mathrm{CaO}$ & $\mathrm{Cr}_{2} \mathrm{O}_{3}$ & $\mathrm{MnO}$ & $\mathrm{NiO}$ & Mg\# \\
\hline s126-ol-1 & 509.48 & 39.32 & 0.01 & 0.004 & 0.07 & 19.06 & 0.17 & 41.61 & 0.06 & 0.06 & 0.26 & 0.16 & 79.56 \\
\hline s126-ol-2 & 09.48 & 39.76 & 0.01 & 0.01 & 0.03 & 18.44 & 0.03 & 41.75 & 0.06 & n.d. & 0.27 & 0.15 & 80.14 \\
\hline s126-ol-3 & 509.48 & 39.72 & n.d. & 0.002 & 0.06 & 18.64 & 0.02 & 41.71 & 0.04 & n.d. & 0.30 & 0.17 & 79.96 \\
\hline s26-ol-2-1 & 518.16 & 38.20 & 0.03 & n.d. & n.d. & 22.46 & 0.02 & 40.70 & 0.06 & 0.02 & 0.35 & 0.06 & 76.36 \\
\hline s26-ol-2-2 & 518.16 & 37.82 & 0.03 & n.d. & n.d. & 22.49 & n.d. & 40.83 & 0.03 & n.d. & 0.43 & 0.11 & 76.40 \\
\hline s26-ol-2-3 & 518.16 & 38.58 & n.d. & n.d. & 0.03 & 22.21 & n.d. & 41.08 & 0.05 & 0.07 & 0.42 & 0.15 & 76.73 \\
\hline s26-ol-2-4 & 518.16 & 38.31 & 0.01 & n.d. & 0.06 & 21.88 & n.d. & 40.69 & 0.00 & 0.03 & 0.36 & 0.14 & 76.83 \\
\hline s26-ol-2-5 & 518.16 & 38.28 & 0.02 & 0.01 & 0.02 & 22.37 & n.d. & 40.72 & 0.04 & 0.05 & 0.38 & 0.13 & 76.44 \\
\hline s65a-ol-13-1 & 723.32 & 38.17 & n.d. & 0.003 & n.d. & 25.70 & n.d. & 36.51 & 0.02 & n.d. & 0.50 & 0.11 & 71.69 \\
\hline s65a-ol-13-2 & 723.32 & 37.88 & 0.01 & n.d. & 0.02 & 27.06 & n.d. & 35.32 & 0.05 & 0.02 & 0.43 & 0.08 & 69.94 \\
\hline s65a-ol-7-1 & 723.32 & 37.74 & n.d. & 0.01 & 0.02 & 27.08 & n.d. & 35.37 & 0.05 & n.d. & 0.41 & 0.06 & 69.96 \\
\hline s65a-ol-7-2 & 723.32 & 38.16 & n.d. & 0.01 & 0.05 & 27.08 & n.d. & 35.36 & 0.03 & n.d. & 0.44 & 0.07 & 69.95 \\
\hline s65a-ol-9-1 & 723.32 & 37.85 & 0.01 & 0.02 & 0.01 & 27.21 & n.d. & 35.33 & 0.05 & 0.01 & 0.43 & 0.07 & 69.83 \\
\hline s65a-ol-9-2 & 723.32 & 38.10 & 0.01 & n.d. & 0.05 & 27.08 & 0.02 & 35.18 & 0.07 & 0.02 & 0.40 & 0.04 & 69.85 \\
\hline s65a-ol-8-1 & 723.32 & 37.79 & n.d. & 0.01 & 0.02 & 27.38 & n.d. & 35.13 & 0.01 & n.d. & 0.45 & 0.10 & 69.58 \\
\hline s65a-ol-8-2 & 723.32 & 37.56 & 0.003 & n.d. & 0.04 & 26.90 & n.d. & 35.40 & 0.03 & 0.01 & 0.38 & 0.10 & 70.11 \\
\hline$-3-1$ & 871.80 & 37.48 & n.d. & n.d. & 0.03 & 27.63 & 0.01 & 36.85 & 0.07 & 0.01 & 0.44 & 0.03 & 70.40 \\
\hline & 871.80 & 37.13 & 0.01 & n.d. & 0.01 & 27.07 & n.d. & 37.15 & 0.07 & 0.03 & 0.42 & 0.08 & 70.99 \\
\hline s65-ol-3-3 & 871.80 & 37.51 & 0.02 & 0.01 & 0.01 & 27.77 & 0.04 & 36.86 & 0.08 & 0.04 & 0.41 & 0.10 & 70.30 \\
\hline s65-ol-3-4 & 871.80 & 36.79 & n.d. & n.d. & n.d. & 27.26 & 0.01 & 36.92 & 0.06 & 0.03 & 0.44 & 0.04 & 70.71 \\
\hline s65 & 871.80 & 37.32 & 0.04 & n.d. & n.d. & 26.84 & n.d. & 37.20 & 0.06 & n.d. & 0.36 & 0.14 & 71.19 \\
\hline s95-ol-1-01 & 956.35 & 37.09 & n.d. & n.d. & n.d. & 29.27 & 0.01 & 35.35 & 0.07 & 0.04 & 0.47 & 0.08 & 68.29 \\
\hline s95-ol-1-02 & 956.35 & 37.08 & 0.02 & 0.02 & n.d. & 29.44 & 0.01 & 35.34 & 0.05 & 0.01 & 0.46 & 0.07 & 68.15 \\
\hline-03 & 956.35 & 53.30 & 0.04 & n.d. & 0.31 & 17.53 & 1.17 & 26.81 & 1.16 & 0.07 & 0.44 & 0.09 & 73.17 \\
\hline s28a-ol-9-1 & 1001.20 & 36.81 & n.d. & n.d. & 0.02 & 32.38 & n.d. & 33.17 & 0.05 & 0.03 & 0.55 & 0.02 & 64.62 \\
\hline s28a-ol-9-2 & 1001.20 & 36.45 & n.d. & n.d. & 0.02 & 32.67 & n.d. & 33.30 & 0.05 & 0.06 & 0.53 & 0.12 & 64.50 \\
\hline s28a- & 1001.20 & 36.59 & 0.03 & n.d. & n.d. & 32.80 & 0.01 & 32.85 & 0.04 & n.d. & 0.47 & 0.09 & 64.10 \\
\hline s28a-ol-9-4 & 1001.20 & 36.68 & n.d. & n.d. & n.d. & 32.43 & 0.01 & 32.77 & 0.05 & 0.10 & 0.50 & 0.05 & 64.31 \\
\hline s28a & 1001.20 & 36.53 & n.d. & n.d. & 0.03 & 32.40 & n.d. & 32.56 & 0.04 & n.d. & 0.55 & 0.06 & 64.18 \\
\hline s69- & 1044.71 & 37.37 & n.d. & n.d. & n.d. & 27.27 & 0.01 & 36.80 & 0.03 & 0.04 & 0.40 & 0.07 & 70.64 \\
\hline s69- & 1044.71 & 37.07 & 0.01 & n.d. & n.d. & 27.71 & n.d. & 36.38 & 0.04 & 0.07 & 0.41 & 0.10 & 70.07 \\
\hline & 1044.71 & 36.83 & n.d. & 0.01 & n.d. & 27.54 & 0.01 & 36.03 & 0.03 & n.d. & 0.43 & & 69.99 \\
\hline $\mathrm{s} 69$ & 1044.71 & 37.41 & 0.01 & 0.01 & n.d. & 27.20 & n.d. & 36.86 & 0.05 & n.d. & 0.41 & 0.06 & 70.73 \\
\hline s69- & 1044.71 & 37.26 & n.d. & 0.01 & n.d. & 27.60 & 0.02 & 36.68 & 0.07 & n.d. & 0.39 & 0.01 & 70.32 \\
\hline s117-ol-01 & 1150.71 & 36.76 & n.d. & 0.01 & n.d. & 34.43 & 0.01 & 31.78 & 0.08 & 0.06 & 0.63 & 0.06 & 62.20 \\
\hline |-02 & 71 & 36.55 & n.d. & n.d. & 0.03 & 34.58 & n.d. & 31.75 & 0.09 & 0.01 & 0.59 & 0.08 & 62.08 \\
\hline $\mid-03$ & 50.71 & 36.40 & 0.02 & n.d. & 0.01 & 33.97 & 0.01 & 31.32 & 0.07 & 0.07 & 0.59 & 0.09 & 62.18 \\
\hline s117-ol-04 & 1150.71 & 36.40 & 0.02 & n.d. & 0.01 & 34.00 & n.d. & 31.44 & 0.04 & 0.06 & 0.49 & 0.00 & 62.24 \\
\hline s11 & & 36.20 & 0.02 & n.d. & n.d. & 33.72 & 0.01 & 31.60 & 0.07 & 0.02 & 0.62 & 0.04 & 62.56 \\
\hline $8-1$ & 6.80 & 38.12 & 0.06 & 0.02 & 0.00 & 24.89 & n.d. & 38.48 & 0.07 & 0.01 & 0.39 & 0.04 & 73.38 \\
\hline s31-ol-8-2 & 06.80 & 38.11 & 0.04 & 0.01 & 0.03 & 24.94 & n.d. & 38.62 & 0.05 & n.d. & 0.42 & 0.06 & 73.41 \\
\hline & & & n.d. & n.d. & 0.04 & 24.79 & n.d. & & 0. & 0.01 & 0.34 & & 73.56 \\
\hline & & 38.22 & 0.02 & 0.02 & 0.03 & 25.15 & 0.01 & 38.59 & 0.06 & n.d. & 0.39 & 0.07 & 73.23 \\
\hline s16-ol-6-1 & 1402.20 & 39.50 & 0.03 & n.d. & 0.02 & 17.40 & 0.02 & 43.32 & 0.03 & n.d. & 0.26 & 0.13 & 81.61 \\
\hline & & & n. & n.d. & 0. & & $\mathrm{n}$. & & & 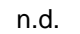 & 0.22 & & 81.44 \\
\hline & 20 & & n.d. & 0.002 & 0.04 & 17.54 & 0.02 & 43.06 & 0.02 & n.d. & 0.24 & 0.12 & 81.40 \\
\hline s16-ol-5-2 & 1402.20 & 39.89 & 0.01 & 0.003 & 0.00 & 17.58 & n.d. & 43.09 & 0.01 & 0.003 & 0.30 & 0.16 & 81.38 \\
\hline & & 36.21 & 0.03 & 0.00 & 0.05 & 27.91 & 0.01 & & 0. & & 0.42 & & 69.10 \\
\hline & & 37.33 & 0.05 & 003 & n. & 28.33 & 0.02 & 36.32 & 0. & 0.07 & 0.45 & 0.09 & 69.57 \\
\hline s5-ol-1-03 & 1431.00 & 37.74 & 0.02 & 0.01 & n.d. & 27.70 & n.d. & 36.10 & 0.04 & 0.01 & 0.50 & 0.08 & 69.91 \\
\hline & & 37.46 & 0.04 & 0.01 & n.d. & 27.98 & 0.01 & 36.83 & 0.06 & 0.04 & 0.59 & 0.03 & 70.12 \\
\hline & & 37.40 & 0.0 & n. & n.d. & 27.11 & & & 0.06 & 0 & 0.59 & 0.16 & 70.85 \\
\hline s17-ol-2-1 & 33.36 & 38.76 & 0.01 & 0.02 & 0.05 & 22.81 & n.d. & 38.87 & 0.04 & n.d. & 0.36 & 0.09 & 75.24 \\
\hline & 36 & 38.81 & 0.00 & 0.02 & n.d. & 22.70 & 0.01 & 38.55 & 0.03 & 0.02 & 0.39 & 0.07 & 75.17 \\
\hline & & 38.51 & 0.02 & n.d. & 0.01 & 23.27 & 0.02 & 38.40 & 0.05 & n.d. & 0.35 & 0.10 & 74.63 \\
\hline s17-ol-6-2 & 1433.36 & 38.63 & 0.03 & n.d. & 0.002 & 23.38 & 0.01 & 38.54 & 0.05 & 0.01 & 0.33 & 0.07 & 74.61 \\
\hline s55-ol-5-1 & 41.00 & 38.62 & 0.01 & 0.01 & 0.01 & 24.63 & 0.02 & 37.06 & 0.01 & n.d. & 0.35 & 0.06 & 72.84 \\
\hline & & 38.73 & 0.01 & n.d. & n.d. & 24.06 & 0.01 & 37.35 & 0.04 & n.d. & 0.38 & 0.05 & 73.46 \\
\hline s55 & 41.00 & 38.80 & n.d. & n.d. & n.d. & 24.37 & n.d. & 37.40 & 0.04 & n.d. & 0.33 & 0.10 & 73.24 \\
\hline s55-ol-1-2 & 1441.00 & 38.75 & 0.01 & 0.02 & 0.003 & 24.30 & n.d. & 37.42 & 0.05 & n.d. & 0.41 & 0.10 & 73.30 \\
\hline
\end{tabular}

Note: n.d. = Not detected. 
Shown in Figure 4.5, nickel concentrations of studied olivines are highly variable and do not correlate well with forsterite content, although the highest nickel concentrations are related to olivines with highest forsterite content. This trend has also been verified and interpreted to be a result of modification by postcumulus processes and reequilibration with late stage melt (Dick et al., 2002).

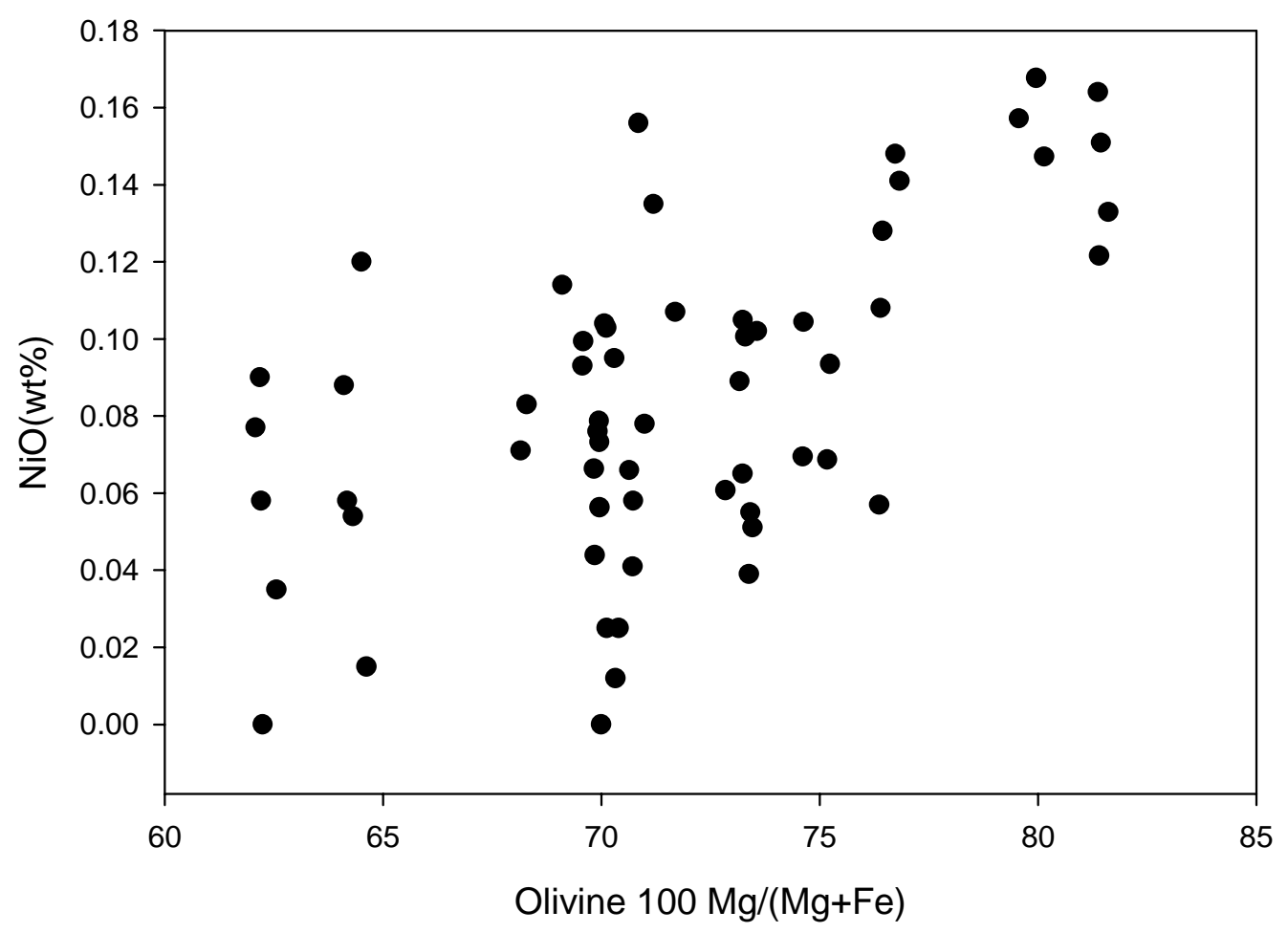

Fig. 4.5 Plot of $\mathrm{NiO}$ content (wt \%) vs. $\mathrm{Mg} \#(100 \mathrm{Mg} /[\mathrm{Mg}+\mathrm{Fe}])$ of olivine in Leg 176 gabbros.

\subsection{Clinopyroxene}

Clinopyroxene is generally present in near-cotectic proportions with plagioclase and olivine, with mode compositions ranging from $15 \%$ to $45 \%$ for the majority of Hole 735B gabbros (Dick et al., 1999). Clinopyroxene often behaves as large 
oikocrysts, enclosing plagioclase and olivine, but also is present as coarse granular grains.

In the pyroxene quadrilateral plot, clinopyroxene in Leg 176 gabbros largely overlap with existing data and fall into a narrow range of augite (Figure 4.6). However, there are fewer than 10 out of 223 analysis plotting outside the main cluster that fall into the area of orthopyroxene. These few exceptions out of the major group represent poor analytical points on either orthopyroxene or low-Ca pyroxene produced at subsolidus stage (exsolution lamella /patch or alteration) in clinopyroxene. Due to the thickness of the thick section used for this research, the mineral phase can only be identified under reflected light, so it is not possible to distinguish all small orthopyroxenes from clinopyroxene. The major element compositions of analyzed clinopyroxene are listed in Table 4.3.

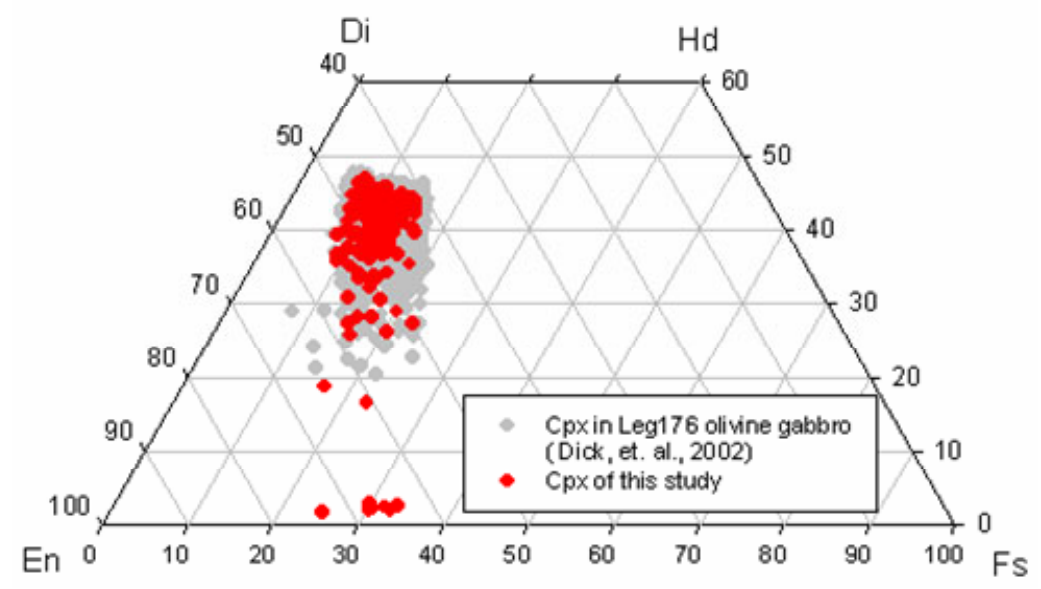

Fig. 4.6 Compositional variation of clinopyroxene in Hole 735B (Leg 176) gabbros (composition data are listed in Table 4.3). Di=Diopside, $\mathrm{Hd}=$ Hedenbergite, $\mathrm{En}=$ Enstatite, and Fs=Ferrosilite. Notice that in agreement with the existing data, most of the measured clinopyroxenes in this study are in the range of augite. A few data point at the bottom are in the range of orthopyroxene, which represent orthopyroxene or low-Ca pyroxene exsolution lamella (or exsolution patch) in clinopyroxene (see text for details). 


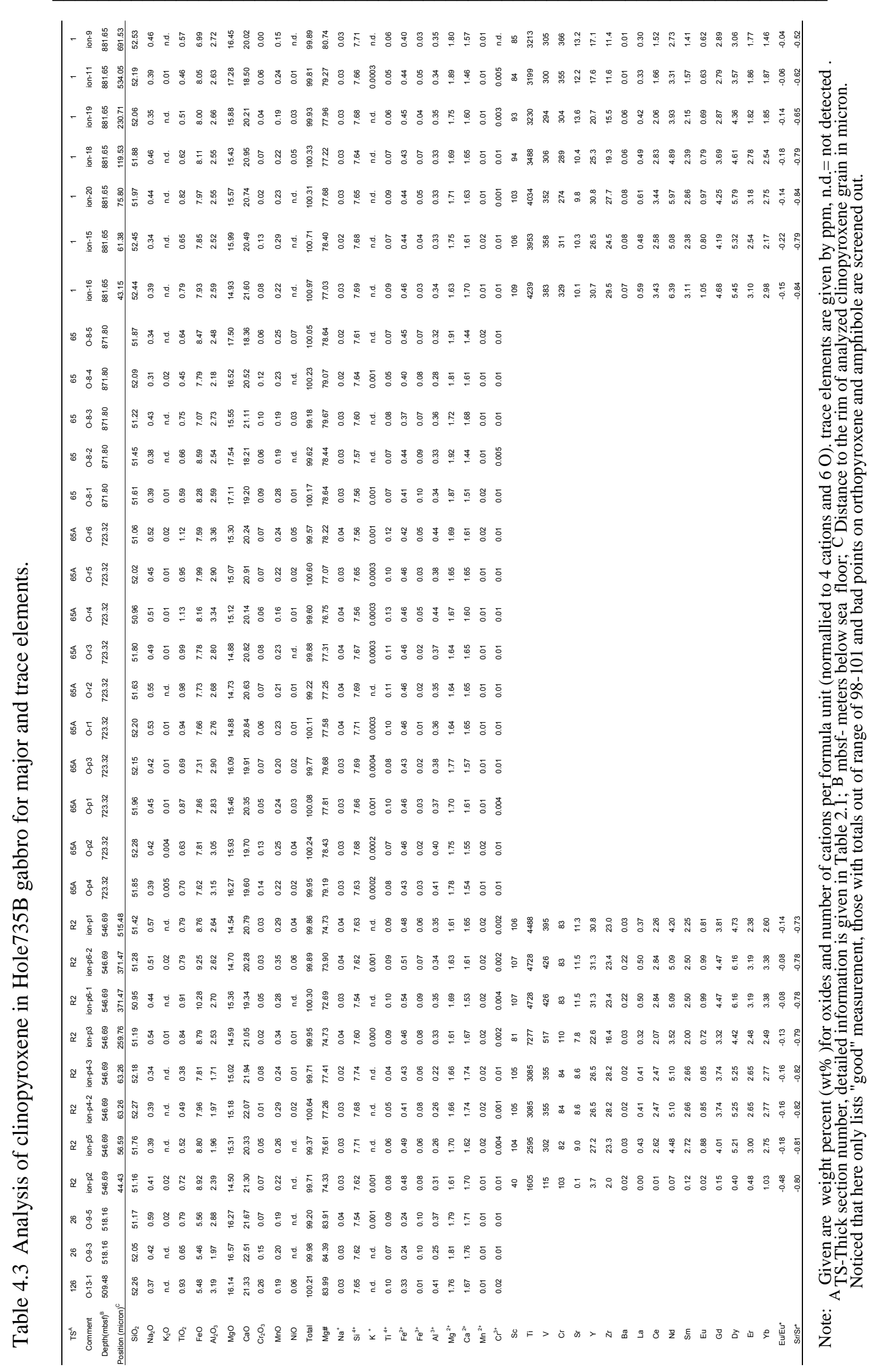




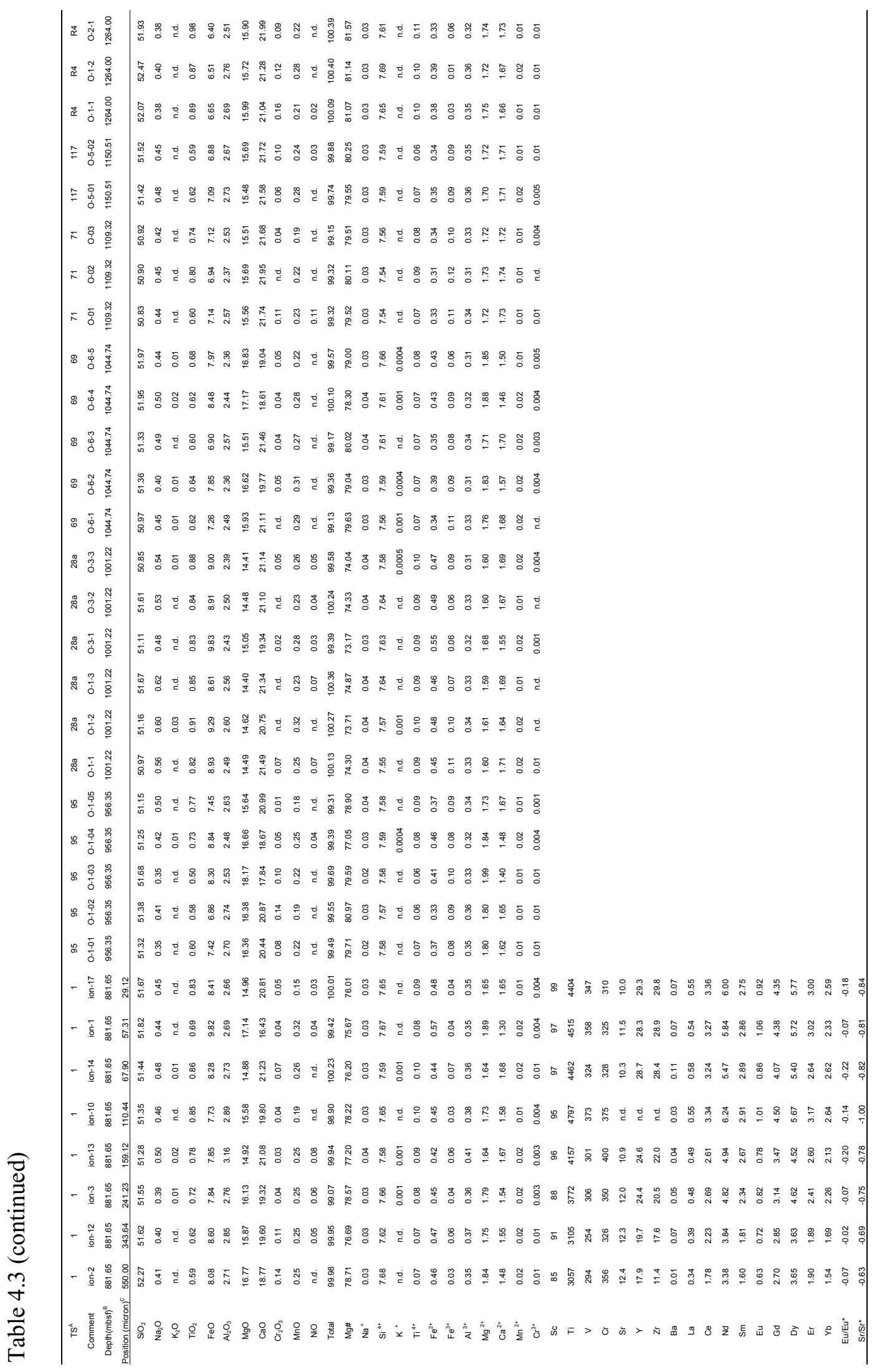




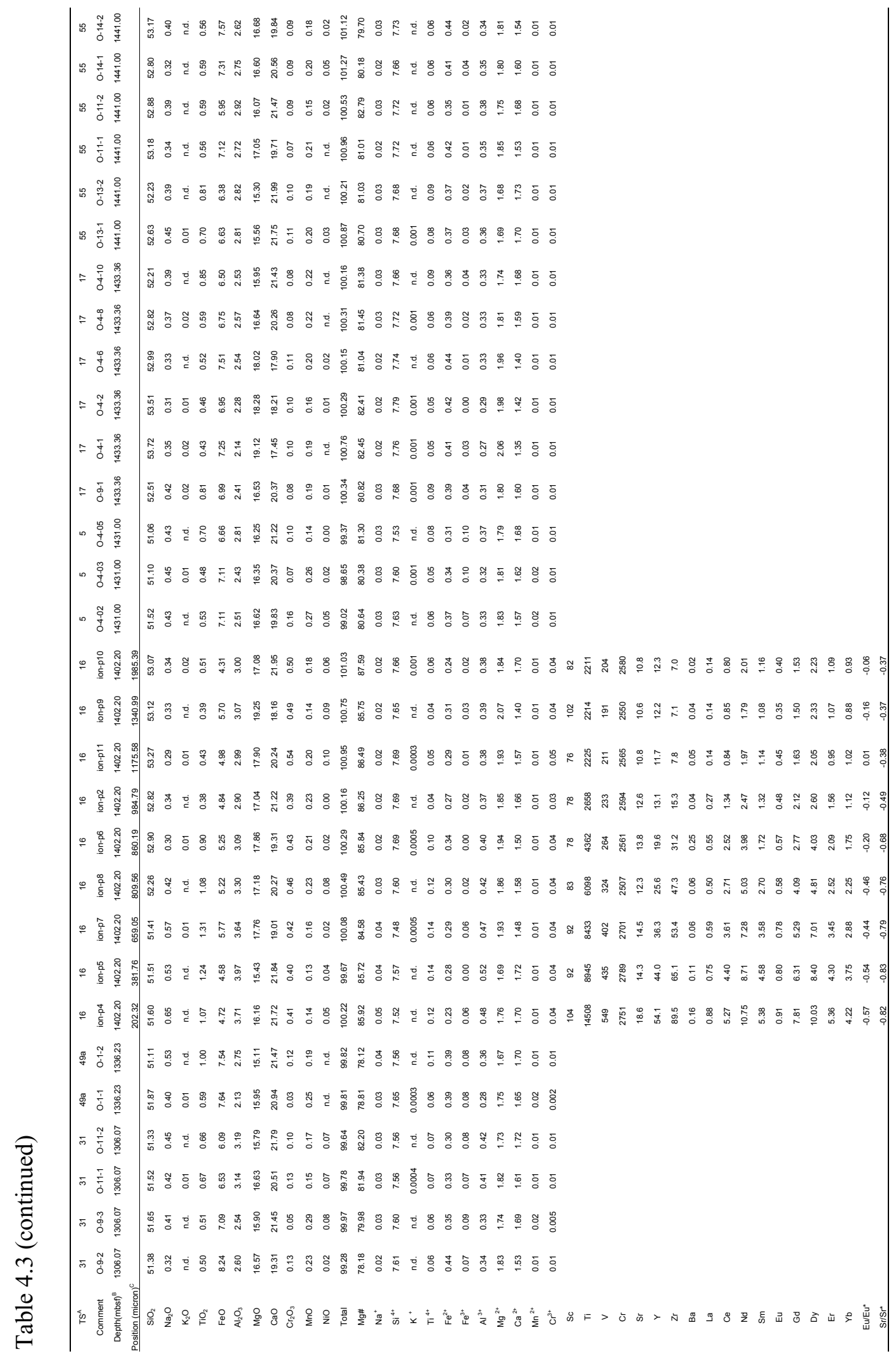




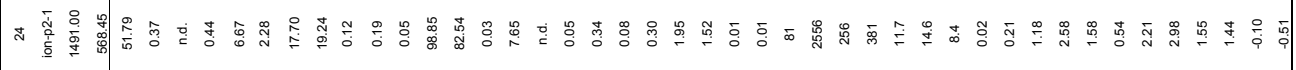

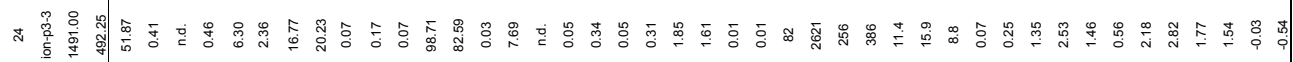

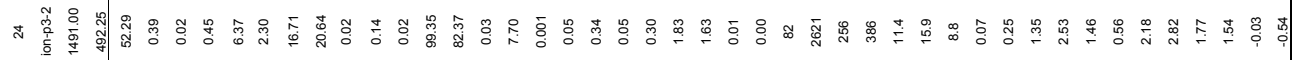

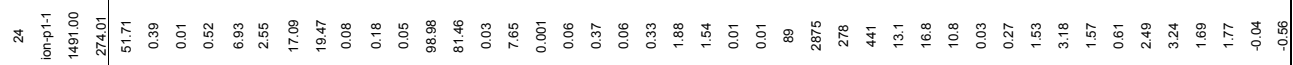

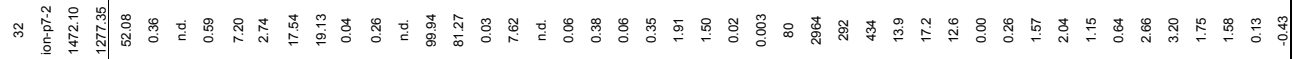

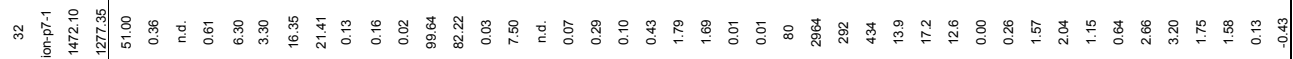

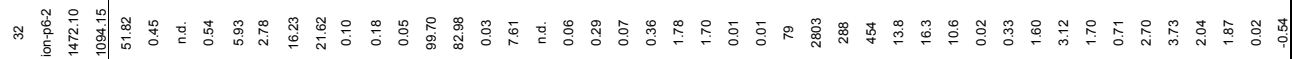

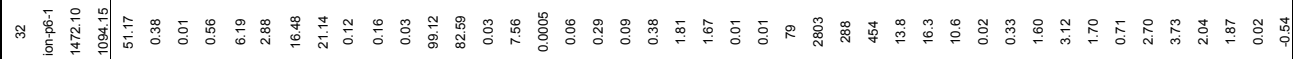

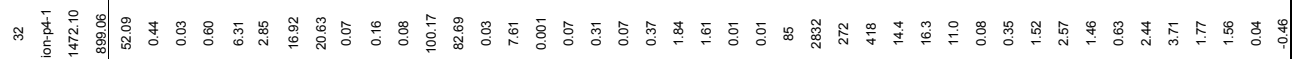

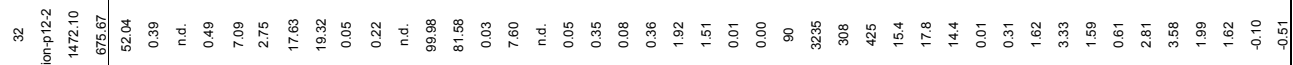

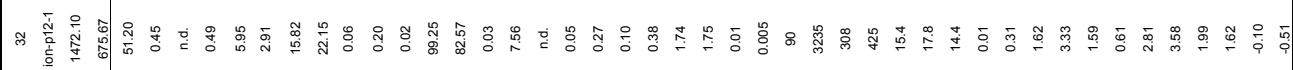

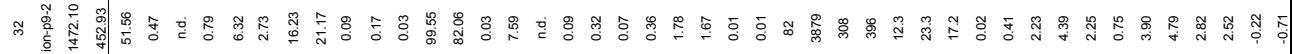

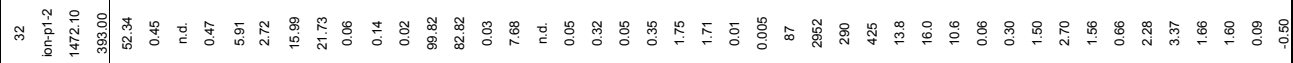

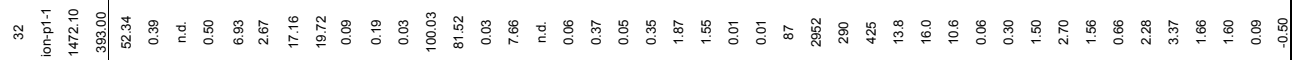

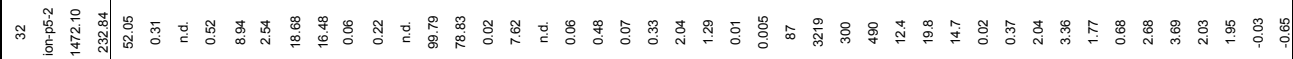

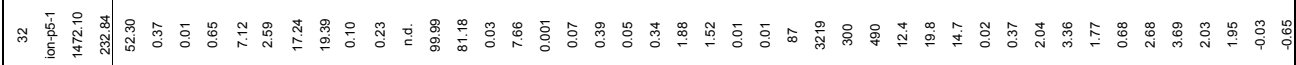

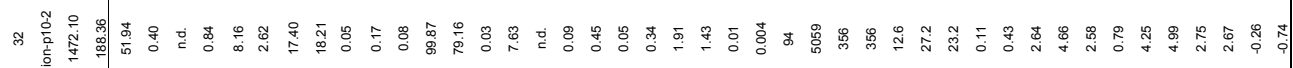

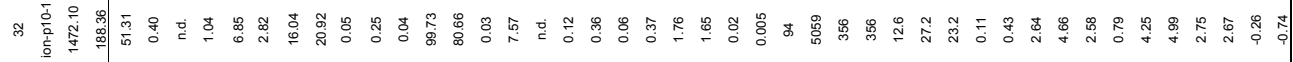

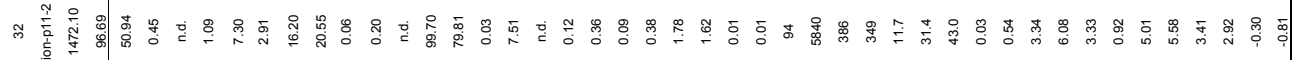

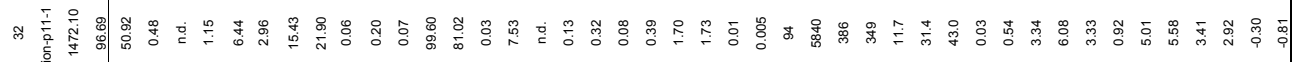

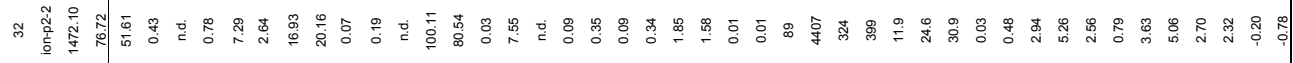

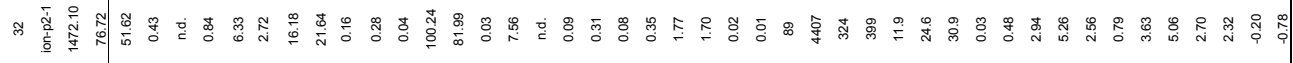

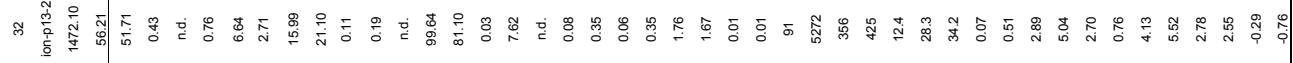

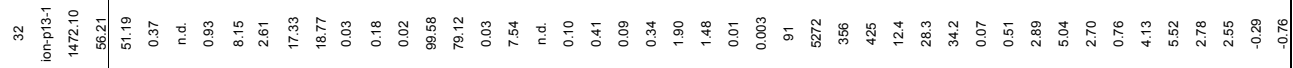

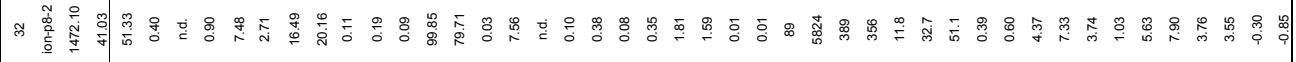

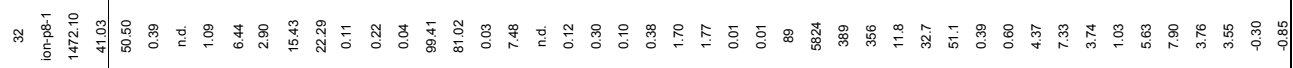

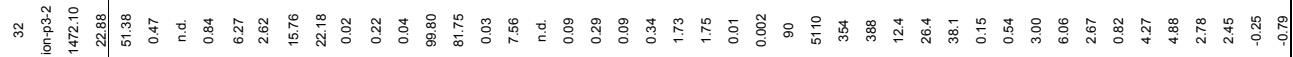

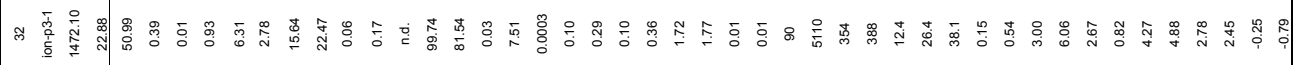

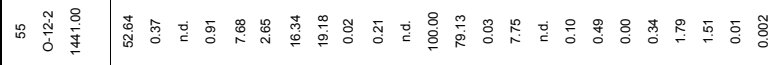

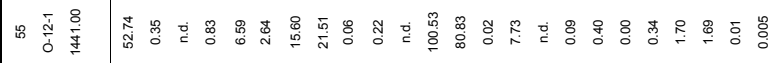

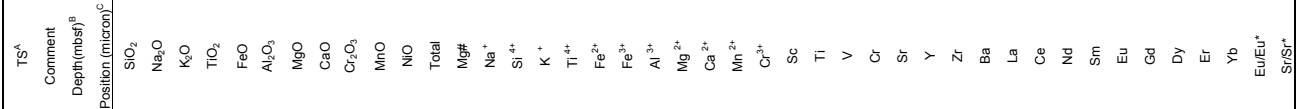




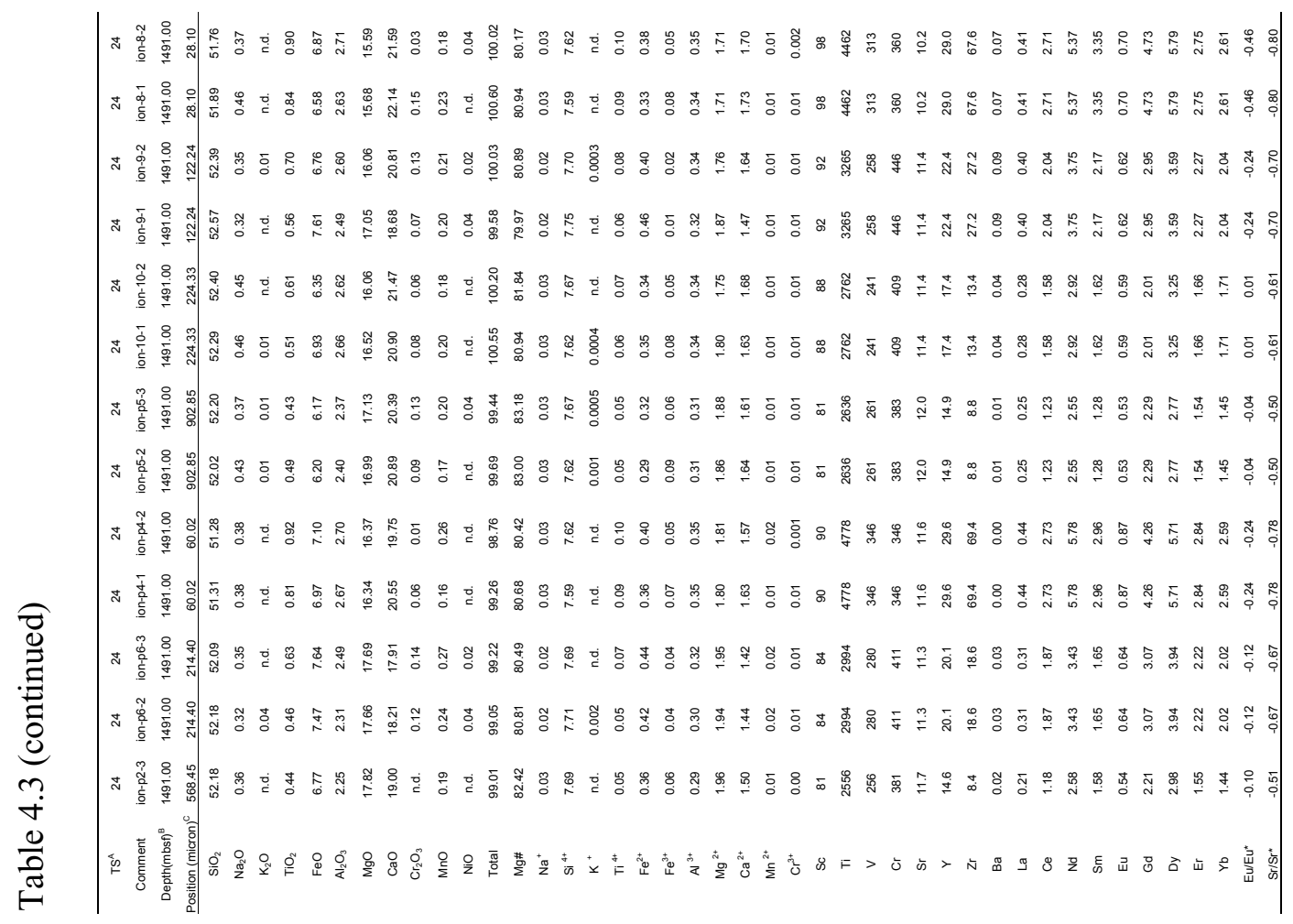


As shown in Figure 4.7, minor elements $\mathrm{Cr}, \mathrm{Al}$, and $\mathrm{Na}$ are roughly correlated with $\mathrm{Mg} \#(100 \mathrm{Mg} /[\mathrm{Mg}+\mathrm{Fe}])$ of clinopyroxene along the trend of differentiation by

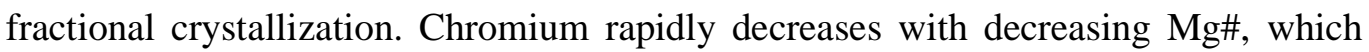
reflects the fact that $\mathrm{Cr}$ is highly compatible to pyroxene relative to melt during cotectic crystallization of the basltic melt. Alumina decreases while sodium increases

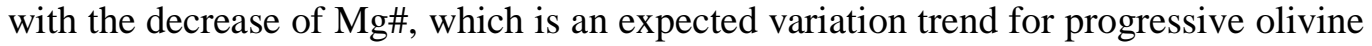
+ plagioclase +/- clinopyroxene crystallization.

Most strikingly, titanium is not correlated with Mg\# of clinopyroxene, although as an incompatible element it is expected to be strongly controlled by fractional crystallization. For a given $\mathrm{Mg \#}$ of clinopyroxene, the variation range for titanium can be up to a factor of 2. Dick et al., (2002) argued that the extremely large variation of Ti requires for extensive postcumulus melt-rock interaction between crystals and late stage melts.
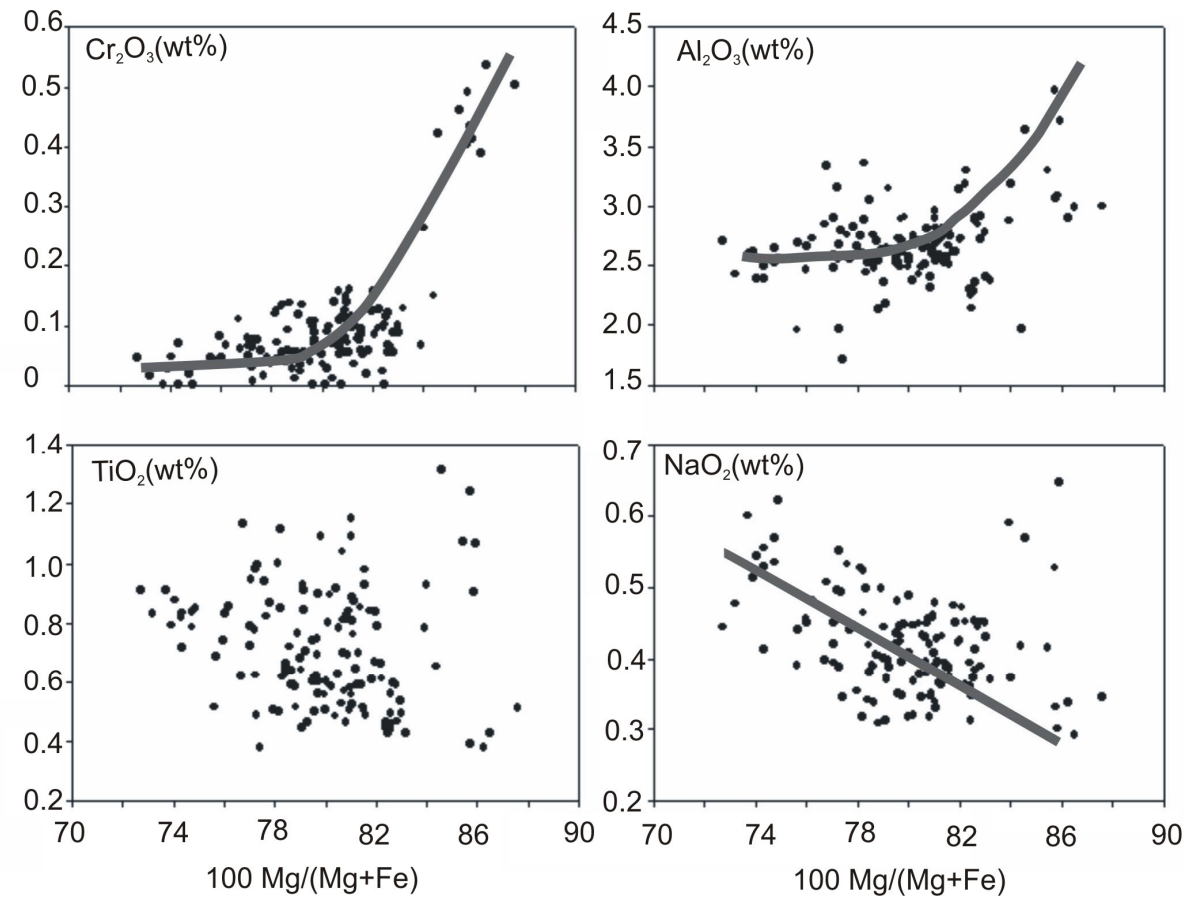

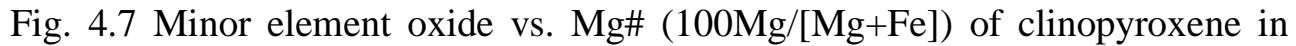
Leg 176 gabbros. 
As the most important host mineral of REE and other geochemically important trace elements, the geochemistry of clinopyroxene plays a key role in understanding the formation and evolution of lower oceanic crust, especially in constraining melt migration in crystal mush (Coogan et al., 2000a; Coogan et al., 2000b; Dick et al., 2002; Van Orman et al., 2002a). Therefore, both major and trace element compositions of clinopyroxene have been investigated in-situ to obtain detailed informations on mineral zoning for 5 thick-sections. The results are listed in Table 4.3 .

Except sample 16, 4 other samples (sample R2, sample 1, sample 32, and sample 24) have also been investigated by ion probe for trace element zoning in plagioclase. Sample 16 is a relatively fresh troctolite located at $1402.20 \mathrm{mbsf}$ of Hole 735B (Table 2.1). It was selected because clinopyroxene in this sample (troctolite) has the most primitive $\mathrm{Mg} \#[100 \mathrm{Mg} /(\mathrm{Mg}+\mathrm{Fe})]$ value of about 86 among all the investigated samples. The other 4 samples represent typical gabbros from the top, middle and bottom of Leg 176 gabbro (see Section 4.1.1).

Except for sample R2, the investigated crystals in the other samples all show continuous core to rim zoning patterns. As discussed above, zoning profiles obtained at high temperature stages may have been disturbed due to later stage alteration observed in this sample. Trace element zoning in component minerals (plagioclase and clinopyroxene) of gabbros seems to represent a common phenomenon in Hole 735B. In summary, three types of zoning pattern are observed for the investigated clinopyroxene.

The first type of zoning is represented by clinopyroxene in sample 24 , termed as type A. In general, incompatible trace elements such as REE are regularly enriched 
from core to rim, while compatible elements such as $\mathrm{Sr}$ have a relatively constant concentration throughout the whole crystal (Figure 4.8).
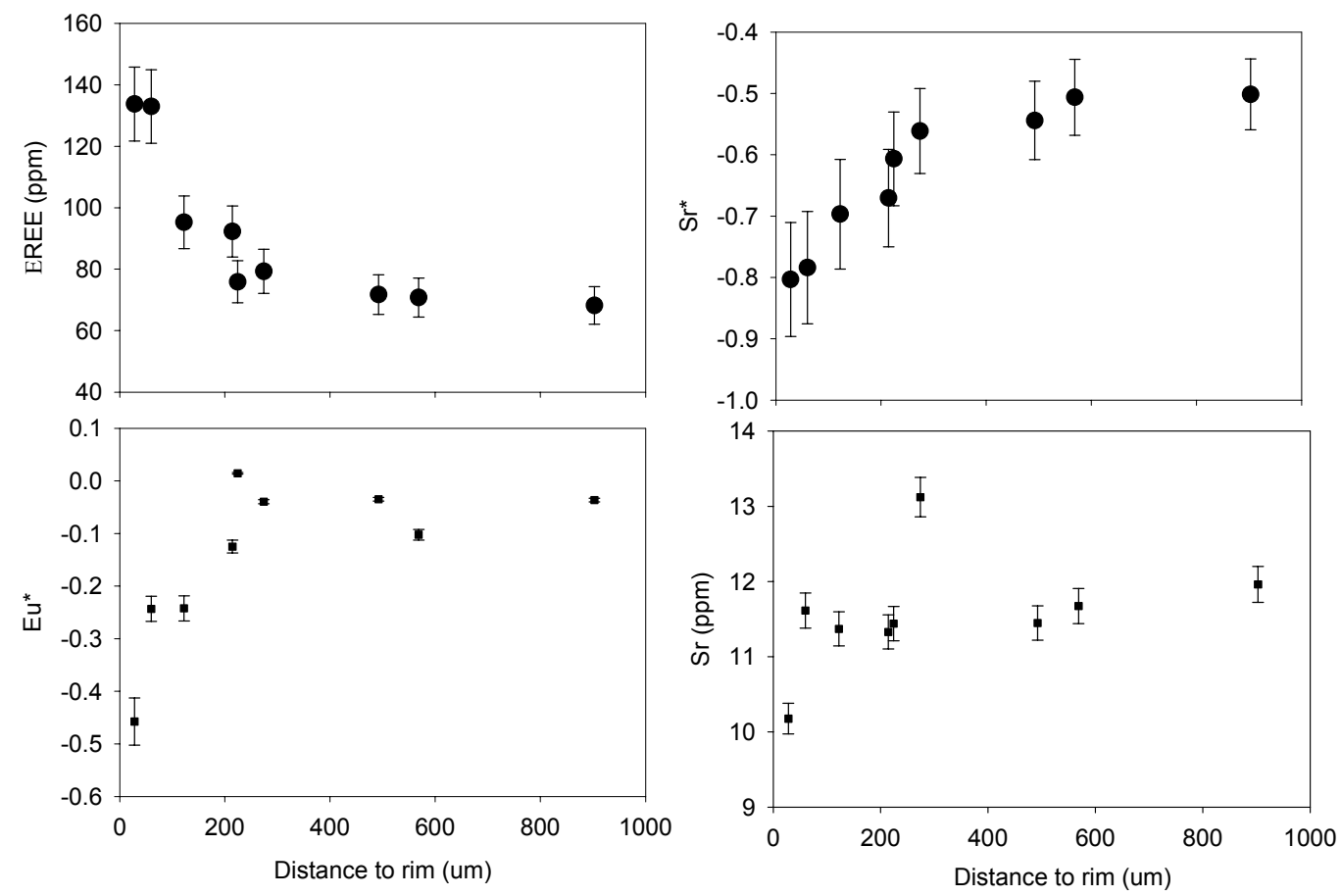

Fig. 4.8 Compositional profile of clinopyroxene in sample 24. EREE = total concentration of REEs, $\mathrm{Eu}^{*}(\mathrm{Eu}$ anomaly $)=\mathrm{Eu}_{\mathrm{N}} /\left[(\mathrm{Sm})_{\mathrm{N}}(\mathrm{Gd})_{\mathrm{N}}\right]^{1 / 2}-1, \mathrm{Sr}^{*}(\mathrm{Sr}$ anomaly) $=\mathrm{Sr}_{\mathrm{N}} /\left[(\mathrm{Ce})_{\mathrm{N}}(\mathrm{Nd})_{\mathrm{N}}\right]^{1 / 2}-1$ (Wood et al., 1979), where subscript $\mathrm{N}$ means chondrite normalization.

As shown in Figure 4.8, concentrations of rare earth elements increase continuously outward to the rim at the outer $400 \mu \mathrm{m}$ of the investigated clinopyroxene crystal with concentrations becoming uniform beyond that point toward the core. The REEs are nearly two times enriched at the rim compared to the core. Along with the increase of REEs, the negative Eu anomaly and Sr anomaly also continuously increase toward the rim from a nearly constant core area with no anomalies. All of these observations argue for a fractionation of plagioclase from a melt in a closed system, 
such as fractional crystallization of trapped melt. However, nearly constant compositions of $\mathrm{Sr}$ throughout the crystal are not in line with this idea. Sr as a highly compatible element for plagioclase, its concentration in the residual melt will drop quickly along with the ongoing crystallization of plagioclase. So it seems that an increase of $\mathrm{Ce}$ and $\mathrm{Nd}$ should account for the increase of negative $\mathrm{Sr}$ anomaly rather than a decrease of Sr.

Another important observation of trace element zoning is found in sample 16, which represents the second type of zoning, termed type B. In this investigated clinopyroxene crystal, incompatible and compatible elements are both continuously enriched toward the rim. As shown in Figure 4.9, La is about 10 times enriched at the rim relative to the core, while $\mathrm{Cr}$ and $\mathrm{Sr}$ are about 1 to 2 times enriched at the rim respectively. Obviously, neither plagioclase nor clinopyroxene fractional crystallization can account for this observation, simply because $\mathrm{Sr}$ is highly compatible in plagioclase while $\mathrm{Cr}$ is compatible in clinopyroxene. The concentrations of $\mathrm{Sr}$ and $\mathrm{Cr}$ will be expected to decrease in the residual melts along with the proceeding of the crystalliazion of plagioclase and clinopyroxene, respectively. One possibility to explain the simultaneous enrichment of $\mathrm{La}$ and $\mathrm{Sr}$ is an olivine fractionation in a closed system, as both $\mathrm{La}$ and $\mathrm{Sr}$ are incompatible in olivine. In such a case, enrichment of $\mathrm{La}$ and $\mathrm{Sr}$ in residual melt will simply be a result of volume reduction caused by olivine crystallization. Obviously a high degree fractionation of olivine (about 90\%) will be required to account for the nearly 10 times enrichment of $\mathrm{La}$, and this will cause a significant drop of both $\mathrm{Mg}$ and $\mathrm{Fe}$ in the residual melt. However as shown in table 4.3, the investigated clinopyroxene has a quite uniform concentration for both $\mathrm{MgO}$ and $\mathrm{FeO}$ with less than $2 \%$ relative standard deviations. At the same time, melting experiments show that it is quite 
unlikely to get olivine sole fractionation for trapped melt under low pressure conditions (about $1.5 \mathrm{kbar}$ for Hole 735B gabbro) at a low temperature stage (Hess, 1993). Furthermore, olivine fractionation by itself will not be able to explain the observed variation of negative $\mathrm{Eu}$ and $\mathrm{Sr}$ anomalies, which increase continuously from core to rim (Figure 4.9).
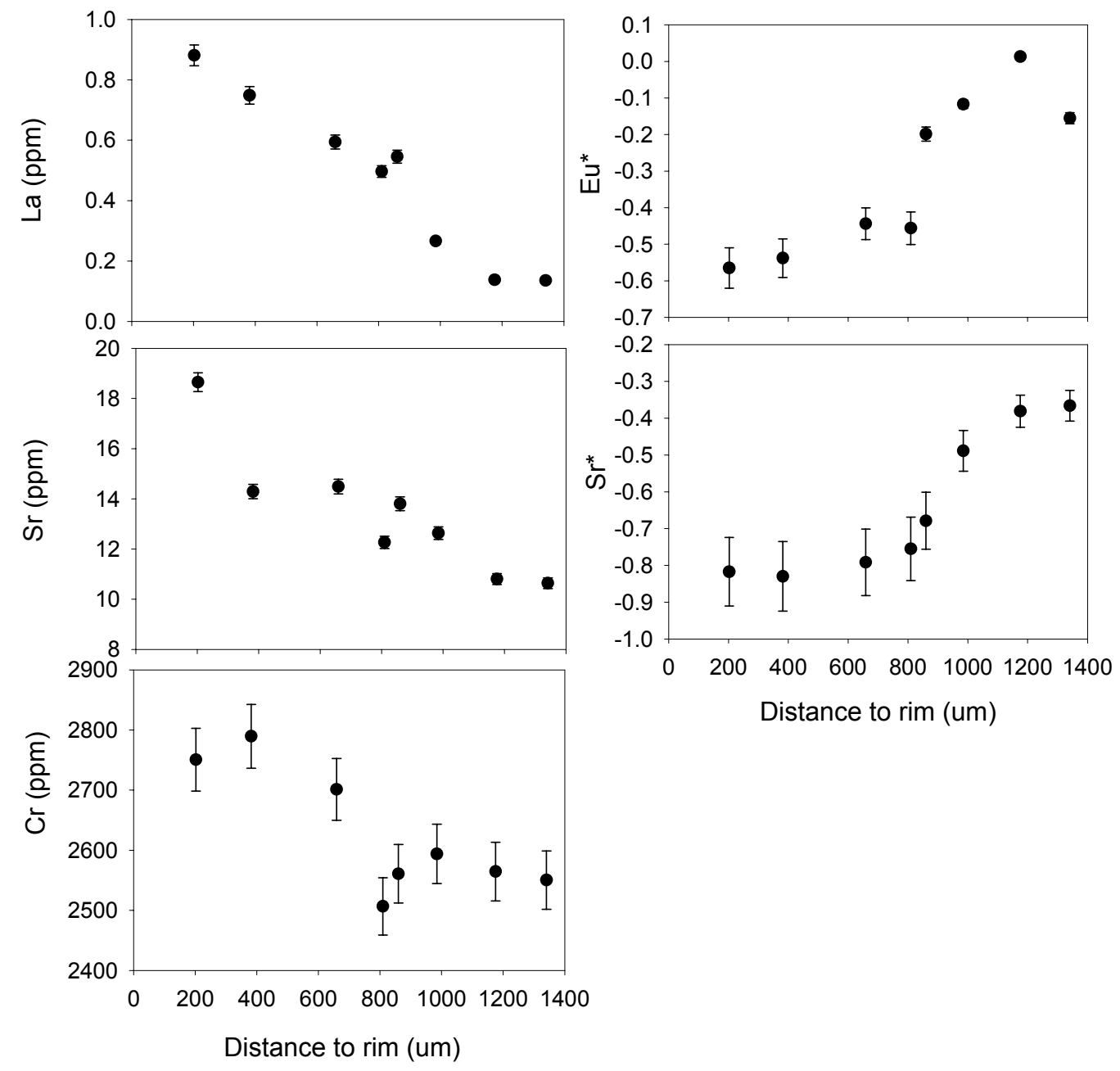

Fig. 4.9 Compositional variation of one clinopyroxene crystal in sample 16. Definitions for $\mathrm{Sr}^{*}$ and $\mathrm{Eu}^{*}$ are given in the caption of Figure 4.8.

The most interesting type of compositional zoning for clinopyroxene is observed in sample 1 and sample 32, termed type C. Compared to the other two types, the trace 
element zoning in these two samples seems more likely to be a result of fractional crystallization in a closed system. As shown in Figure 4.10, with the increase of La (a typical incompatible element) $\mathrm{Sr}$ and $\mathrm{Cr}$ (usually regarded as compatible elements) decrease outward from core to rim.
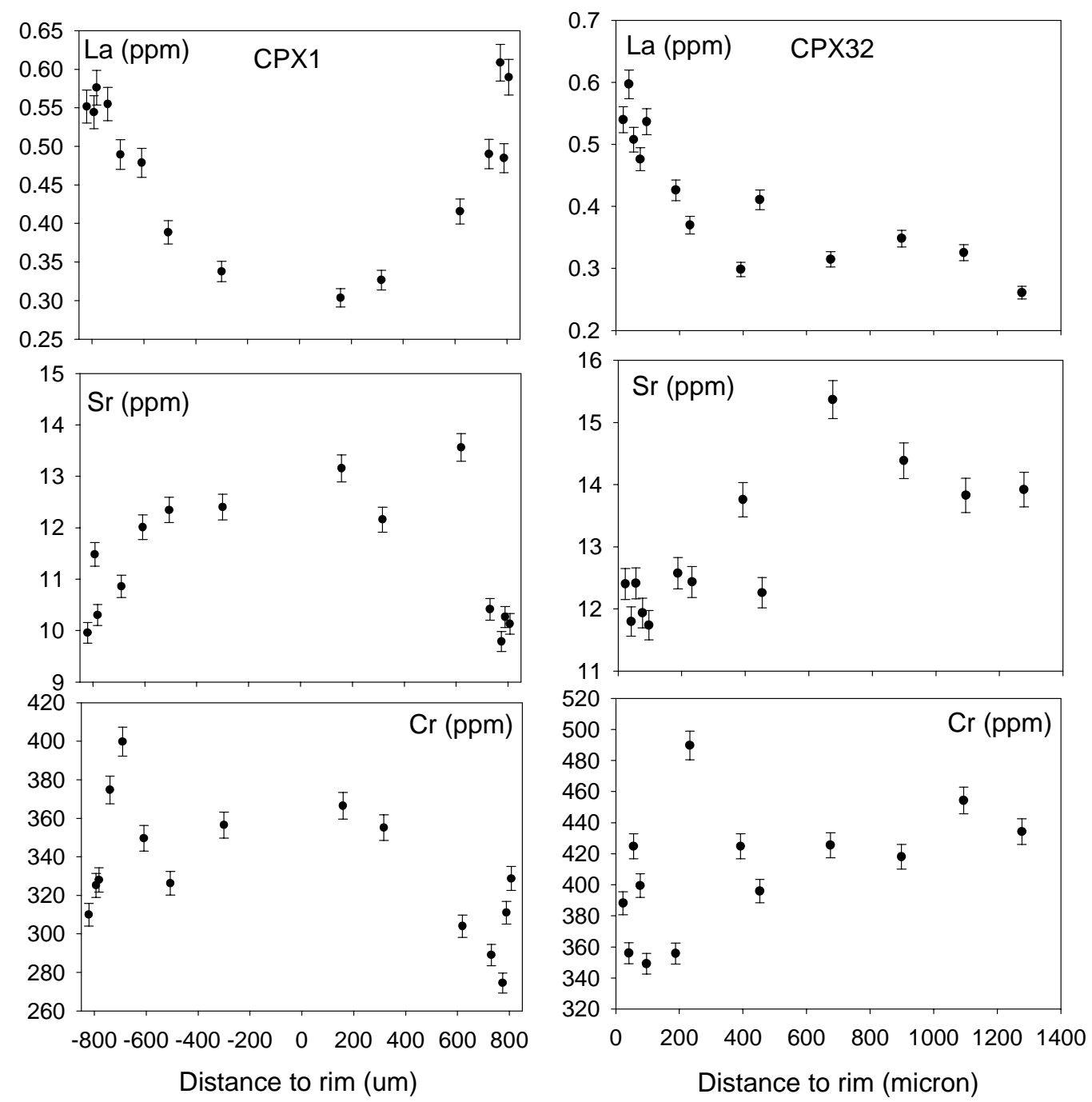

Fig. 4.10 Trace element zoning profiles acquired by in-situ ion probe analysis in CPX 1 and CPX 32. Sr and Cr show larger space variations, however most data points are still following along continually changed zoning profiles.

In summary, trace element zoning in component minerals of gabbro, including plagioclase and clinopyroxene, is well developed and preserved in Hole 735B. Compositional zonations in component minerals of gabbros may represent a common 
feature in the lower ocean crust, at least for those formed beneath slow-spreading ridges. Although a preliminary evaluation of the observed zoning profiles has been given above, various processes can cause the formation of mineral zoning, including both primary magmatic and secondary metasomatic processes (Tracy, 1982; Loomis, 1983; Chakraborty and Ganguly, 1991; Griffin et al., 1996). At the same time, it has been shown that mineral zonations in the lower ocean crust may provide the best means of understanding postcumulus processes, late-stage melt migration, and meltrock interaction, which are critical to constrain the formation of ocean crust (Coogan et al., 2000a; Coogan et al., 2000b; Dick et al., 2002). So the origin and its significance of the observed mineral zonations will be further discussed in Chapter 6. 


\section{Chapter 5 OXYGEN ISOTOPE GEOCHEMISTRY}

The $\delta^{18} \mathrm{O}$ data are summarized in Table 5.1 and plotted in Figure 5.1, the detailed measurement results are given in appendix (Table AT2). All the measured results have been corrected against standards (UWG-2 Garnet (+5.9\%o), San Carlos Olivine $(+5.2 \%)$, and MORB Glass $(+5.7 \%))$, and also includes the drift correction for daily measurements. The reference values for interpreting $\delta^{18} \mathrm{O}$ variations of mantle olivine, pyroxene, and plagioclase are 5.2\%o (Eiler et al., 1997), 5.6\%o (Mattey et al., 1994) and $6.1 \%$ (derived from the typical magmatic fractionation between plagioclase and pyroxene of $0.5 \%$, Gregory et al., 1981) respectively.

Table 5.1 Averages of oxygen isotope compositions for Hole 735B (Leg 176) gabbros.

\begin{tabular}{|c|c|c|c|c|c|c|c|c|c|}
\hline \multirow{2}{*}{$\begin{array}{c}\text { TS } \\
\text { number }\end{array}$} & \multirow{2}{*}{$\begin{array}{l}\text { Depth } \\
\text { (mbsf) }\end{array}$} & \multicolumn{6}{|c|}{ UV-Laser Analysis } & \multirow{2}{*}{$\begin{array}{c}\text { Plag } \\
\text { Conv. }\end{array}$} & \multirow{2}{*}{$\begin{array}{c}\text { Bulk } \\
\text { Analysis }\end{array}$} \\
\hline & & Plag & sd & Cpx & sd & OI & sd & & \\
\hline 126 & 509.48 & 6.0 & 0.2 & 5.5 & 0.1 & 5.1 & 0.1 & 6.1 & N.A. \\
\hline 43 & 517.88 & 6.2 & 0.2 & 5.5 & 0.1 & 5.1 & 0.1 & 6.2 & 5.2 \\
\hline 26 & 518.16 & 6.5 & 0.4 & 5.6 & 0.2 & 5.1 & 0.2 & N.A. & N.A. \\
\hline $\mathrm{R} 2$ & 546.89 & 6.5 & 0.4 & 5.1 & 0.4 & 5.0 & 0.2 & 6.3 & N.A. \\
\hline R1C & 719.86 & N.A. & & N.A. & & N.A. & & 5.5 & N.A. \\
\hline $65 \mathrm{a}$ & 723.32 & 4.0 & 0.4 & 5.2 & 0.2 & 5.8 & 0.2 & 3.7 & N.A. \\
\hline 6 & 777.5 & N.A. & & N.A. & & N.A. & & 5.1 & N.A. \\
\hline 65 & 871.8 & 6.1 & 0.2 & 5.4 & 0.2 & 5.0 & 0.2 & N.A. & N.A. \\
\hline 1 & 881.65 & 6.6 & 0.2 & 5.6 & 0.4 & 5.1 & 0.2 & 6.5 & 5.7 \\
\hline 95 & 956.35 & 6.2 & 0.2 & 5.5 & 0.2 & 5.1 & 0.1 & N.A. & N.A. \\
\hline $28 \mathrm{~A}$ & 1001.22 & 6.2 & 0.2 & 5.1 & 0.2 & 4.5 & 0.2 & N.A. & N.A. \\
\hline 69 & 1044.74 & 6.4 & 0.2 & 5.6 & 0.2 & 5.0 & 0.1 & N.A. & N.A. \\
\hline 71 & 1109.32 & 6.2 & 0.1 & 5.2 & 0.2 & & & N.A. & N.A. \\
\hline 117 & 1150.51 & 6.0 & 0.2 & 5.1 & 0.1 & 5.0 & 0.1 & N.A. & N.A. \\
\hline R4 & 1264 & 6.5 & 0.1 & 5.4 & 0.2 & 5.0 & 0.1 & N.A. & N.A. \\
\hline $26 a$ & 1278.51 & N.A. & & N.A. & & N.A. & & 6.3 & N.A. \\
\hline 31 & 1306.07 & 6.2 & 0.2 & 5.4 & 0.2 & 5.0 & 0.2 & N.A. & N.A. \\
\hline $49 a$ & 1336.23 & 6.2 & 0.2 & 5.4 & 0.1 & N.A. & & 6.4 & N.A. \\
\hline 16 & 1402.2 & 6.3 & 0.1 & 5.6 & 0.1 & 5.0 & 0.1 & N.A. & N.A. \\
\hline 5 & 1431 & 6.3 & 0.1 & 5.4 & 0.2 & 5.0 & 0.2 & 6.8 & N.A. \\
\hline 17 & 1433.36 & 6.1 & 0.2 & 5.4 & 0.2 & 5.0 & 0.1 & 6.2 & N.A. \\
\hline 55 & 1441 & 6.4 & 0.1 & 5.4 & 0.2 & 5.0 & 0.1 & 6.1 & N.A. \\
\hline 32 & 1472.1 & 6.4 & 0.1 & 5.2 & 0.2 & N.A. & & N.A. & 5.5 \\
\hline 24 & 1491.4 & 6.4 & 0.1 & 5.3 & 0.1 & N.A. & & 6.4 & N.A. \\
\hline Mud A & & & & & & & & & 5.4 \\
\hline Mud B & & & & & & & & & 5.1 \\
\hline Mud C & & & & & & & & & 6.3 \\
\hline
\end{tabular}

Note: Detailed information for these samples is listed in Table 2.1. Plagplagioclase, Cpx-clinopyroxene, Ol-olivine, $\mathrm{Conv}-\delta^{18} \mathrm{O}$ value of plagioclase measured by conventional method, N.A. = no analysis, sd is the standard deviation of all measurements in the sample, which represents the degree of in-sample variations. 


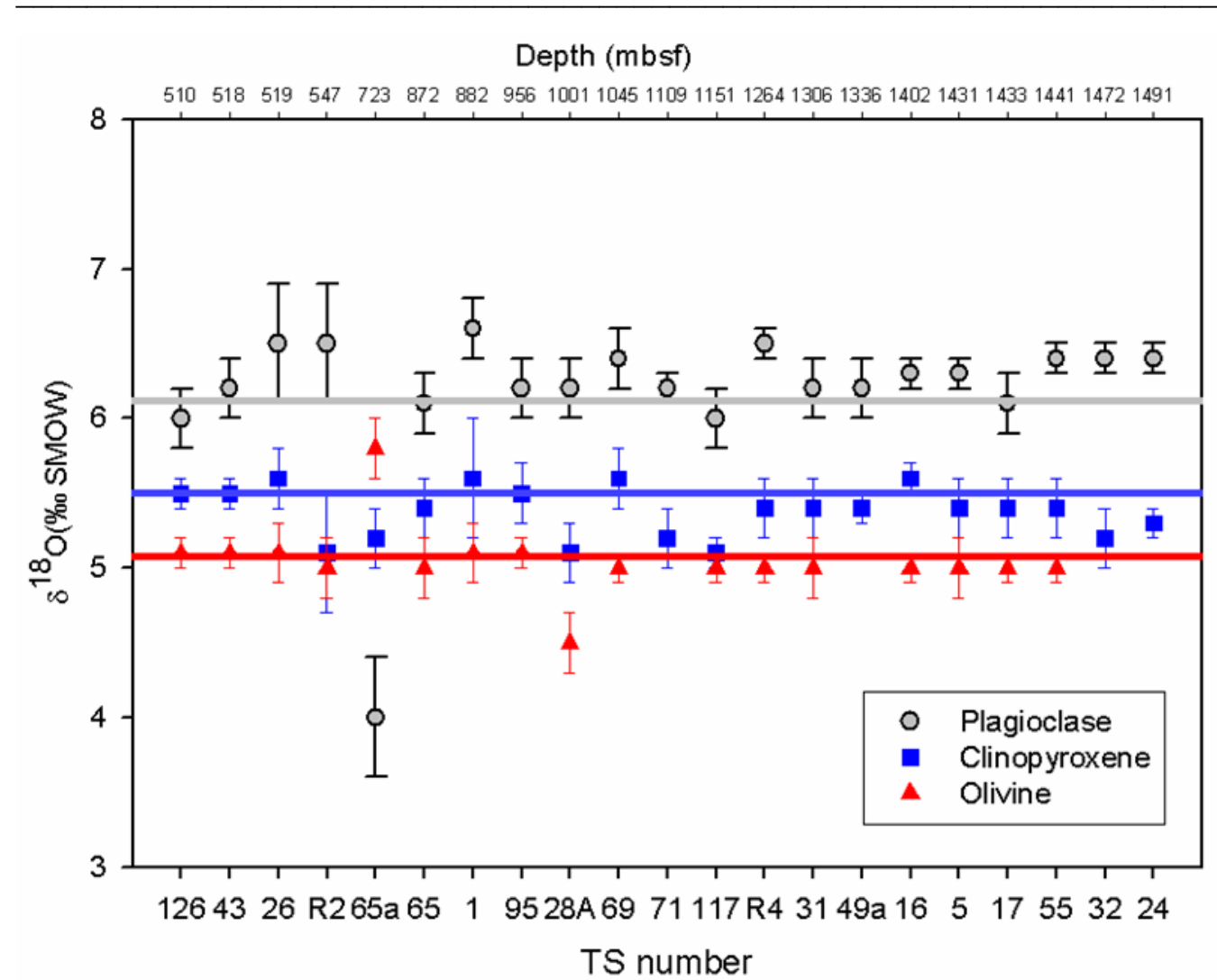

Fig. 5.1 Oxygen isotopic composition of the constituent minerals in Hole 735B (Leg 176) gabbros. cpx-clinopyroxene; plag-plagioclase, solid lines represent the mantle reference values. Error bars represent in-sample variations.

In general the $\delta^{18} \mathrm{O}$ values for the compositional minerals in these gabbros are in the order of $\delta^{18}$ Oplag $>\delta^{18} \mathrm{Ocpx}>\delta^{18}$ Oolivine. Among them, olivine has the most uniform $\delta^{18} \mathrm{O}$ composition. Except for two samples (sample 65a and sample 28A), all the other olivines have oxygen isotope compositions around its mantle reference value of $+5.2 \%$. Olivine in sample $65 \mathrm{a}$ and sample $28 \mathrm{~A}$ has $\delta^{18} \mathrm{O}$ value of $5.8 \pm 0.2 \%$ and $4.5 \pm 0.2 \%$, respectively. Clinopyroxene has a larger variation than olivine, with few samples showing slightly depleted $\delta^{18} \mathrm{O}$ values. However, as shown in Figure 5.2, more than $90 \%$ of the measured $\delta^{18} \mathrm{O}$ values of clinopyroxenes ( 24 out of 27 samples in total) fall into the range of its mantle reference value of the $+5.5 \%{ }_{0} \pm 0.2 \%$. Plagioclase shows the largest variation, compared with its mantle reference value of 
$+6.1 \%$, both depleted and enriched $\delta^{18} \mathrm{O}$ values are observed. However, shown in Figure 5.2, most of the analyzed plagioclases are slightly enriched in ${ }^{18} \mathrm{O}$.

Suggested by the small values of the standard deviations within individual grains, there is no obvious systematic core to rim variation of $\delta^{18} \mathrm{O}$ for plagioclase, clinopyroxene, and olivine, even for large crystals. $\delta^{18} \mathrm{O}$ values for plagioclase analyzed with the UV-laser ablation method are in good agreement with values for single plagioclase crystals from the same sample measured with the conventional method. The good agreements suggest that plagioclase can be precisely in-situ determined with our analytical procedure despite the oxygen isotope analytical problem for in-situ laser based analysis of feldspars caused by fluorination at room temperatures (Elsenheimer and Valley, 1993).

In a closed system, the mineral oxygen isotopic composition in an igneous rock is determined by its source magma composition and fractionation among coexisting minerals. In an open system, i.e. the rock exchanges oxygen with an external reservoir, the final composition of an individual mineral will be mainly controlled by the temperature of exchange and the compositions of the reservoir as well as its actual mass ratio to minerals.

MORBs (mid-ocean ridge basalts) are regarded to be representative of the bulk character of the upper, sub-oceanic mantle. MORBs have a very uniform oxygen isotope composition of $+5.7 \%$, with a standard deviation of $0.2 \%$ o that is equivalent to the analytical uncertainty typically reported in the literature for individual oxygen isotope ratio measurements of silicate rocks and minerals (Harmon and Hoefs, 1995). The uniformity of oxygen isotope composition in the upper mantle has also been verified by the investigation of mantle peridotite, which gave a bulk mantle $\delta^{18} \mathrm{O}$ of $+5.5 \%$ o (Mattey et al., 1994). Recently several investigation on MORB have revealed 
that ${ }^{18} \mathrm{O}$ depleted or enriched mantle may exist locally caused by recycling of crust (Eiler et al., 1997; Eiler et al., 2000; Macpherson et al., 2000; Cooper et al., 2004). However, given the uniform composition of investigated olivine and clinopyroxene, source magma variations can be excluded to account for the mineral $\delta^{18} \mathrm{O}$ variations.

The original oxygen isotope compositions of a mineral obtained during the crystallization by equilibrium fractionation between mineral and melt tend to be adjusted during subsolidus cooling, especially for slowly cooled rocks such as plutonic gabbros (Eiler et al., 1993). Mineral-mineral fractionation factors tend to increase with decreasing temperatures (Chacko et al., 2001). As a result in a slowly cooling gabbro, plagioclase becomes heavier and clinopyroxene becomes lighter with decreasing temperatures.

In an open system, where an external reservoir with oxygen isotope compositions differing from that in equilibrium with the minerals, oxygen isotope exchange will occur via solid diffusion or dissolution-precipitation process. For oceanic gabbro, the degree of oxygen exchange is determined by the mineral- $\mathrm{H}_{2} \mathrm{O}$ fractionation factors and water/mineral ratio. Oxygen isotope fractionation factors between rock forming minerals and water at near Earth surface temperatures are large $(1000 \ln \alpha \approx+15$ to $35 \%$ ), while the fractionation factors decrease in magnitude with increasing temperatures and even change its directions of ${ }^{18} \mathrm{O}$ exchange at certain temperatures (Muehlenbachs, 1998b; Chacko et al., 2001). At equilibrium, silicate-water ${ }^{18} \mathrm{O} /{ }^{16} \mathrm{O}$ fractionations change from positive to negative at high temperatures (Matthews, 1983). The equlibrium $\Delta_{\text {olivine-H2O }}$ is suggested to be about $-1.5 \%$ at $1000^{\circ} \mathrm{C}$, becoming more negative as temperature increases, down to a minimum of about $2.5 \%$ at about $600^{\circ} \mathrm{C}$; at lower temperatures it may again increase. Thus at low temperature, the exchange will cause enrichment of ${ }^{18} \mathrm{O}$ in minerals whereas at higher 
temperature ${ }^{18} \mathrm{O}$ will partition into $\mathrm{H}_{2} \mathrm{O}$ and cause a decrease of $\delta^{18} \mathrm{O}$ values of mineral. For instance, the transitional temperature for feldspar is found to be about $250^{\circ} \mathrm{C}$ (Mattews et al., 1983).

\subsection{Olivine and Clinopyroxene}

Compared to plagioclase, most of the measured clinopyroxenes and olivines have a small range of variation for their $\delta^{18} \mathrm{O}$ values (Table 5.1 and Figure 5.1). With few exceptions, most of the $\delta^{18} \mathrm{O}$ values for clinopyroxene and olivine are within $0.2 \%$ of the average value for their reference values in the mantle. This suggests that most of the clinopyroxene and olivine have preserved their primary mantle values.

As shown in Figure 5.2, there is a uniform fractionation between olivine and its coexisting clinopyroxene, with an average $\Delta_{\text {cpx-olivine }}\left(\delta^{18} \mathrm{O}_{\mathrm{cpx}}-\delta^{18} \mathrm{O}_{\text {olivine }}\right)$ value of $+0.5 \%$ o $(+0.4 \%$ o to $+0.6 \%$ o $)$. This difference is in the order of isotopic equilibrium observed at temperatures of about $1200^{\circ} \mathrm{C}$ (Chiba et al., 1989) and still in the range of fractionations between clinopyroxene and olivine in mafic extrusive rocks of $+0.22 \%$ o to $+0.67 \%$ (Anderson et al., 1971). The predicted larger fractionations accompanying slow cooling of plutonic gabbros (Eiler et al., 1993) are not observed. The above observations suggest that the majority of this gabbro block has been rapidly quenched to a temperature at which both olivine and clinopyroxene are closed to further oxygen isotope exchange with an external reservoir such as sea water. Derived from the difference between $\mathrm{U}-\mathrm{Pb}$ ages of zircons from grainitic veins and the age of magnetization of the gabbros, it is believed that Hole 735B gabbros have an rapid initial quench history with a cooling of about $800^{\circ} \mathrm{C}$ in the first 0.5 million years (Natland and Dick, 2002). 


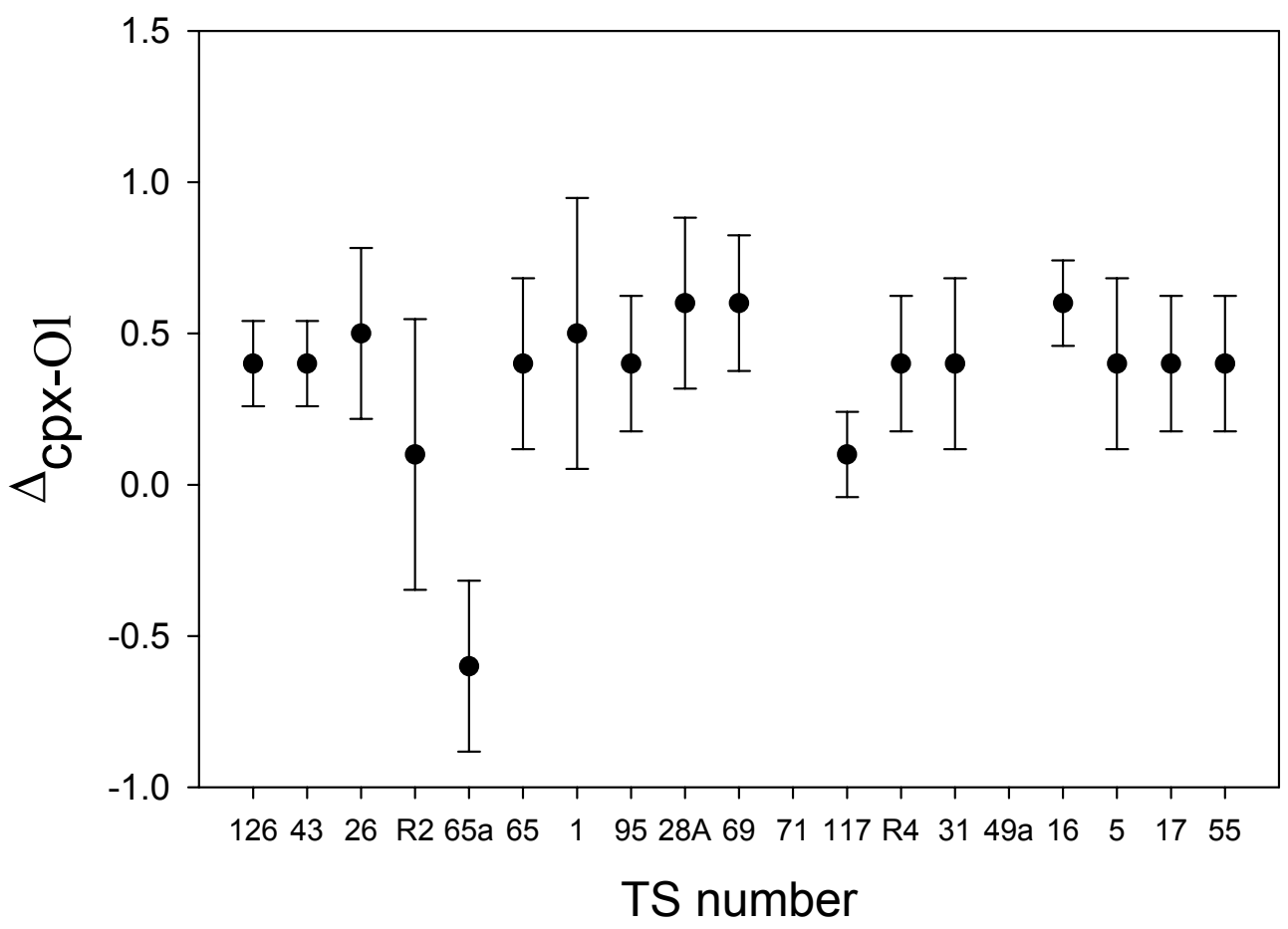

Fig. 5.2 Comparison of $\delta^{18} \mathrm{O}$ compositions of clinopyroxene and olivine in Hole 735B (Leg 176) gabbros, where $\Delta_{\text {cpx-olivine }}=\delta^{18} \mathrm{O}_{\mathrm{cpx}}-\delta^{18} \mathrm{O}_{\text {olivine. }}$. Detailed sample information related to TS number is given in Table 2.1.

In contrast to the uniform positive $\Delta_{\text {cpx-olivine }}$ values, a negative fractionation between clinopyroxene and olivine of $-0.6 \%$ is observed in sample $65 \mathrm{a}$. Negative $\Delta_{\text {cpx-olivine }}$ fractionations have been interpreted as a result of exchange with fluids having variable $\delta^{18} \mathrm{O}$ compositions (Gregory et al., 1989b). As shown in Table 5.1, this negative fractionation is caused by the unusually high $\delta^{18} \mathrm{O}$ value of $\sim 5.8 \%$ for olivine. Low temperature alteration products related to the formation of clay minerals or serpentine can cause the increase of $\delta^{18} \mathrm{O}$ composition of olivine. However, optical examination and microprobe analyses of this olivine grain showed that it does not contain any serpentine or any cracks filled with clay minerals. At the same time, if low temperature alteration has occurred in this sample, plagioclase and clinopyroxene would show significantly heavier oxygen isotope compositions rather than the 
observed depleted $\delta^{18} \mathrm{O}$ values. Indeed, the plagioclase in this sample shows the lowest $\delta^{18} \mathrm{O}$ values of about $+4.0 \%$. Thus causes other than open system alterations must account for the observed high $\delta^{18} \mathrm{O}$ values of olivine, such as a magma source with an extremely high $\delta^{18} \mathrm{O}$ composition. We do note, however, that this may represent a poor analysis, as it is not possible to make any further UV-laser analysis on this olivine grain due to its relatively small size.

It is interesting to note that there are two samples (sample R2 and sample 117) showing quite small $\Delta$ cpx-olivine values of $+0.1 \%$. The clinopyroxenes in these two samples have relatively depleted $\delta^{18} \mathrm{O}$ values of $\sim 5.1 \%$, which is the cause for the observed small fractionations between clinopyroxene and olivine. In contrast to clinopyroxene, the plagioclase in sample $\mathrm{R} 2$ has an enriched $\delta^{18} \mathrm{O}$ value of $6.5 \%$, while in sample 117 the plagioclase appears to have a normal mantle value of $6.0 \%$. Thus, it seems neither low temperature alteration nor high temperature alteration can account for the observed mineral $\delta^{18} \mathrm{O}$ compositions. However, as pyroxene has a much higher closure temperature (about $500^{\circ} \mathrm{C}$ ) to oxygen exchange than plagioclase, this can be interpreted by a two-stage alteration. At the high temperature stage, $\delta^{18} \mathrm{O}$ of both pyroxene and plagioclase was lowered by exchange with an external reservoir with low $\delta^{18} \mathrm{O}$ value. But at a later stage with lower temperatures, pyroxene became closed to oxygen exchange, so that their depleted $\delta^{18} \mathrm{O}$ values have been preserved, whereas the depleted $\delta^{18} \mathrm{O}$ values of plagioclase became enriched caused by oxygen exchange occurring at lower temperatures.

A process of subsolidus oxygen exchange between pyroxene and plagioclase may be able to account for this observation. In a closed system with a fixed whole rock $\delta^{18} \mathrm{O}$ value, with slowly decreasing temperature, plagioclase should become heavier 
and pyroxene should become lighter in oxygen isotope compositions (Ito and Clayton, 1983). However, as discussed above, the uniform $\Delta$ cpx-olivine observed in the majority of gabbros throughout the whole section suggests that the necessary condition for an extensive subsolidus exchange between plagioclase and clinopyroxene, i.e. a slow cooling rate does not exist. However, sample R2 and sample 117 may have a localized different cooling rate. As this contrasting behavior of $\delta^{18} \mathrm{O}$ compositions between plagioclase and clinopyroxene is not observed in other samples, even several meters apart from these two samples, the rocks are required to have an extremely highly localized cooling history down a scale of meters. Although, it has been shown that the cooling rate of lower oceanic crust varies with depth (Coogan et al., 2002), so far there is no evidence for a localized cooling rate difference to such small scale.

Previous studies on Hole 735B gabbro have shown that alteration has occurred over a range of temperatures and that in some samples the contrasting isotopic effects of high and low temperature alteration can be superimposed (Stakes and O'Neil, 1982; Alt and Anderson, 1991; Hart et al., 1999). At solidus temperature, all minerals have been in oxygen isotopic equilibrium. As the rocks cooled, olivine remained closed to oxygen exchange, but pyroxene, plagioclase, and possibly oxide minerals continued to equilibrate. However, due to the rapid initial cooling rate $\left(\sim 1600^{\circ} \mathrm{C} / \mathrm{Ma}\right)$, this subsolidus exchange did not cause significant adjustment of the $\delta^{18} \mathrm{O}$ compositions of clinopyroxene and plagioclase. Later, with the beginning of deformation rock begins to shear and some fractures form, which leads to hydrothermal fluid (seawater or seawater derived fluid) infiltration into the rocks. As conditions for the percolation of water to great depth did not exist beneath the rift valley, and alteration was largely limited to the upper portions of the gabbroic crust. However, hydrothermal fluids can 
also ingress deeper at some locations along cracks and microfractures in the lower section. During this process, ${ }^{18} \mathrm{O}$ was extracted from both clinopyroxene and plagioclase into the seawater related hydrothermal fluid.

Before a normal cooling profile could be established, however, the massif was unroofed and rapidly uplifted to the sea floor. With re-establishment of a normal conductive geotherm, circulation of seawater occurred through a relatively restricted set of open fractures. During the uplift and fracturing of the basement block to form the transverse ridge and core complex, different styles of low-grade alteration that are related to fluid percolation were superimposed on the high-temperature alterations. At this stage, the exchange rates for pyroxene became too slow for the continuation of oxygen exchange, thus its depleted $\delta^{18} \mathrm{O}$ value obtained at high temperature stage were preserved. Whereas, plagioclase can still exchange its oxygen with fluids and the

reverse of the exchange direction for ${ }^{18} \mathrm{O}$ at low temperature (Chacko et al., 2001) caused to the reset of its depleted $\delta^{18} \mathrm{O}$ value to become enriched.

\subsection{Plagioclase}

It is well known that plagioclase is more sensitive to subsolidus hydrothermal ${ }^{18} \mathrm{O}$ exchange than any other silicate (Criss et al., 1987; Gregory et al., 1989a). Plagioclase can exchange oxygen with seawater at least 10 to 20 times faster than coexisting pyroxene and continues to exchange oxygen at an observable rate to temperatures lower than $350^{\circ} \mathrm{C}$ after olivine and pyroxene have become closed to oxygen exchange (Ito et al., 1983).

As shown in Table 5.1 and Figure 5.2, although there are several samples with either depleted or enriched $\delta^{18} \mathrm{O}$ values, $\delta^{18} \mathrm{O}$ compositions of more than $60 \%$ of 
measured plagioclase fall in the range of compositions for its mantle reference value of $6.1 \% \circ \pm 0.2 \%$.

There is only one sample that shows significantly lighter $\delta^{18} \mathrm{O}$ values of $\sim 4.0 \%$, with a negative fractionation with clinopyroxene of $-1.2 \%$. Under equilibrium conditions, $\Delta$ (plagioclase-pyroxene) is positive (Chacko et al., 2001; Chiba et al., 1989; Gregory et al., 1989). The reverse relation is a sign of disequilibrium exchange in open systems involving an external reservoir whose oxygen isotope composition is lighter than that of clinopyroxene (Muehlenbachs and Clayton, 1976; Gregory and Taylor, 1981b; Muehlenbachs, 1998a). In the case of oceanic gabbro, seawater is most likely the external oxygen reservoir.

Among the plagioclases, a few of them have elevated $\delta^{18} \mathrm{O}$ values of about $6.5 \%$ o (Table 5.1). Several possibilities exist to cause the enrichment in plagioclase: (1) Subsolidus exchange with pyroxene, in a closed system with fixed rock $\delta^{18} \mathrm{O}$, plagioclase becomes heavier and pyroxene become lighter with exchange at decreasing temperatures; (2) exchange with an external reservoir and (3) contamination by intergrowths, inclusions, or exsolution of another phase.

The third possibility is quite unlikely, as great caution has been paid to avoid such a contamination when the point was selected for the measurement with the aid of a 1/3-inch CCD camera and two achromats, which can enable a magnification from 10 to 100 times (Wiechert and Hoefs, 1995). However it is possible that some mineral grains may contain residues of partial melting, as they are only detectable in the backscattered electron images (Koepke et al., 2003). But at the temperature of partial melting (up to $1000^{\circ} \mathrm{C}$, Koepke et al., 2003), the fractionation between mineral and water tends to be zero. So given the general small water/rock ratio at lower section, 
the modification of oxygen isotope caused by reaction with seawater during partial melting process will not be detectable.

As the coexisting clinopyroxene in the samples containing plagioclase with elevated $\delta^{18} \mathrm{O}$ values does not show the predicted lower $\delta^{18} \mathrm{O}$ values caused by subsolidus exchange with plagioclase, the first possibility can also be excluded. The discussion on the uniform $\Delta c p x$-olivine has also verified the idea that extensive subsloidus exchange caused by slow cooling rate did not occur in this gabbro section.

Thus, the enrichment of ${ }^{18} \mathrm{O}$ argues for the penetration of seawater at a relative low temperature but still higher than the closure temperature for plagioclase, most probably at temperatures around $250^{\circ} \mathrm{C}$.

In summary, we conclude that in contrast to the obvious seawater penetrations in the upper 500-meter section (Hart et al., 1999), seawater penetration was very limited in the lower part of Hole 735B gabbro. But fluids related to seawater do penetrate into the lower part at some locations, which may be related to deformation or fault acting as pathway. 


\section{Chapter 6 DISCUSSION}

\subsection{Chemical Evolution of Hole 735B Gabbros}

\subsubsection{Mineral Co-variations}

Shown in Figure 6.1 are plots of co-variations among plagioclase, olivine, and clinopyroxene. Overall there are good correlations among them, i.e. plagioclase anorthite contents are positively related with $\mathrm{Mg} \#(100 \mathrm{Mg} /[\mathrm{Mg}+\mathrm{Fe}])$ for both olivine and clinopyroxene, and $\mathrm{Mg \#}$ for the latter two ferromagnesian minerals is also positively related with each other. These co-variation trends are consistent with crystallization along olivine-plagioclase, olivine-plagioclase-clinopyroxene cotectics, which indicates magmatic differentiation along a tholeiitic liquid line of descent is the primary control of the evolution of this gabbro section.
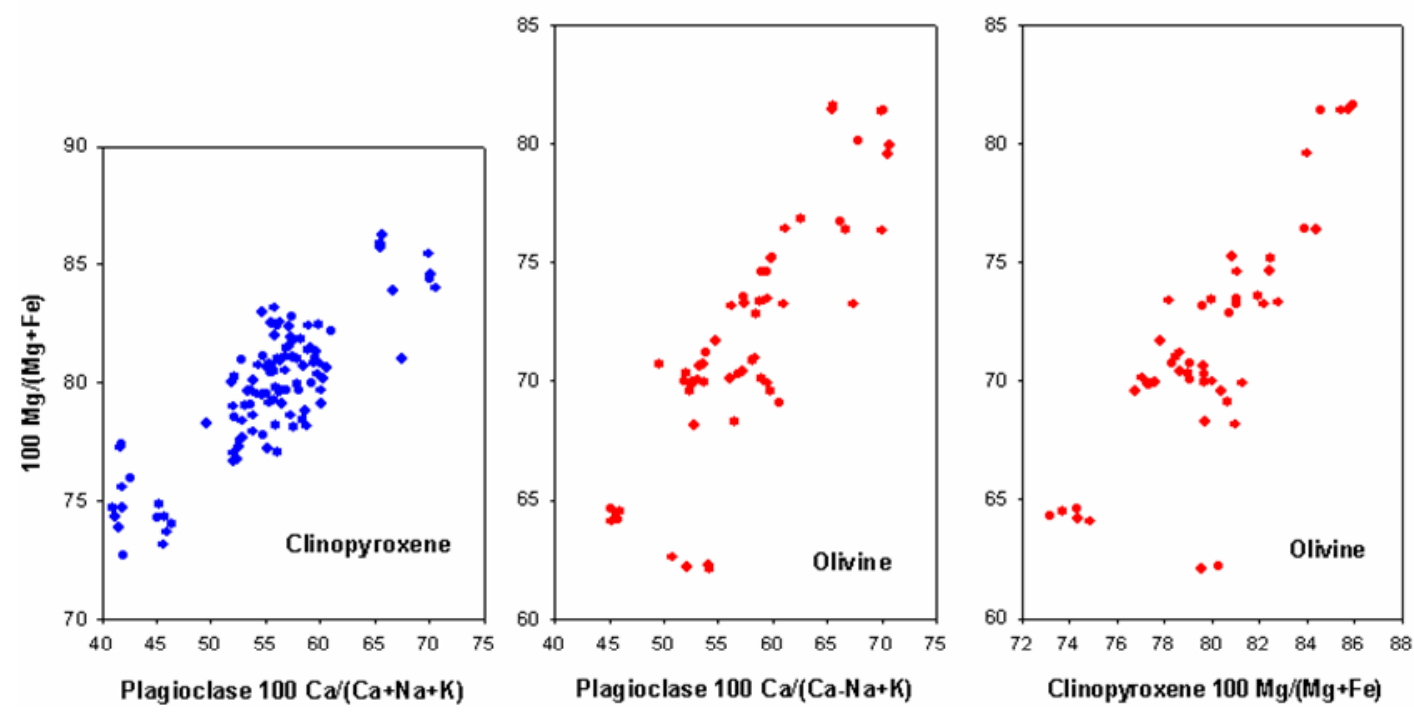

Fig. 6.1 Molar ratio co-variations of plagioclase anorthite and Mg\# (100 $\mathrm{Mg} /[\mathrm{Mg}+\mathrm{Fe}])$ of clinopyroxene and olivine in Hole 735B (Leg176) gabbros.

However there is a large scatter, with about $10 \mathrm{~mol} \%$ or greater variation for anorthite contents at a given $\mathrm{Mg \#}$ of clinopyroxene and olivine and $\sim 10 \mathrm{~mol} \%$ 
variations for any particular Mg\# value of olivine or clinopyroxene. This is far outside the analytical precision of the electron microprobe. It could be a result of intrusion and crystallization of different melts differing in the degrees of mantle melting (Meyer et al., 1989) or it could be due to postcumulus processes such as the interaction between crystals and liquids migrating along grain boundaries. However, as pointed out by Dick et al., (2002), the observed extremely large scatter of $\mathrm{TiO}_{2}$ in clinopyroxene (Fig. 4.7) is difficult to explain by source difference of primary mantle melts. So the observed large scatters suggest considerable local disequilibrium due to reaction with late-stage liquids.

\subsubsection{Down-Hole Chemical Variations}

Although a mineral down-hole stratigraphy has been constructed based on a large data base for Hole 735B gabbros (Dick et al., 2002; Natland and Dick, 2002), the new obtained data provide an additional constraint.

Figure 6.2 represents down-hole plots of the composition of clinopyroxene. For comparison similar plots from Dick et al. $(2000,2002)$ of Mg\# down-hole variation for whole-rock and clinopyroxene are shown in Figure 6.3. Clinopyroxene has been selected, as it represents the most dominant ferromagnesian mineral in olivine gabbro, and as it is one of the most resistant phases in gabbros against rapid reequilibration with exotic melts or fluids. Cation diffusion rates in olivine are in general more than one order of magnitude faster than those in clinopyroxene (Brady and McCallister, 1983). Thus clinopyroxene provides the best record of magmatic evolution in this gabbro section.

As shown in figures 6.2 and 6.3, the Mg\# down-hole variations of clinopyroxene in Leg 176 gabbros agree well with the igneous stratigraphy constructed from both whole-rock and mineral chemistry. The systematic upward decrease of Mg\# defines 
three cycles of evolution trends with significant discontinuities around 1321, 960, and 528 mbsf, respectively. This has been interpreted as boundaries among major intrusive cycles in the olivine gabbros (Dick et al., 2000; Natland and Dick, 2001), although it is suspected that the two discontinuities in the lower part of the Hole (1321 mbsf and $960 \mathrm{mbsf}$ ) may result from the influence of late stage melts while the host olivine gabbro was still partially molten (Dick et al., 2002).

In contrast to $\mathrm{Mg \#}, \mathrm{TiO}_{2}$ does not show any kind of systematic variation trend along with depth but shows extremely broad variation of $\mathrm{TiO}_{2}$ at any given depth. As has been discussed in Chapter 4, we suspect that the original systematic down-hole variation of $\mathrm{TiO}_{2}$ developed during a high-temperature stage by the evolution of intrusive melt has been disturbed by percolation of late stage melt. And this may hold true for other incompatible trace elements as well.

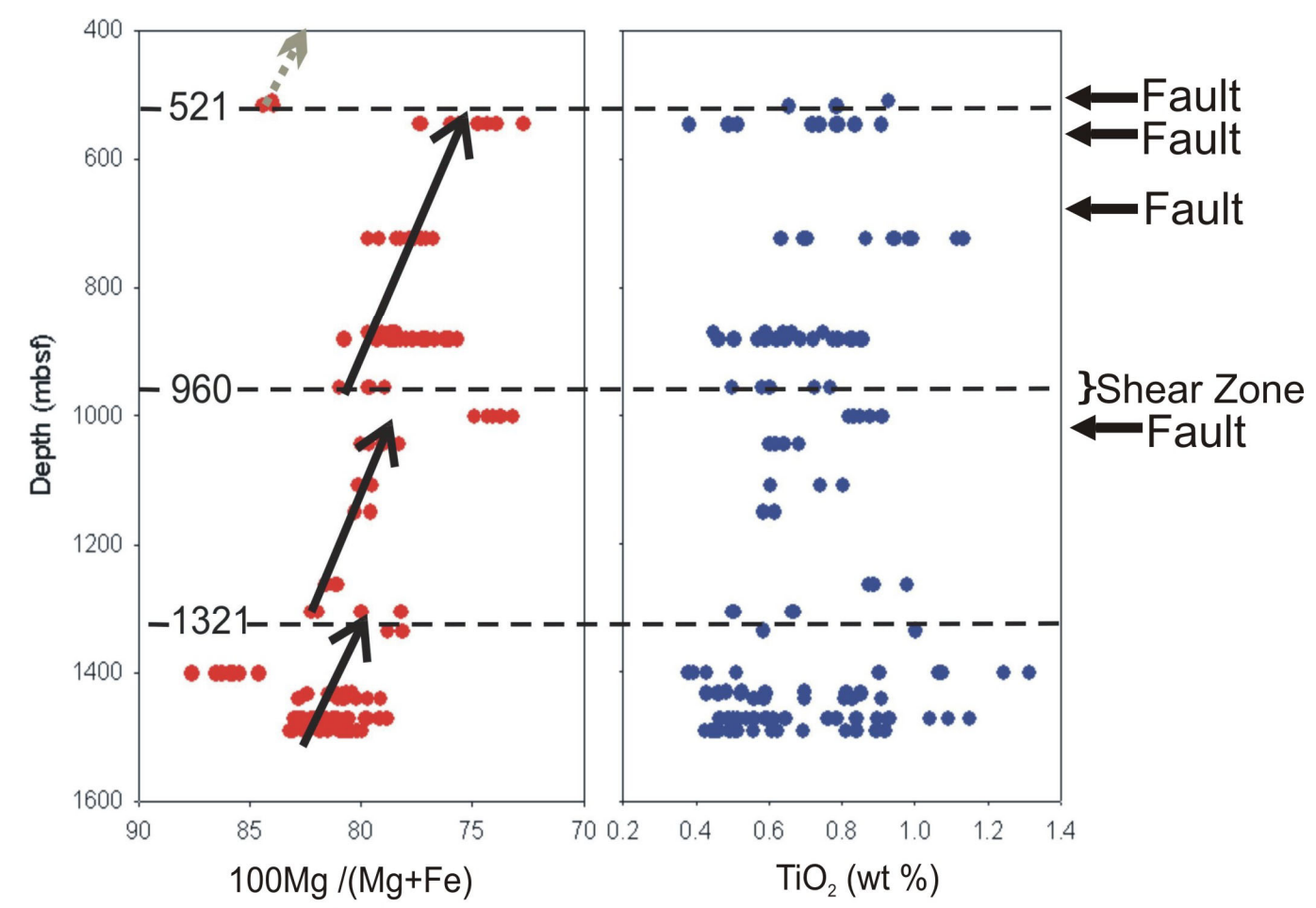

Fig. 6.2 Down-hole compositional variation of clinopyroxene in Hole 735B Leg 176 gabbros. 


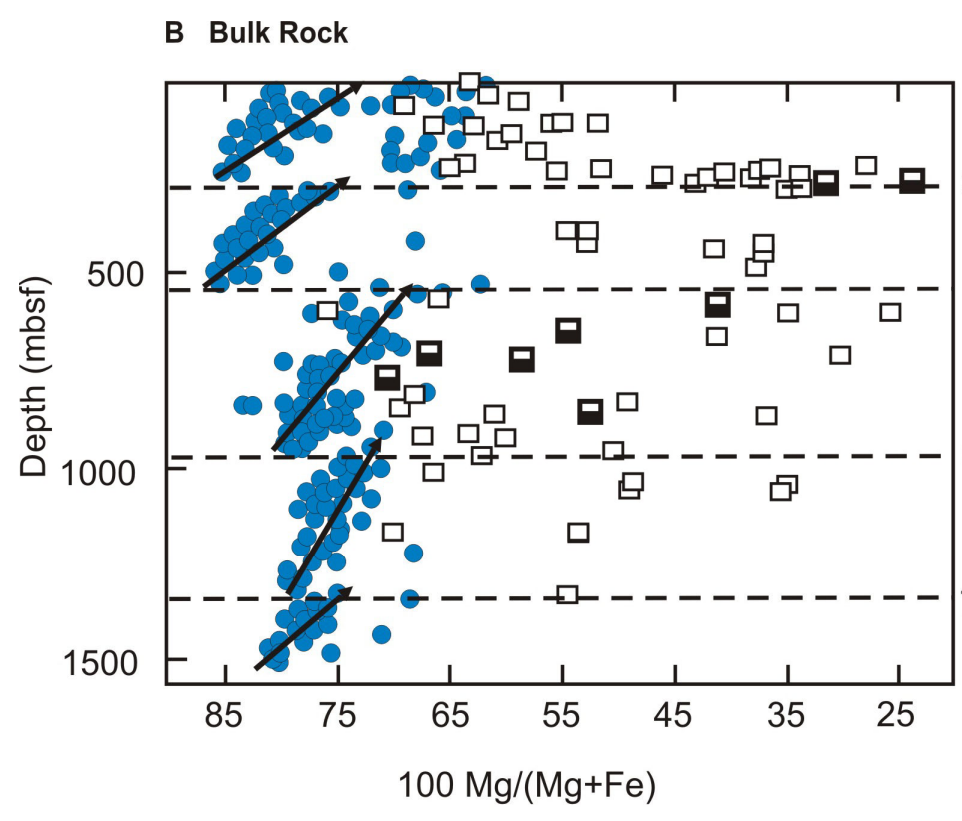

B Clinopyroxene

Samples with $\mathrm{TiO}_{2}<0.7 \%$, mainly troctolites and olivine gabbros

Samples with $\mathrm{TiO}_{2}>0.7 \%$, mainly oxide-bearing and oxide rich gabbros and gabbronorite

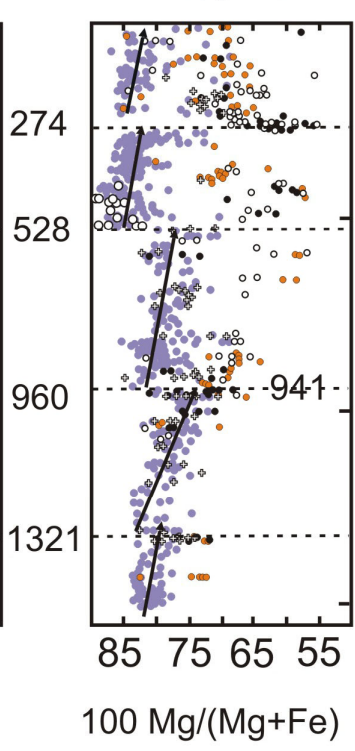

Samples with $\mathrm{SiO}_{2}>56 \%$, including ferrodiorites, trondhjemites, and one granite

Troctolites

- Olivine gabbro

O Gabbronorite

- Oxide olivine gabbro

O Oxide gabbro

↔ Disseminated oxide olivine gabbro

Fig. 6.3 Depth variation of $\mathrm{Mg \#}$ for whole-rock (Plot A, modified from Natland et al., 2001) and clinopyroxene (Plot B, modified from Dick et al., 2002) in Hole 735B gabbros.

\subsection{Evidence on Late-Stage Melt Migrations}

One of the most interesting features of Hole $735 \mathrm{~B}$ gabbros is that late-stage melt migration and crystallization has played a main role in the formation and evolution of this gabbro section, which represents the nearly whole layer 3 of oceanic crust.

\subsubsection{Bulk versus Mineral Composition}

During progressive cotectic crystallization of a melt in a closed system, the compositions of coexisting minerals will maintain a well correlated covariation. For instance, one would expect a positive linear correlation between anorthite contents of 
plagioclase and forsterite contents for olivine. However, the existence of large scale melt migration along grain boundaries will destroy this correlation, due to large differences in solid diffusion rates of cations for olivine, pyroxene, and plagioclase and differences in reaction rates for different elements (Korenaga and Kelemen, 1997; Korenaga and Kelemen, 1998).

As shown in section 6.11, although there is an overall correlation among plagioclase, clinopyroxene, and olivine, there are extremely large scatters (Fig. 6.1). Evidence for the existence of migration of late-stage melts also comes from the geochemistry of pyroxene and olivine, where titanium and nickel show large variations respectively. And most particularly, observations and modeling of mineral zoning of both plagioclase and clinopyroxene give the strongest support for the existence of late-stage melt that migrated along grain boundaries in the crystal mush of gabbro.

It is interesting to compare the trace element compositions of clinopyroxene obtained by in-situ ion probe analysis and its corresponding bulk compositions analyzed by ICP-MS. Figure 6.4 is the plot of calculated bulk partition coefficients for a series of trace elements in clinopyroxene for TS1 and TS16. The bulk partition coefficients are simply calculated by $\mathrm{C}_{\mathrm{cpx}} / \mathrm{C}_{\mathrm{bulk}}$, where $\mathrm{C}_{\mathrm{cpx}}$ is the concentration in clinopyroxene and $\mathrm{C}_{\text {bulk }}$ is the concentration in sample powder (bulk composition). As can be seen, neither core nor rim of investigated crystals of clinopyroxene are in equilibrium with their bulk compositions. Except for $\mathrm{Sr}$, all the other elements show extremely high values of bulk $\mathrm{D}$, which are about 10 to 100 times higher than those calculated with the experimentally determined partition coefficients. Among these elements, $\mathrm{Sr}$ is the only element that behaves as a typical compatible element during the crystallization of gabbro, all the others are incompatible elements. Obviously, bulk 
compositions are definitely too "depleted" for clinopyroxene to be crystallized from it. This suggests that after the crystallization of clinopyroxene, some portions of melts which are significantly enriched in incompatible trace elements have been escaped before final solidification of the gabbro.

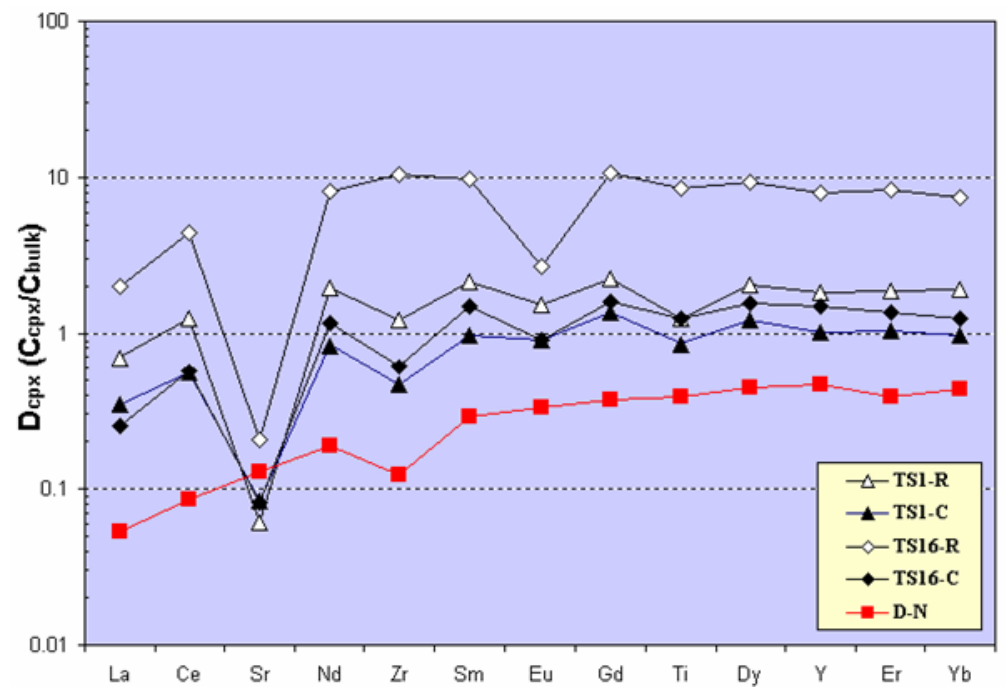

Fig. 6.4 Plot of calculated bulk partition coefficients of trace elements for clinopyroxene in TS1 and TS16, R noted as rim, C noted as core, and D-N represents the calculated bulk partition coefficients using experimentally determined partition coefficients. The data for this plot are listed in Table 6.1.

Table 6.1 Data used for plot in Figure 6.4.

\begin{tabular}{|c|c|c|c|c|c|c|c|}
\hline & & & & TS1 & & TS 16 & \\
\hline & $D^{*}{ }_{c p \gamma}$ & Bulk & CPX-Rim & $\begin{array}{l}\text { CPX- } \\
\text { Core }\end{array}$ & Bulk & $\begin{array}{l}\text { CPX- } \\
\text { Rim }\end{array}$ & $\begin{array}{l}\text { CPX- } \\
\text { Core }\end{array}$ \\
\hline $\mathrm{La}$ & 0.05 & 0.88 & 0.61 & 0.30 & 0.55 & 1.10 & 0.14 \\
\hline $\mathrm{Ce}$ & 0.09 & 2.76 & 3.44 & 1.52 & 1.47 & 6.50 & 0.84 \\
\hline $\mathrm{Nd}$ & 0.19 & 3.25 & 6.40 & 2.73 & 1.52 & 12.5 & 1.78 \\
\hline Sm & 0.29 & 1.45 & 3.11 & 1.41 & 0.66 & 6.50 & 1.00 \\
\hline Eu & 0.33 & 0.69 & 1.06 & 0.62 & 0.38 & 1.04 & 0.35 \\
\hline $\mathrm{Gd}$ & 0.37 & 2.06 & 4.68 & 2.80 & 0.93 & 10.0 & 1.50 \\
\hline Dy & 0.44 & 2.83 & 5.77 & 3.50 & 1.27 & 12.0 & 2.00 \\
\hline $\mathrm{Er}$ & 0.39 & 1.70 & 3.18 & 1.77 & 0.77 & 6.40 & 1.05 \\
\hline $\mathrm{Yb}$ & 0.43 & 1.54 & 2.98 & 1.51 & 0.72 & 5.40 & 0.90 \\
\hline $\mathrm{Sr}$ & 0.13 & 149 & 9.0 & 12.4 & 129 & 26.5 & 10.5 \\
\hline $\mathrm{Cr}$ & 3.8 & 41.0 & 300 & 366 & 82 & 3100 & 2550 \\
\hline $\mathrm{Ti}$ & 0.38 & 3597 & 4515 & 3055 & 1738 & 15000 & 2200 \\
\hline $\mathrm{Zr}$ & 0.12 & 24.4 & 29.8 & 11.4 & 11.5 & 120 & 7.0 \\
\hline Y & 0.47 & 16.9 & 30.77 & 17.12 & 7.74 & 62.0 & 11.5 \\
\hline
\end{tabular}

Note: * $D_{c p x}$ is the partition coefficients for clinopyroxene, references for which are given in Table 6.3. Bulk compositions obtained by ICP-MS, concentrations of clinopyroxene are analyzed by ion probe, both are given in ppm. 
This, on one hand, is an evidence of the cumulate nature of Hole 735B gabbros, on the other hand this provides strong support of the existence of late-stage migrating melt. The late-stage melts were squeezed out of the olivine gabbros at depth and then migrated and intruded upward at higher levels where they crystallized to form evolved gabbros (Dick et al., 2002). Hydrous partial melting is also able to extract incompatible element enriched melts out of the gabbros (Koepke et al., 2003). As a result of this process, on would expect to find zoned trace element profiles with incompatible elements more depleted at rim positions in residual clinopyroxene and plagioclase. In contrast to this prediction, zoning profiles showing gradually increase from core to rim of incompatible element were found to broadly existed (Chapter 4). So it looks like that the broad existence of partial melting process still need more evidence to support.

Thus, our data suggest that a large-scale melt flow has occurred in Hole 735B gabbros, which is in contrast to the situation for fast-spreading ridges represented by Oman ophiolite (Korenaga and Kelemen, 1997; Korenaga and Kelemen, 1998). And this difference has been considered to be due to the influence of larger initial porosity and well developed deformations under slow-spreading ridges (Dick et al., 2002).

\subsubsection{Mineral Zoning}

Zoning within crystals can be generalized into two types: primary zoning and secondary zoning. The former type will occur during the growth of a crystal caused by continuous or discontinuous change in composition of the parental material supplied to its surface (Tracy, 1982). It can be a result of either compositional variations of parental melt or changes in partition coefficients with time due to variations of physical conditions (Loomis, 1983), such as the oscillatory zoning in volcanic plagioclase (Hattori and Sato, 1996; Jang and Naslund, 2001), or just be a record of a 
quenched diffusion profile in the melt (Nakamura and Kushiro, 1998) and Van Orman (personal communication).

The latter type of zoning is developed on a pre-existing crystal (Tracy, 1982; Chakraborty and Ganguly, 1991). This type of zoning can be generated in a homogeneous or heterogeneous crystal given a relatively high temperature (higher than diffusive closure temperature) and the existence of a chemical potential gradient (providing driving force) between the crystal and its contact phase, which can be either a neighboring mineral or an inter-granular fluid (melt).

As summarized in Chapter 4, three kinds of zonations are observed in the studied clinopyroxenes. It has been argued there that it is quite unlikely to be a record of primary zoning for type A and type B zonations, based on the observations for the spatial distribution of compatible trace elements and the information on major element compositions, whereas type $\mathrm{C}$ zonations may represent a primary zoning caused by fractional crystallization of trapped melts.

Type $\mathrm{C}$ zonations are observed in sample 32 and sample 1. As shown in Figure 6.5 , the whole grain of one clinopyroxene crystal in sample1 has been investigated by ion probe, which represents the most detailed studied crystals. This crystal has a quite homogeneous major element composition (Table 6.2) and has few cracks or visible inclusions under the microscope. So the following discussions are based on observations in this sample, with the clinopyroxene in this sample labeled as CPX1. 
Table 6.2 Major element composition of the clinopyroxene in sample1 (CPX1).

\begin{tabular}{|c|c|c|}
\hline oxide & wt $\%$ & $\operatorname{sd}(n=29)$ \\
\hline $\mathrm{SiO}_{2}$ & 51.91 & 0.56 \\
\hline $\mathrm{TiO}_{2}$ & 0.68 & 0.12 \\
\hline $\mathrm{Al}_{2} \mathrm{O}_{3}$ & 2.70 & 0.16 \\
\hline $\mathrm{Cr}_{2} \mathrm{O}_{3}$ & 0.07 & 0.04 \\
\hline $\mathrm{FeO}$ & 8.01 & 0.41 \\
\hline $\mathrm{MnO}$ & 0.23 & 0.03 \\
\hline $\mathrm{MgO}$ & 15.98 & 0.83 \\
\hline $\mathrm{CaO}$ & 20.08 & 0.89 \\
\hline $\mathrm{Na}_{2} \mathrm{O}$ & 0.42 & 0.04 \\
\hline $\mathrm{K}_{2} \mathrm{O}$ & 0.01 & 0.01 \\
\hline Total & 100.10 & 0.81 \\
\hline Mg\# & 78.01 & 1.33 \\
\hline
\end{tabular}

Note: Wt \% is average result of number of analysis points (n) across the crystal, sd means one standard deviation.

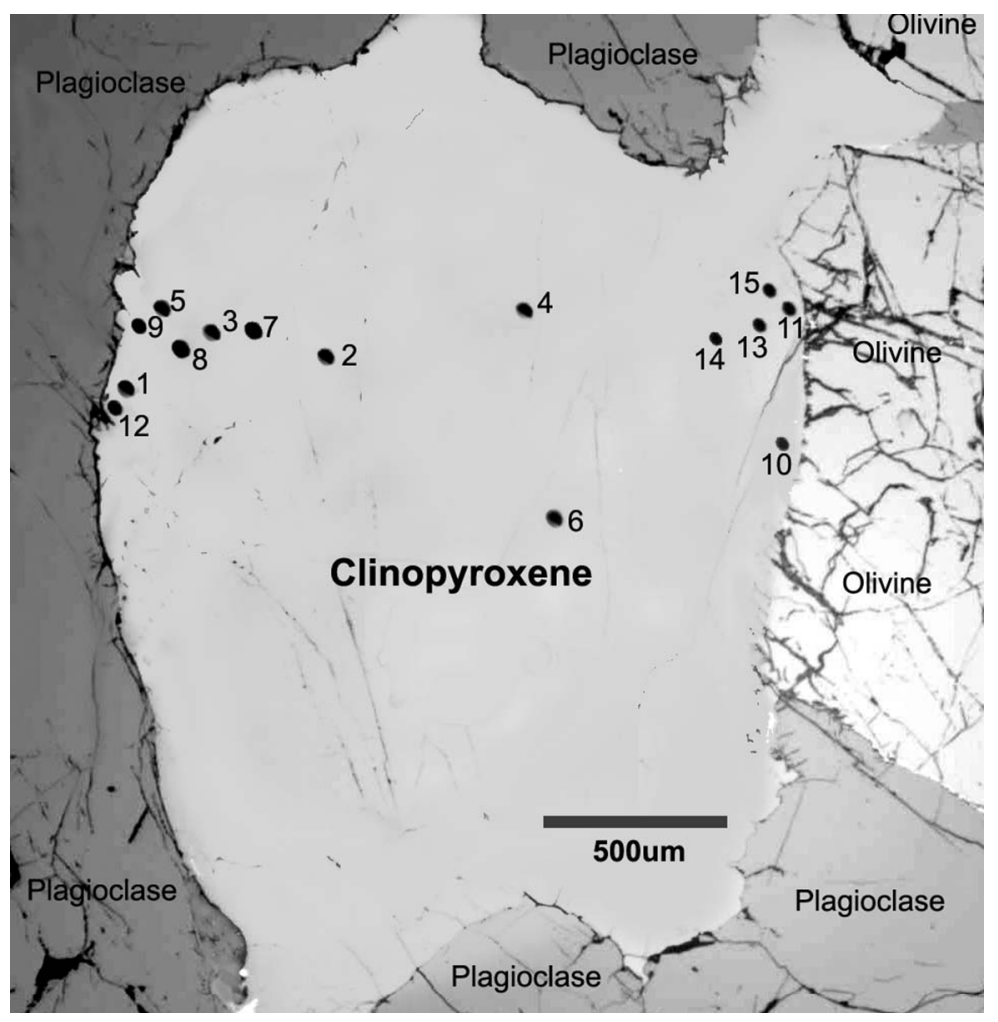

Fig. 6.5 Reflected light photograph of analyzed clinopyroxene grain in sample 1 (cpx 1), which is surrounded by plagioclase and olivine. Analysis numbers are given beside ion probe pits (black dot). Analysis run across the whole grain with most pits in the outmost $\sim 400$ microns rim area to define the zoning profile of trace element, beyond that distance the concentrations of measured trace elements become constant in the core area (see text for discussions). 
The observed smoothly changing concentrations of the trace elements toward the rims of crystals and the nearly unchanged REE patterns along with large variations in concentration (Figure 6.6) are inconsistent with the possibility of source variation.
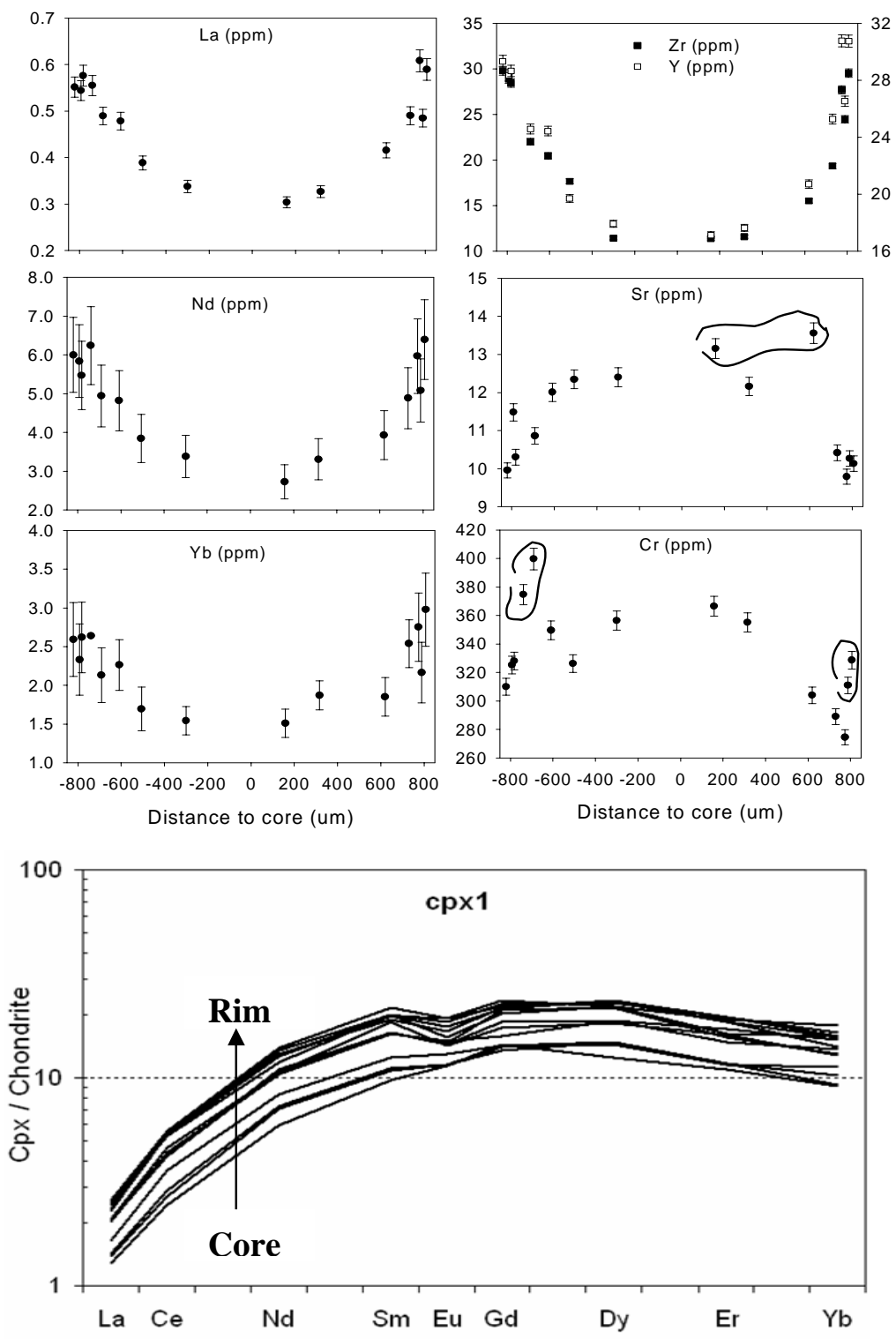

Fig. 6.6 Trace element zoning profiles and chondrite normalized REE patterns in CPX1. Concentrations are measured by ion probe with analytical precisions for individual elements generally better than 10\% RSD (relative stardard devation). Notice that all elements have nearly symmetric zoning profiles to both sides of the rim, no matter the rim is neighboured by plagioclase $(\mathrm{Pl})$ or by olivine $(\mathrm{Ol}) . \mathrm{Sr}$ and $\mathrm{Cr}$ show larger scatter, however, except for several points marked with circles, most data points are still following along continually changed zoning profiles. It is also important to note that REE patterns at different positions across the crystal are nearly parallel with each other. 
$\mathrm{Zr}$, Y and REEs behave as incompatible elements throughout most of the crystallization of a gabbro, hence their concentrations in the melt will increase as a result of progressive crystallization. Therefore theoretically the enrichment from core to rim can be caused by this process, given the assumptions of fractional crystallization for these elements (Loomis, 1983). This possibility can be simply tested by investigations on the covariations of some element pairs. Theoretically two elements with virtually identical bulk distribution coefficients will maintain a constant ratio throughout crystallization (Langmuir et al., 1993). $\mathrm{Zr}$ and La are selected for this purpose. Throughout most of the crystallization of gabbro, La is much more incompatible than $\mathrm{Zr}$ in clinopyroxene, while in plagioclase it is the other way around. So that given appropriate proportions of plagioclase and clinopyroxene, these two elements can have an equal or quite similar bulk partition coefficients (bulk D). Futhermore, La has very similar partition coefficient for clinopyroxene and plagioclase, so bulk D of La is not sensitive to mode compositions and that will make the investigation of fractionation between $\mathrm{Zr}$ and $\mathrm{La}$ to be relatively simple.

Sample1, which is the host gabbro of CPX1, has a mode composition of $60 \%$ plagioclase $+35 \%$ clinopyroxene $+5 \%$ olivine. The calculated bulk D for La $(0.0440)$ and $\mathrm{Zr}(0.0439)$ is nearly identical with this mode composition. Thus one would expect that a constant ratio of $\mathrm{Zr} / \mathrm{La}$ will be preserved throughout the whole crystal of clinopyroxene, as long as the mineral proportion did not change significantly in the crystallization process.

As shown in Figure 6.7, the ratio of $\mathrm{Zr} / \mathrm{La}$ continuously increases outward from the core to the rim by a factor of $\sim 1.5$. So obviously a simple crystallization process in a closed system, such as crystallization of trapped melt, will not be able to account for the observed core-rim variation for the ratio of $\mathrm{Zr} / \mathrm{La}$. 


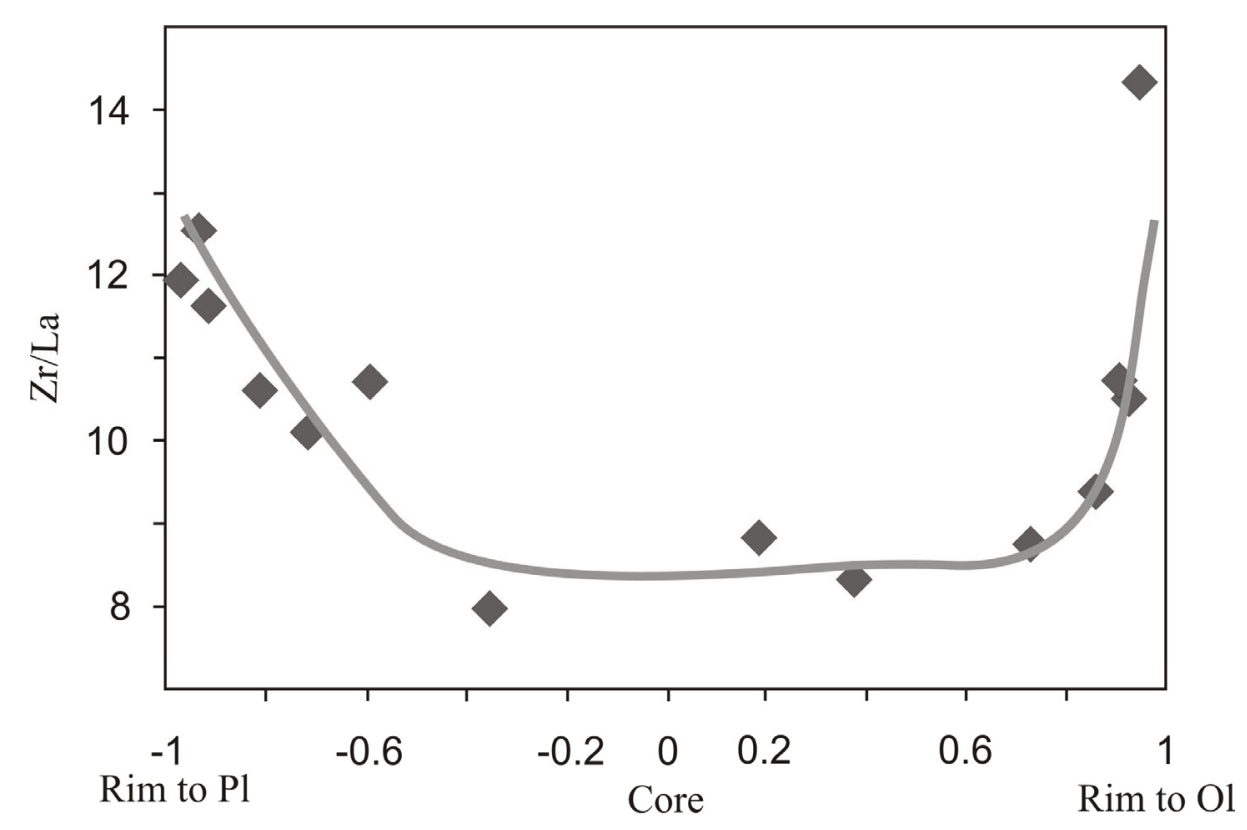

Normalized radius

Fig. 6.7 $\mathrm{Zr} / \mathrm{La}$ variations across the crystal of cpx1, note that the ratio of $\mathrm{Zr} / \mathrm{La}$ increases to the rim by a factor of about 1.5 .

However, the bulk $\mathrm{D}$ for La and $\mathrm{Zr}$ may also be quite different as the mineral proportion may be different in the actual crystallization. For example, given a very high proportion of plagioclase to clinopyroxene, $\mathrm{Zr}$ will be considerably more imcompatible than La due to the very small $\mathrm{D}_{\mathrm{Zr}}$ for plagioclase. To check this possibility, the covariation of $\mathrm{Zr}$ and $\mathrm{La}$ is modeled for both equilibrium fractionation and Rayleigh fractionation with different mode compositions of clinopyroxene (Figure 6.8). Although the presence of crystal zoning suggests that perfect equilibrium crystallization did not occur, it is shown as a limit to the $\mathrm{Zr} / \mathrm{La}$ fractionation that can be obtained by partial equilibration during the crystallization of trapped melt. Perfect fractional crystallization could occur through in-situ crystallization of trapped melt (Coogan et al., 2000a). The partition coefficients for La and $\mathrm{Zr}$ used for this modeling are presented in Table 6.3. Given the extremely low partition coefficients for both La 
and $\mathrm{Zr}$ in olivine, and its small proportion in the studied gabbro, olivine can be neglected in the modeling. Thus the decrease of the percentage of clinopyroxene is just compensated by the increase of plagioclase. Maximum fractionation of $\mathrm{Zr}$ to $\mathrm{La}$ was obtained when the there is no clinopyroxene crystallized from the liquid.

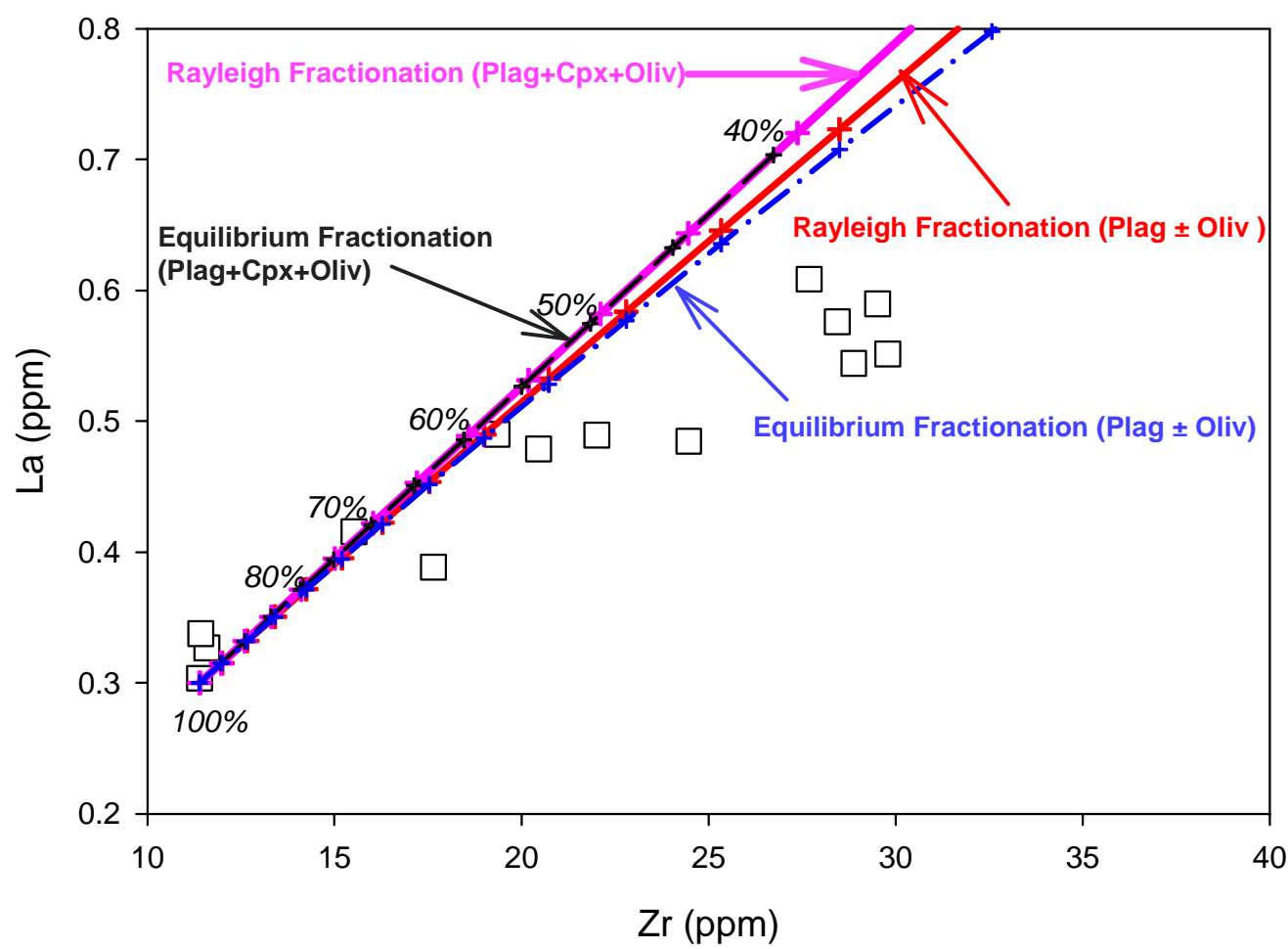

Fig. 6.8 Fractional crystallization modeling of the covariation of $\mathrm{Zr}$ and La. Pink solid line and black dash line indicate fractionations with plagioclase (plag, 60\%) + clinopyroxene (cpx, 35\%) + olivine (oliv, 5\%). Red solid line and blue dash-dot line indicate plagioclase \pm olivine fractionation. Notice that fractionation of $\mathrm{Zr}$ and $\mathrm{La}$ is not sensitive to the proportion of plagioclase and olivine, because olivine can be regarded as totally incompatible to $\mathrm{Zr}$ and $\mathrm{La}$ (see text for detail). Crosses indicate 5\% changes of melt fraction, which are labeled with numbers (in italics).

Figure 6.8 shows modeling for CPX1, the data used are given in Table 6.2. Obviously neither Rayleigh nor equilibrium crystallization can account for the observed covariation in $\mathrm{Zr}$ and La. As a test for the sensitivity of this modeling to the values of bulk $\mathrm{D}$ used, the bulk $\mathrm{D}$ of $\mathrm{La}$ is calculated to be $\sim 0.28$ to match the observed $\mathrm{Zr} / \mathrm{La}$ increasing trend for Rayleigh fractionation without the existence of 
clinopyroxene. This value of bulk $\mathrm{D}$ for $\mathrm{La}$ is considerably outside the range of a likely value.

Thus, crystallization of in-situ trapped melt can not explain the observed fractionation of $\mathrm{Zr}$ from La. Furthermore there is no evidence for overgrowth of clinopyroxene crystals by crystallization of trapped or migrating melt, suggested by the fairly homogeneous major element composition of this pyroxene crystal (Table $6.2)$.

The observed zoning profiles of trace elements in studied clinopyroxene can be explained by a process of secondary modification between crystals and its contact phase, which can be either a neighbored mineral or an inter-granular fluid (melt). However, as the concentration of most measured trace elements in cpx1 are all simultaneously either increasing or decreasing toward the rim independent of being in contact with plagioclase or olivine, it is unlikely that the adjustment has taken place between clinopyroxene and its neighboring mineral. In other words, the presence of an inter-granular fluid (melt) is required for the evolution of the observed trace element zoning.

The mechanism of this secondary modification, i.e. interaction between crystals and melt can be diffusive or dissolution-reprecipitation. To differentiate between these two possibilities, diffusion modeling of the observed trace element zoning profiles is given in the next section.

\subsubsection{Model formulation}

The studied minerals are always surrounded by other solid or liquid phases which served as diffusion source. It is thus logical to model the diffusion process in natural minerals by diffusion into finite media rather than into semi-infinite media. In 
practice, a plane sheet or a cylinder is taken as the geometry for minerals with diffusive anisotropy, while a sphere is used for homogeneous media (Crank, 1975).

Studies of $\mathrm{Sr}, \mathrm{Ca}$, and $\mathrm{Pb}$ diffusion in pyroxene (Sneeringer et al., 1984; Dimanov and Jaoul, 1998; Cherniak, 1998a) have found no evidence of significant anisotropy. REE is expected to behave similarly to those elements, because they all occupy the same crystallographic site (M2) in the pyroxene crystal structure. Thus, the diffusion process in clinopyroxene is modeled by a concentration independent (with a constant diffusion rate) radial diffusion into a sphere. The general equation for diffusion with constant $\mathrm{D}$ into a sphere with radius of a is (Crank, 1975):

$$
\frac{\partial C}{\partial t}=D\left(\frac{\partial^{2} C}{\partial r^{2}}+\frac{2}{r} \frac{\partial C}{\partial r}\right)
$$

where $\mathrm{C}$ refers to the concentration at position $\mathrm{r}$ after time $\mathrm{t}$, and $\mathrm{r}$ is distance to the sphere center.

$$
\begin{aligned}
& \text { Setting } \begin{array}{l}
\mathrm{u}=\mathrm{Cr} \\
\text { equation (1) becomes } \\
\qquad \frac{\partial u}{\partial t}=D \frac{\partial^{2} u}{\partial r^{2}}
\end{array}
\end{aligned}
$$

Thus the problem of radial diffusion into a sphere is simplified to a linear flow in one dimension.

Mathematically, solution of equation (3) highly depends on constraints of initial and boundary conditions, which are crucial for modeling of diffusion process in natural crystals (Costa et al., 2003). For this modeling, the boundary and initial conditions are taken as:

$$
\begin{gathered}
u=0, \quad r=0, \quad t>0 \\
u=a \mathrm{C}_{0}, \quad r=a, \quad t>0
\end{gathered}
$$




$$
u=r \mathrm{C}_{\mathrm{i}}, \quad t=0,0<r<\mathrm{a}
$$

where $\mathrm{C}_{0}$ is the concentration at the interface, $\mathrm{C}_{\mathrm{i}}$ is the initial concentration in the crystal, $t$ is time of diffusion, and D is the diffusion coefficient.

The given boundary conditions correspond to two assumptions: (1) before diffusion, the crystal has a uniform initial concentration distribution of a given element (i.e. $t=0, \mathrm{C}=\mathrm{C}_{\mathrm{i}}, 0<\mathrm{r}<\mathrm{a}$ ); (2) during diffusion, the concentration of a given element at the surface of the crystal remains constant (i.e. $t>0, \mathrm{r}=\mathrm{a}, \mathrm{C}=\mathrm{C}_{0}$ ).

As already shown in Table 6.2, CPX1 has a quite uniform major element composition throughout the whole crystal, and it also has been illustrated that the observed zoning profiles of trace element are not likely to be a primary growing pattern. So assumption (1) is regarded to be a reasonable expression of the actual situation of initial concentration distribution. We have taken constant compositions from the central area of crystals to be the initial concentration $\left(\mathrm{C}_{\mathrm{i}}\right)$, where its composition is believed to have been kept intact from later diffusive metasomatism. The second assumption requires that for any given trace element the surface of crystals always keeps in equilibrium with an external diffusion source with constant composition during the process of diffusion. A melt which has migrated along grain boundaries is taken as the diffusion source in this case. The concentration at the interface can easily be maintained given the very fast diffusion rate in melt for trace elements (Van Orman et al., 2001). The composition of the melt is quite likely to be changed with time, especially for a small melt/mineral ratio. However given the quite small partition coefficients between clinopyroxene and melt for most studied trace elements (Table 6.3), we believe that the external melt may be regarded as an infinite reservoir, at least for highly incompatible trace elements. Therefore, the second assumption seems to be reasonable too. 
Values of $\mathrm{C}_{0}$ are given by intersections of zoning profiles on the axis of concentration, which represent the elemental content at the surface of the crystal. Values of these modeling parameters are listed in Table 6.3.

Table 6.3 Modeling parameters and calculated diffusion coefficients (D) for 13 trace elements in cpx1.

CPX 1 with a radius of $\mathrm{a}=\mathbf{0 . 8 5} \mathrm{mm}$

\begin{tabular}{|c|c|c|c|c|c|c|c|c|c|}
\hline \multicolumn{6}{|c|}{ Partition coefficients } & \multicolumn{2}{|c|}{$\begin{array}{l}\text { Boundary } \\
\text { conditions }\end{array}$} & \multicolumn{2}{|c|}{$\begin{array}{c}\text { Diffusion coefficients (D) } \\
\left(\mathrm{m}^{2} \mathbf{s}^{-1}\right)\end{array}$} \\
\hline $\mathbf{K}_{\mathrm{cpx} / \mathrm{melt}}$ & $\operatorname{Ref}$ & $\mathbf{K}_{\text {plag/melt }}$ & Ref & $\mathbf{K}_{\text {oliv/melt }}$ & Ref & $\begin{array}{c}\mathbf{C}_{\mathbf{0}} \\
(\mathrm{ppm})\end{array}$ & $\begin{array}{c}\mathbf{C}_{\mathbf{i}} \\
(\mathrm{ppm})\end{array}$ & $\mathrm{t}=0.05 \mathrm{Ma}$ & $\mathrm{t}=0.4 \mathrm{Ma}$ \\
\hline La 0.0536 & {$[1]$} & 0.042 & [2] & 0.0004 & {$[5]$} & 0.61 & 0.30 & $3.24 \mathrm{E}-20$ & $4.05 \mathrm{E}-21$ \\
\hline Ce 0.0858 & [1] & 0.036 & [2] & 0.0007 & [7] & 3.44 & 1.52 & $3.00 \mathrm{E}-20$ & $3.75 \mathrm{E}-21$ \\
\hline Nd 0.1873 & [1] & 0.029 & [2] & 0.0002 & {$[8]$} & 6.40 & 2.73 & $2.80 \mathrm{E}-20$ & $3.50 \mathrm{E}-21$ \\
\hline Sm 0.291 & {$[1]$} & 0.022 & [2] & 0.0013 & {$[5]$} & 3.11 & 1.41 & $2.60 \mathrm{E}-20$ & $3.25 \mathrm{E}-21$ \\
\hline Eu 0.3288 & {$[1]$} & 0.22 & [2] & 0.0016 & {$[5]$} & 1.06 & 0.62 & $1.60 \mathrm{E}-20$ & $2.00 \mathrm{E}-21$ \\
\hline Gd 0.367 & {$[1]$} & 0.014 & [2] & 0.0003 & {$[8]$} & 4.68 & 2.80 & $2.00 \mathrm{E}-20$ & $2.50 \mathrm{E}-21$ \\
\hline Dy 0.442 & [1] & 0.013 & [2] & 0.007 & [9] & 5.77 & 3.50 & $2.00 \mathrm{E}-20$ & $2.50 \mathrm{E}-21$ \\
\hline Er 0.387 & {$[1]$} & 0.012 & [2] & 0.0017 & {$[8]$} & 3.18 & 1.77 & $2.00 \mathrm{E}-20$ & $2.50 \mathrm{E}-21$ \\
\hline $\mathbf{Y b} 0.43$ & [1] & 0.012 & [2] & 0.0015 & [5] & 3.10 & 1.51 & $1.80 \mathrm{E}-20$ & $2.25 \mathrm{E}-21$ \\
\hline Y 0.467 & {$[1]$} & 0.01 & [3] & 0.009 & [9] & 30.77 & 17.12 & $2.40 \mathrm{E}-20$ & $3.00 \mathrm{E}-21$ \\
\hline Cr 3.80 & {$[1]$} & 0.02 & [4] & 1.2 & [10] & 300 & 366.4 & $1.60 \mathrm{E}-20$ & $2.00 \mathrm{E}-21$ \\
\hline Sr 0.1283 & {$[1]$} & 1.8 & [5] & 0.00004 & [11] & 9.0 & 12.4 & $1.00 \mathrm{E}-20$ & $1.25 \mathrm{E}-21$ \\
\hline Zr 0.1234 & {$[1]$} & 0.001 & [6] & 0.003 & [12] & 29.8 & 11.4 & $1.60 \mathrm{E}-20$ & $2.00 \mathrm{E}-21$ \\
\hline
\end{tabular}

Note: $\mathrm{K}$ is the mineral/melt equilibrium partition coefficient, $\mathrm{C}_{0}$ is the concentration at the interface, $\mathrm{C}_{\mathrm{i}}$ is the initial concentration in the crystal, a is the optimum radius of the crystal, and $t$ is the diffusion time which are given as upper and lower limits respectively. Sources: [1](Hart and Dunn, 1993), [2](Bedard, 1994), [3](Irving, 1978), [4](Furman et al., 1991), [5](McKenzie and O'Nions, 1991), [6](Dunn and Sen, 1994a; Dunn and Sen, 1994b), [7](Frey et al., 1978), [8](Prinzhofer and Allegre, 1985), [9](Nikogosian and Sobolev, 1997), [10](Klock and Palme, 1988), [11](Beattie, 1994), [12](Johnson and Dick, 1992)

\subsubsection{Diffusion rates and diffusion time}

Formation of zoning profiles by diffusion can be simulated by a best fit between the measured data profile and the calculated diffusion profile given a proper diffusion rate and diffusion time. 
The zoning profiles for $\mathrm{La}$ and $\mathrm{Yb}$ are firstly modeled with the diffusion data given by Van Orman et al. (2001), which represents the rare earth element with slowest and fastest diffusivity in diopside respectively.

As shown in Figure 6.9, the calculated diffusion profiles and the measured zoning profiles of both La and $\mathrm{Yb}$ fit close very well.

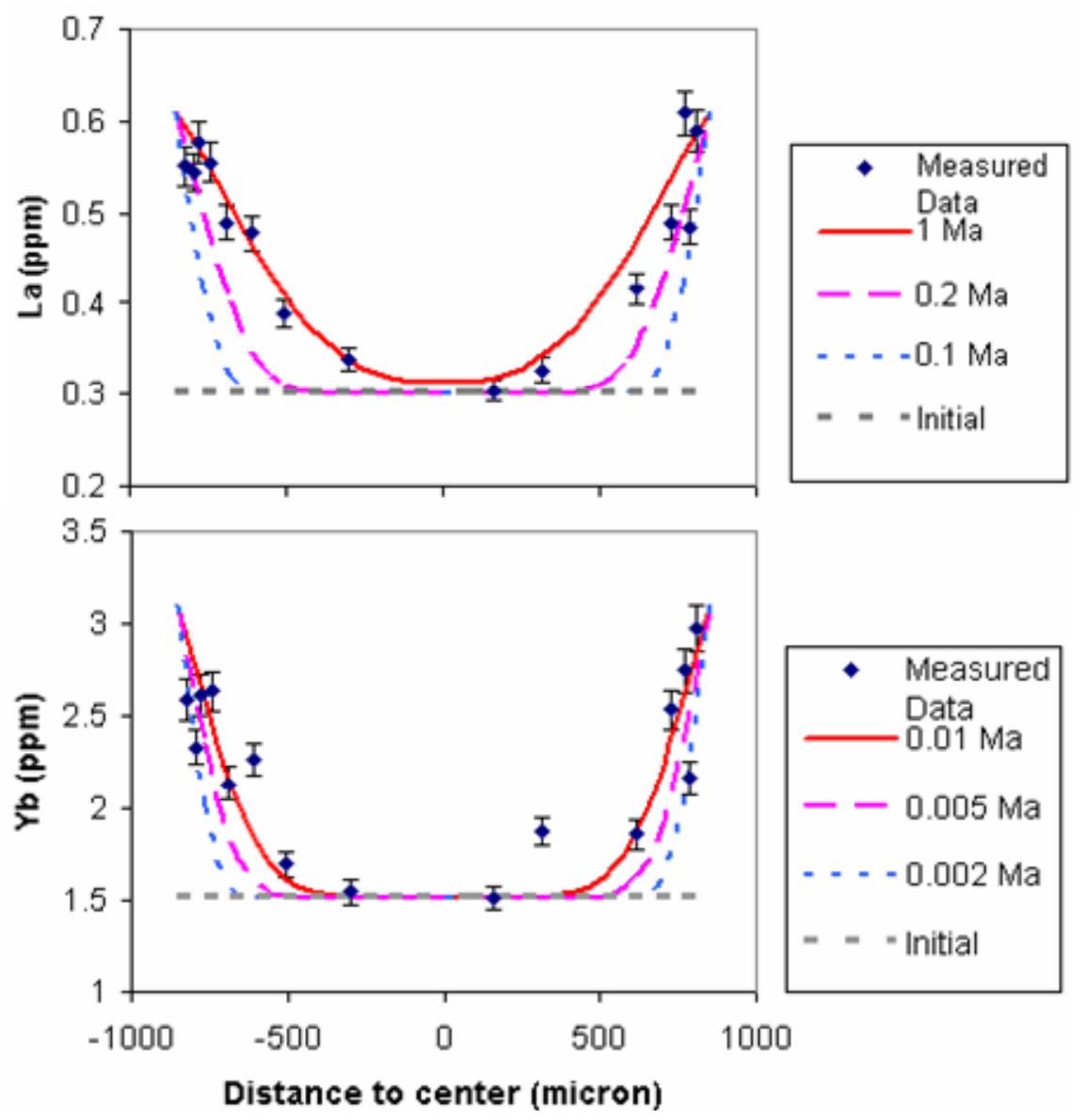

Fig. 6.9 Diffusion modeling of $\mathrm{La}$ and $\mathrm{Yb}$ in CPX1. Measured results are given in Table 4.3, diffusion rates are calculated with the diffusion parameters given by Van Orman et al. (2001) at a temperature of $1200^{\circ} \mathrm{C}$.

The modeling shows that in contrast to the very short diffusion time for $\mathrm{Yb}$ of about $0.01 \mathrm{Ma}$, about $1 \mathrm{Ma}$ is required to account for the observed zoning profile of La. However, in the concept of closure temperature a longer diffusion time for $\mathrm{Yb}$ 
should be expected, not shorter than that of $\mathrm{La}$, just because $\mathrm{Yb}$ has a much faster diffusivity than $\mathrm{La}$ at a given temperature according to the experimental data of Van Orman et al., (2001).

Effective diffusive exchange of one element between different phases occurs only when the temperature is higher than the closure temperature $\left(\mathrm{T}_{\mathrm{C}}\right)$ for that element, and the value of $\mathrm{T}_{\mathrm{C}}$ will depend on the exact cooling history of that system (Dodson, 1973). It has been shown that the Hole 735B gabbro body has rapidly cooled by $800^{\circ} \mathrm{C}$ in the first $0.5 \mathrm{Ma}$ when it was still beneath the axial valley (Natland and Dick, 2002). This gives a corresponding cooling rate of $1600^{\circ} \mathrm{C} / \mathrm{Ma}$. Using this cooling rate and the diffusion data of Van Orman et al., (2001), closure temperatures for REEs in cpx1 with a radius of $0.85 \mathrm{~mm}$ are calculated with equation (Dodson, 1973):

$$
T_{c}=\frac{E / R}{\ln \left[-\frac{A R T_{c}^{2}\left(D_{0} / a^{2}\right)}{E d T / d t}\right]}
$$

where $\mathrm{E}$ is the activation energy for diffusion of one element in that mineral; $\mathrm{A}$ is a constant depending on grain geometry $(A=55$ for spherical grains, and $A=27$ for cylindrical grains); $\mathrm{R}$ is gas constant; $\mathrm{D}_{0}$ is the preexponential factor in the diffusional Arrhenius relation; a is grain size (grain radius for spherical grains) and $d T / d t$ is the cooling rate.

The calculations show that the closure temperatures vary from $1135^{\circ} \mathrm{C}$ for $\mathrm{Yb}$ to more $1287^{\circ} \mathrm{C}$ for $\mathrm{La}$, as shown in Figure 6.10 . The estimated crystallization temperature for basaltic magmas is about $1200^{\circ} \mathrm{C}$ under a pressure of about $2 \mathrm{kbars}$ corresponding to a depth of about $6 \mathrm{~km}$ below the sea floor (Hess, 1993). Thus it seems that the diffusive exchange can only occur for heavy REEs with fast diffusion rates in a very short time less than 0.05 Ma. This is obviously in contrast with the 
modeling results given in Figure 6.9 and is also in contradiction with the observations of well developed zoning profiles for all rare earth elements.

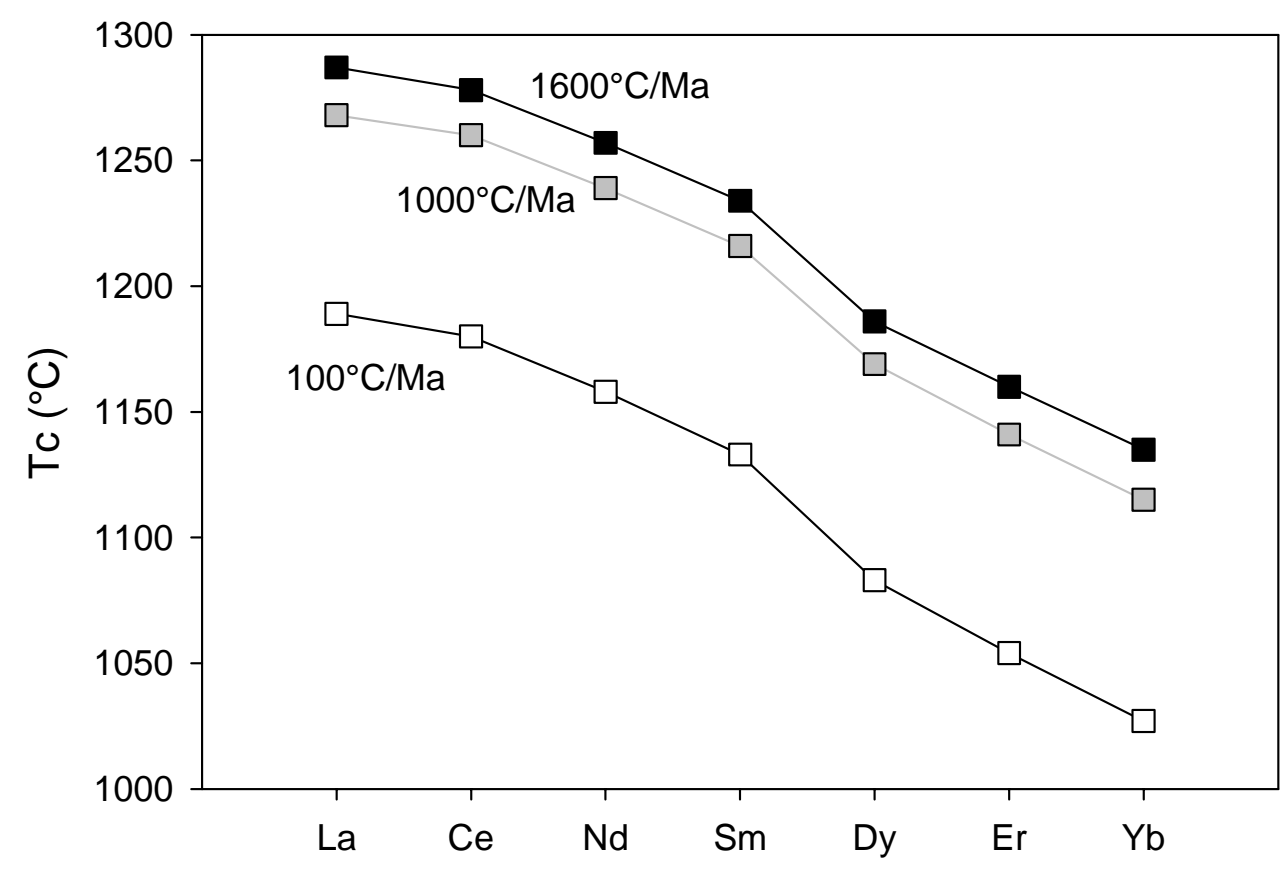

Fig. 6.10 Plot of closure temperatures for REEs in cpx 1 using diffusion data given by Van Orman et al. (2001). Marked numbers beside each line represent cooling rates used for the calculations for the plot.

Thus the formation of the observed zoning profiles argues for higher diffusion rates especially for the light rare earth elements.

Theoretically for a given diffusion profile, the characteristic diffusion parameter $(\mathrm{D} t)^{1 / 2}$ remains constant (Crank, 1975), where D is the diffusion coefficient, and $\mathrm{t}$ is the duration time of diffusion. This indicates that the calculated diffusion rate will depend on the selected diffusion time.

In the case of lower oceanic crustal gabbro, the diffusive metasomatism occurred during porous melt migration along grain boundaries (Korenaga and Kelemen, 1998). Thus the time of melt migration $\left(T_{m}\right)$ provides a minimum evaluation of the diffusion 
time $(t)$, as diffusion may still continue down to the closure temperature during cooling. $T_{m}$ can be calculated with the equation (Korenaga and Kelemen, 1998):

$$
T m=\frac{W v}{2 V}
$$

where $W v$ is the width of the neo-volcanic zone in the rift valley, and $V$ is full spreading rate. Given the $\sim 2 \mathrm{~km}$ width of neo-volcanic zone in the rift valley and the

$2 \mathrm{~cm} / \mathrm{yr}$ full spreading rate in the area of Southwest Indian Rigde where Hole 735B is located (Dick et al., 1991b), $T_{m}$ is calculated to be about $0.05 \mathrm{Ma}$.

The distance from the present ridge axis to the south rift valley wall is $4.3 \mathrm{~km}$. Given a spreading rate of $1.0 \mathrm{~cm} / \mathrm{yr}$ toward this wall, rocks of Hole $735 \mathrm{~B}$ are believed to have a residence time of about 0.4 Ma beneath the rift (Natland and Dick, 2002). Thus $0.4 \mathrm{Ma}$ can be regarded as the upper limit of diffusion time if all crystallization, high-temperature deformation and metamorphism only took place beneath the rift valley. Therefore, the actual diffusion time seems to be in the range of $\sim 0.05-0.4 \mathrm{Ma}$.

\subsubsection{Modeling results}

The development of observed trace element zoning profiles by diffusive exchange is modeled with diffusion times ranging from $0.05 \mathrm{Ma}$ to $0.4 \mathrm{Ma}$. The diffusion rates have been adjusted to give the best fit to the measured data points. Using this modeling approach, the diffusivities of 13 trace elements (REE, $\mathrm{Y}, \mathrm{Cr}, \mathrm{Sr}$, and $\mathrm{Zr}$ ) in CPX1 are investigated. The results are presented in Table 6.3 and plotted in Figure 6.11. The obtained diffusion rates represent the upper and lower limit of the possible diffusivities in the clinopyroxene corresponding to the shortest and longest diffusion 
time respectively. The actual diffusivities should lie in between of this two end members.

As shown in Figure 6.11, in general the obtained diffusion rates fall in the range of the diffusivities obtained in experimental study for pyroxene. However, the diffusion rates for light rare earth elements are found to be about 10 times faster than the experimental data.

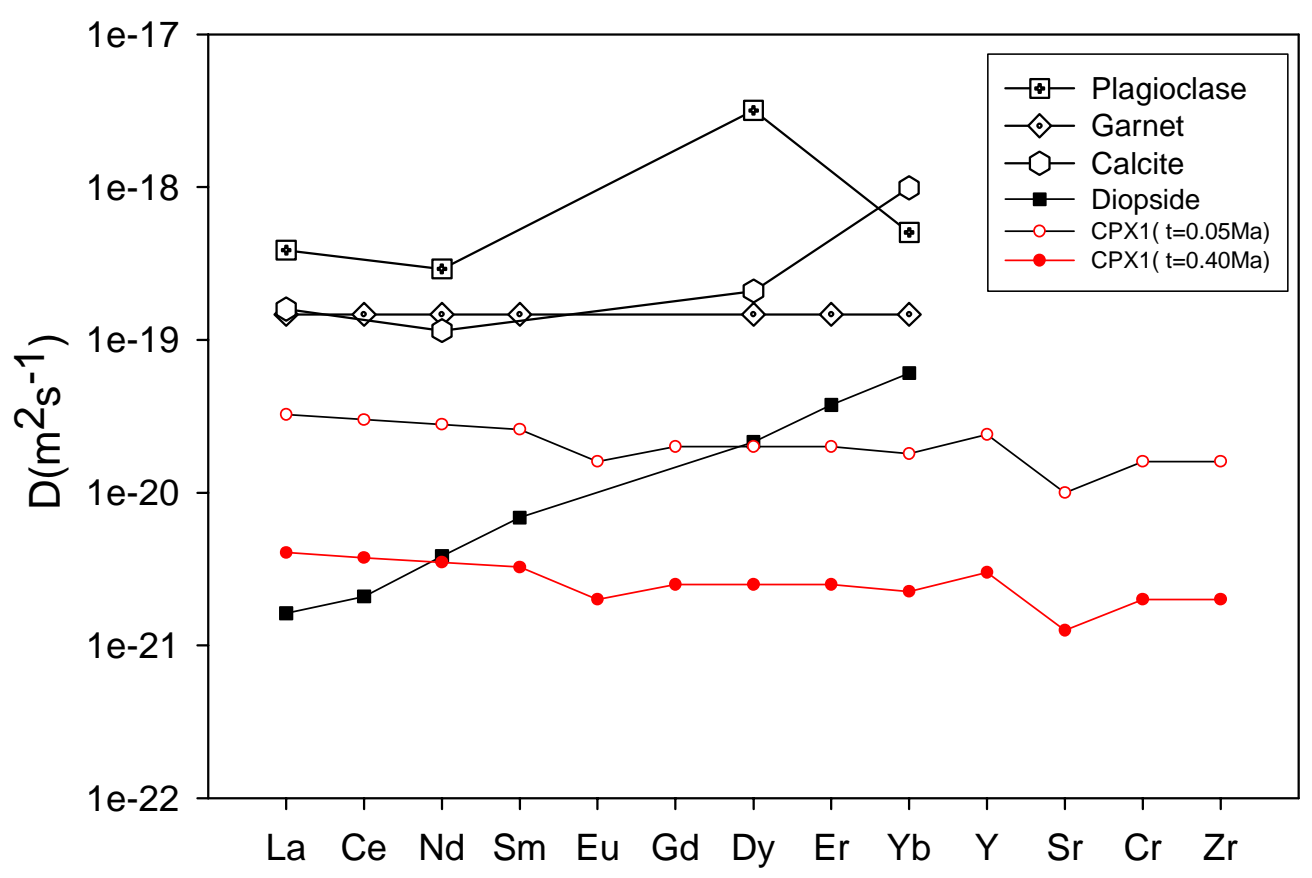

Fig. 6.11 Trace element diffusion coefficients in various minerals. Sources of data: Diopside - Van Orman and Grove, 2001; Garnet - Van Orman et al., 2002; Plagioclase - Cherniak, 2002; Calcite - Cherniak, 1998. For comparison diffusion coefficients in diopside, garnet, calcite, and plagioclase are the calculated at the same temperature of $1200^{\circ} \mathrm{C}$ by Arrhenius equation with diffusion parameters given in the related literature.

Most importantly the largely difference in diffusion rate among REEs are not observed in our data. The large difference in diffusivities of La and $\mathrm{Yb}$ will cause significantly fractionation between them (Van Orman et al. 2002). To evaluate this point in more detail, the fractionation of $\mathrm{Yb}$ relative to $\mathrm{La}$ is calculated with the 
experimental diffusion data given by Van Orman et al. (2001) and the data given by this study. The results are shown in Figure 6.12. Obviously the observed data points are best fitted with our new diffusion data.
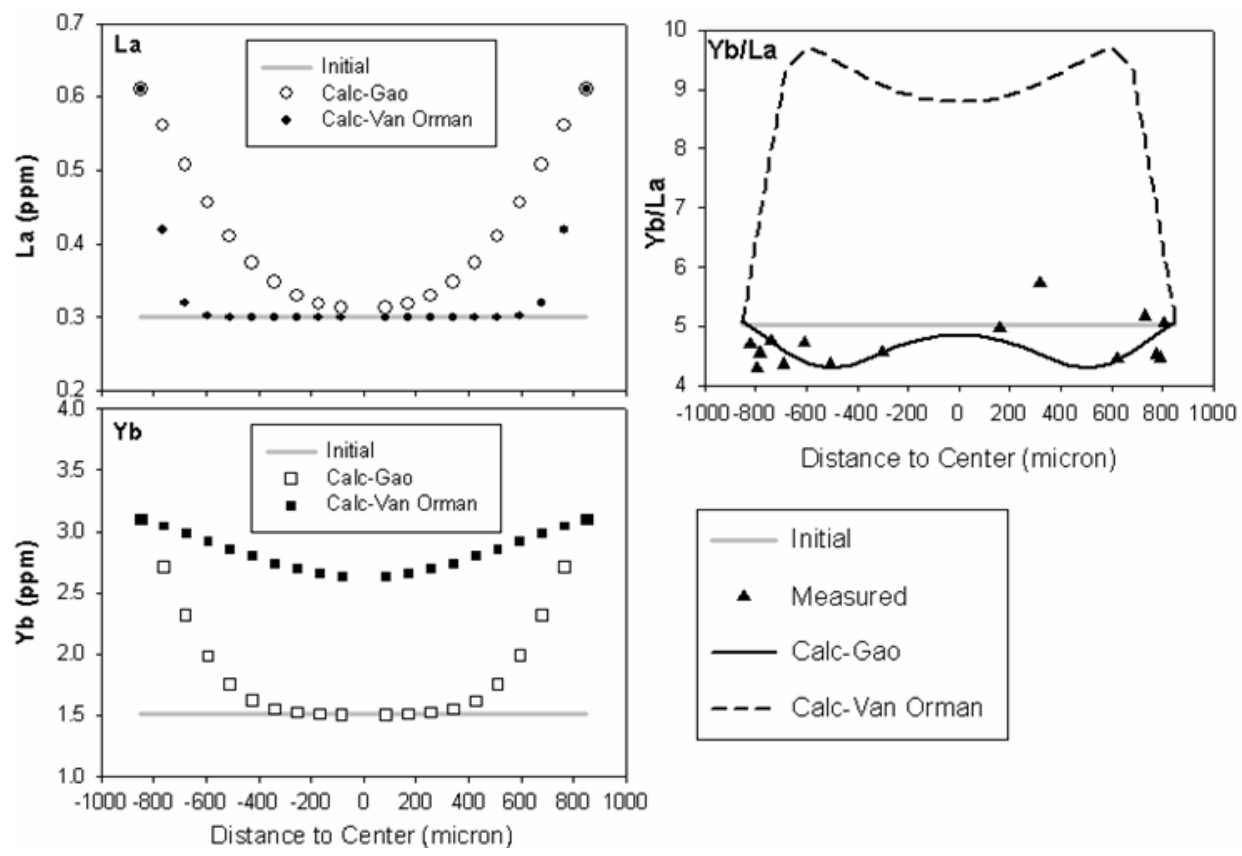

Distance to Center (micron)

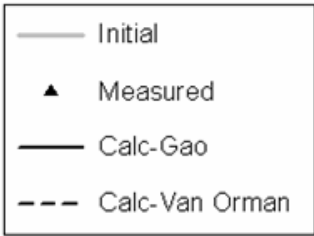

Fig. 6.12 Modeling for fractionation of $\mathrm{Yb}$ to $\mathrm{La}$ in CPX1 developed by diffusive exchange in $0.1 \mathrm{Ma}$ and at a temperature of $1200^{\circ} \mathrm{C}$.

In the view of kinetic concepts for diffusion (Cole and Chakraborty, 2001), differences in diffusion rates among different materials in large part are a consequence of their structural properties. In general, diffusion rates decrease with increasing 'tightness' of chemical bonding (electrostatic energy for crystal and degree of polymerization for melt). More energy is required to move atoms or ions in materials with strong chemical bondings. Cole (2000) reported a very good relationship between the exchange rate of oxygen isotope and the normalized electrostatic lattice energy of different phases of carbonate (Cole, 2000). (Nakamura and Kushiro, 1998) showed that diffusion of trace elements is faster (up to about 3 orders of magnitude) in a less polymerized melt than in a strong polymerized melt. 
Previous diffusion studies show that there is a general relationship between diffusivities of rare earth elements and their ionic radii. In pyroxene (Van Orman et al., 2001) and zircon (Cherniak et al., 1997), the diffusion rates decrease significantly with increasing ionic radii, and this systematic variation was interpreted by an elastic model (Van Orman et al., 2001). However, little variation in diffusion rates among REEs was observed in calcite (Cherniak, 1998c), pyrope (Van Orman et al., 2002b), aluminate garnets (Cherniak, 1998b), and apatite (Cherniak, 2000). According to elastic models for diffusion, the different behaviors are largely caused by the difference in elastic properties of different media. Ionic radius will have a greater influence on diffusivities in phases with stronger chemical bonds than in phases with more flexible structures (Cherniak, 2002).

In Figure 6.13, the diffusion rates for REEs are plotted in an enlarged scale compared to Figure 6.12. Interestingly a positive relationship between diffusion rates and element radii are observed which is similar to variation trends in melts but in contrast to the trend of solid diffusion in diopside. Therefore the obtained faster diffusion rates for trace elements may be interpreted as a diffusion process in a phase, whose chemical bonding is stronger than silicate melts but weaker than solid state crystal. A partially solidified crystal can be a possible candidate of such a phase.

However, it may just reflect the difference between experimental conditions and natural systems, such as the difference between natural crystals and those used in experimental studies, which are usually pure and unstrained synthetic crystals or gemquality natural crystals. In this case, these data may indicate that natural crystals under natural geochemical and geophysical conditions can provide different solid state diffusion pathways than found in experiments so far. 

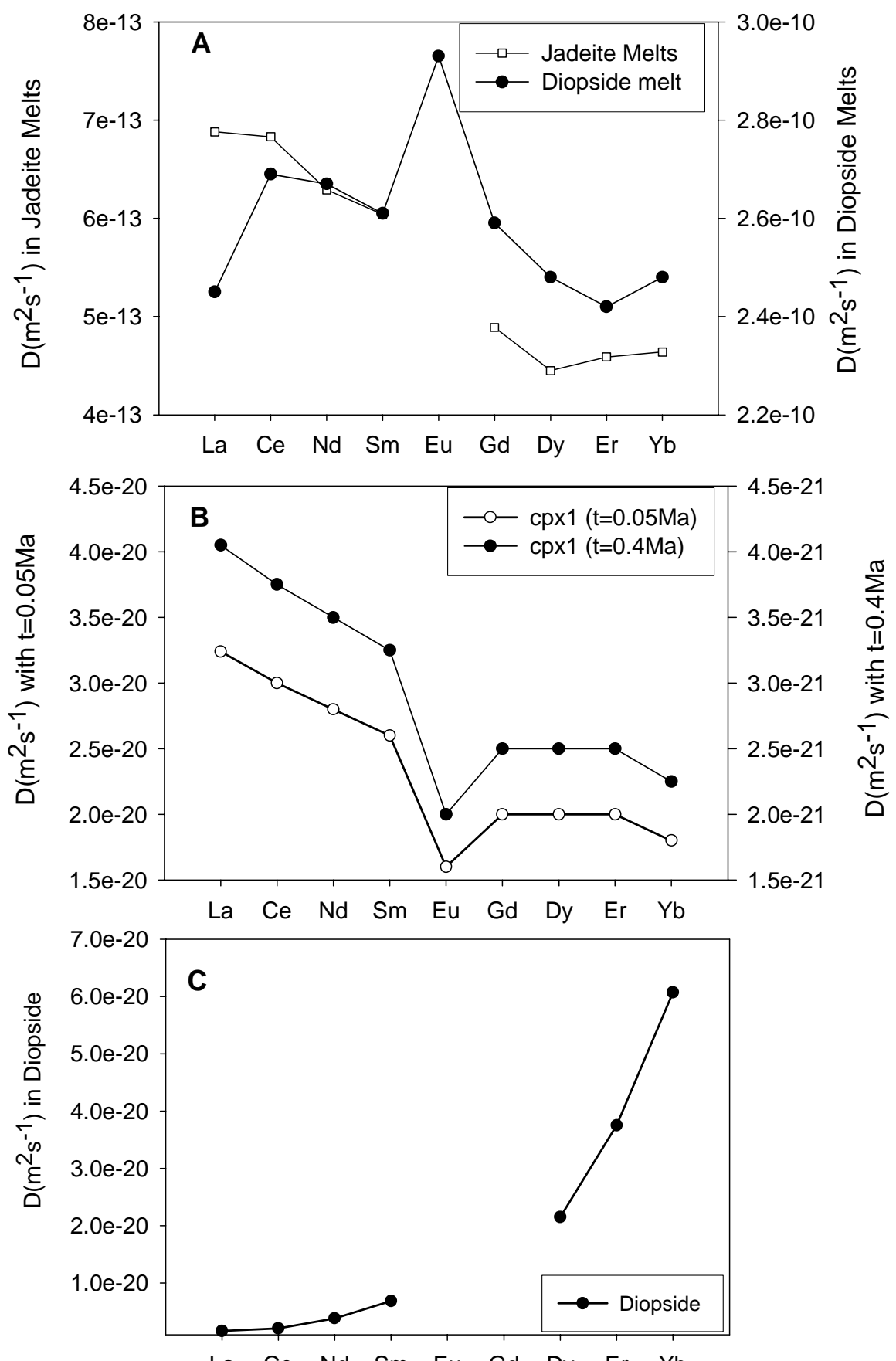

Fig. 6.13 Comparison of REE diffusion coefficients $\left(\mathrm{D}, \mathrm{m}^{2} \mathrm{~s}-1\right)$ in different media: (A) REE diffusion data in jadeite and diopside melt, form experimental studies at 7.5 kbar- $1400^{\circ} \mathrm{C}$ and $10 \mathrm{kbar}-1590^{\circ} \mathrm{C}$ respectively (Nakamura and Kushiro, 1998); (B) REE diffusion data in clinopyroxene, from this study. (C) REE diffusion data in highCa diopside, calculated for $1200^{\circ} \mathrm{C}$ and 1 atm with diffusion parameters given by Van Orman and Grove, 2001. 
In summary, the observed zoning profiles of trace elements in studied clinopyroxene can be explained by a process of secondary modification controlled by diffusive interaction between crystals and its contact phase, which can be either a neighbored mineral or an inter-granular fluid (melt). However, as the concentration of most measured trace elements in cpx1 are all simultaneously either increasing or decreasing to the rim no matter of being in contact with plagioclase or olivine, it is unlikely that the adjustment has taken place between clinopyroxene and its neighboring mineral. In other words, the presence of an inter-granular fluid (melt) is required for the evolution of observed trace element zoning.

Van Orman et al. (2002) have shown that diffusion plays an important control on REE fractionation during intergranular melt transport in the upper mantle, based on their experimental data that there is large difference of diffusion rates among REEs. They find that REE are fractionated less efficiently in residual solid than under equilibrium conditions, as heavy REEs diffuse much more rapidly than light REEs. For example, $\mathrm{Yb}$ is found to diffuse $\sim 38$ times more rapidly than $\mathrm{La}$ in clinopyroxene. Hence, they predict that it will be quite common to find REE zoned clinopyroxene grains from abyssal peridotites.

However, we do not find such a large difference in diffusion rates between La and Yb. It seems that all REEs have a very similar diffusivity. Despite the uncertainty for the values of diffusion rate due to a lack of accurate time constraints of diffusion, this study provides an evaluation of diffusion rates for a series of trace elements under natural conditions. 


\subsection{Oxygen Isotope Composition of Hole 735B Gabbros}

\subsubsection{Down-Hole variations}

Diffusion experiments and direct measurements have shown that the exchange rate of oxygen in $\mathrm{Ca}-\mathrm{Mg}$ silicate mineral (such as pyroxene) at a temperature of $600^{\circ} \mathrm{C}$ or below is much slower than the rate in feldspar (Ito and Clayton 1983; Giletti 1985; 1986). Thus the $\delta^{18} \mathrm{O}$ composition of plagioclase responds rapidly to hydrothermal alteration even before other geochemical effects are registered. At the same time, plagioclase is the most abundant mineral in nearly all of the studied gabbros, so the $\delta^{18} \mathrm{O}$ down-hole variation of ODP Hole 735B gabbro is evaluated in a depth profile of the $\delta^{18} \mathrm{O}$ composition of plagioclase (Figure 6.14).

In the upper part of this hole ( $\sim 60 \mathrm{mbsf}$ above $), \delta^{18} \mathrm{O}$ values are systematically lower than their mantle reference values, which has been interpreted as a result of seawater circulation at high temperatures (Hart et al., 1999). While as shown in Figure $6.13, \delta^{18} \mathrm{O}$ values of plagioclase show an abrupt kink at a depth of about 550-600 meters, below 600 meters, the variation range of $\delta^{18} \mathrm{O}$ is relatively constant with most values falling into the range of its mantle reference value of $+6.1 \pm 0.2 \%$. This suggests that high-temperature fluid inflow was very limited below about 600 mbsf. This trend for oxygen isotope depth variation has also been observed in the investigation of bulk $\delta^{18} \mathrm{O}$ compositions of gabbros (Bach et al., 2001).

At a depth of about 720 meters, there are 3 data points which fall out of the general down-hole variation trend showing depleted $\delta^{18} \mathrm{O}$ value of $+4.0 \%$ o to $+5.5 \%$ o As discussed above, these depleted values indicate a significant ${ }^{18} \mathrm{O}$ exchange of plagioclase with an external oxygen reservoir under relatively high temperature (about $250^{\circ} \mathrm{C}$ or higher) conditions. As shown in Figure 2.2, there is a major fault around 
this depth and 2 other faults about 200 meters above these locations, which may be interpreted that these fault systems have favored seawater penetrations.

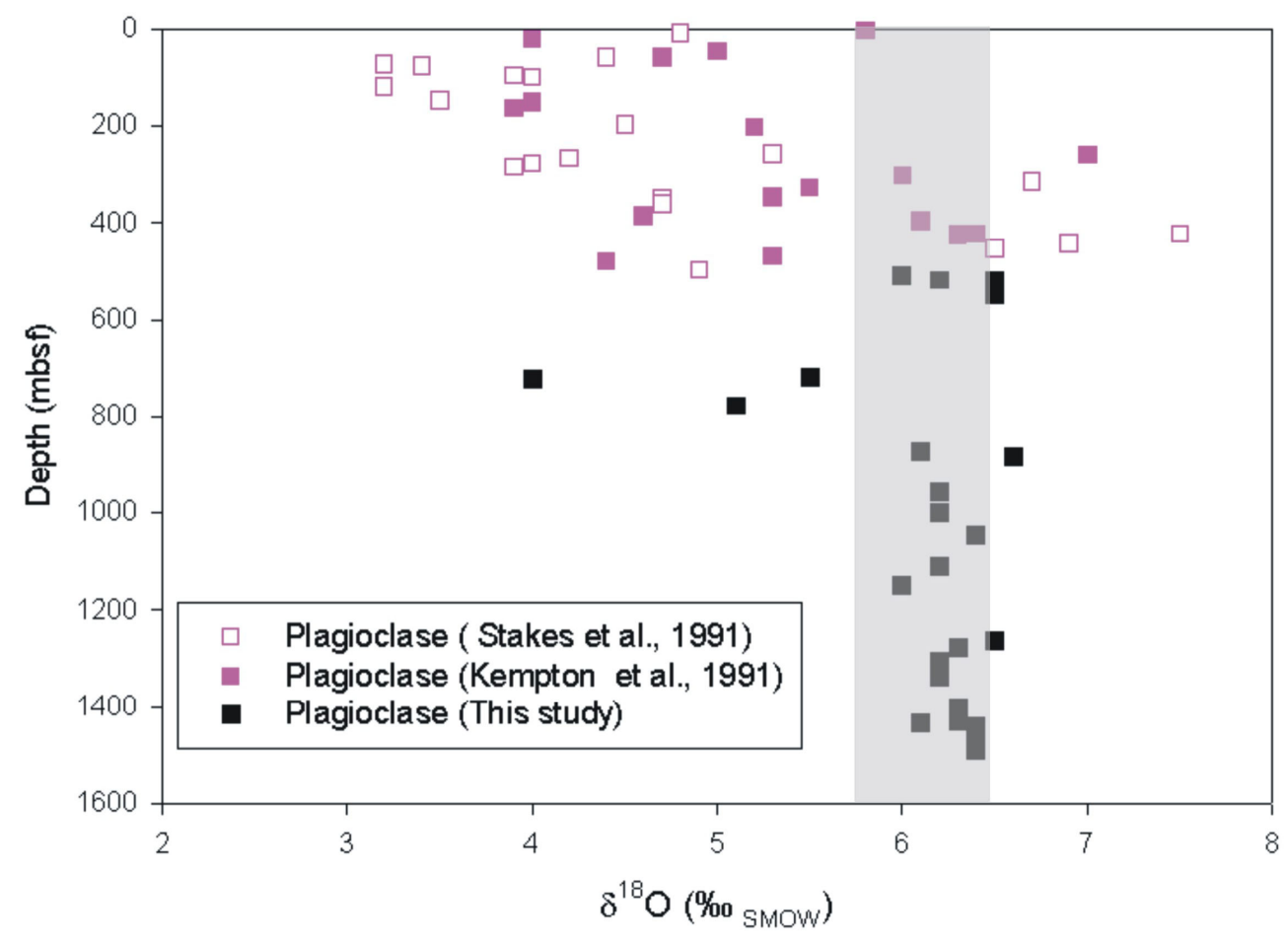

Fig. 6.14 Down-hole variation of $\delta^{18} \mathrm{O}_{\text {plag }}$ in Hole 735B gabbro, shadowed darkgray rectangular represents the mantle reference value of plagioclase $(+6.1 \pm 0.2 \%$ o)

Thus this study shows that abundant seawater penetration is limited to the upper part of lower oceanic crust (the plutonic Layer 3). This is in contrast to observations on the Samail ophiolite in Oman, where Gregory and Taylor (1981) found that seawater had penetrated to a depth of at least $5 \mathrm{~km}$ in the fossilized Tethyan oceanic crust formed initially under fast-spreading ridges. However, it agrees with the study on lower oceanic gabbros from Mid-Cayman Rise (Ito and Clayton, 1983), which represents the only study on the oxygen isotope compositions of lower oceanic crust formed under a slow-spreading ridge. 
Fast spreading ridges are characterized by axial faults restricted to upper crustal levels, where ductile shear zones are generally absent (Bideau et al., 1991). In contrast, slow-spreading ridges have deep axial faults and shear zones which may appear earlier in the lower oceanic crust at temperatures between $600^{\circ} \mathrm{C}$ and $800^{\circ} \mathrm{C}$ (Dick et al., 1991b). These fundamental differences in the timing, occurrence, and spatial distribution of fractures, and shear zones may strongly control seawater penetrations and circulations (Lecuyer and Reynard, 1996). It seems that high temperature shear zones act as some kind of barrier for seawater penetration at slow-spreading ridges. (Baker et al., 1996) has found that near-axis hydrothermal cooling increases linearly with increasing spreading rate. It has also been shown that hydrothermal fluids did not penetrate into plutonic rocks until the section of crust had migrated off-axis, which reflects the particular magmatic-tectonic history and thus may vary significantly in ridges with different spreading rates (Gillis, 1995).

\subsubsection{Mechanism of Oxygen Isotope Exchange}

Oxygen isotope exchange between minerals and hydrothermal waters can occur by means of solution-precipitation, chemical reaction, or diffusion (Hoefs, 2004). A principal difference among the three processes originates from the question of whether or not the solid phase breaks down or goes into solution. In the case of solution-precipitation and chemical reaction, the solid goes into solution, or reacts directly with the fluid, at least in part, and the oxygen isotopes equilibrate with the solution. The solid that then forms is a new phase. In contrast, a diffusion process does not involve any break down of the crystal. Diffusion must happen if the mineral is above its closure temperature, although exchange will only occur if another phase is available with which it can exchange (Giletti, 1985). 
As discussed above, seawater did penetrate into the lower part of Hole 735B, although it is highly localized beneath 600 meters. However the mineralogical and petrological studies show that the component minerals of these gabbros have preserved their magmatic cationic compositions even for those samples which obviously show modification of $\delta^{18} \mathrm{O}$ (see Chapter 4 and Chapter 5 for details). The absence of hydrous minerals in the gabbro and the stability of calcic plagioclase despite their oxygen isotope exchange with an external fluid suggest temperatures of at least $500^{\circ} \mathrm{C}$. At the same time, absence of pervasive crystalline deformation, and the preservation of magmatic compositions, as well as the absence of alteration products suggest that the modification of oxygen isotope composition occurred through a bulk solid state diffusion mechanism.

Because $\mathrm{O}^{2-}$ is the overwhelmingly dominant anion in all silicate crystal structures, the relevant $\mathrm{O}^{2-}$ transport mechanism is a self-diffusion mechanism, rather than a tracer-diffusion (Lee, 2000). With the self-diffusion data for plagioclase, pyroxene and olivine under hydrothermal conditions (Giletti et al., 1978; Giletti et al., 1980; Farver, 1989), the closure temperatures of these minerals are calculated using the equation (7) given in section 6.2.

The calculations show that olivine and clinopyroxene have very high closure temperatures above $600^{\circ} \mathrm{C}$ for effective radii of $0.1 \mathrm{~mm}$ under a cooling rate of $100^{\circ} \mathrm{C} / \mathrm{Ma}$, with $\mathrm{Tc}$ for olivine being $50^{\circ} \mathrm{C}$ to $100^{\circ} \mathrm{C}$ higher than that of pyroxene. While, plagioclase has a much lower closure temperature of about $300^{\circ}-400^{\circ} \mathrm{C}$. The cooling rate used in this calculation is estimated by the crystallization temperature of gabbro $\left(\sim 1000{ }^{\circ} \mathrm{C}\right)$ and the maximum age of this gabbro $(11 \mathrm{Ma})$, which represents the minimum average cooling rate. The calculated variation order of Tc for these component minerals in gabbro is in consistent with the observations for oxygen 
isotope compositions, among them plagioclase shows the most significant signature of oxygen exchange.

\subsubsection{Oxygen Isotope Composition of the Lower Oceanic Crust -The Budget of ${ }^{18} \mathrm{O}$ in Seawater}

Present-day seawater is well mixed with uniform $\delta^{18} \mathrm{O}$ values of $0 \pm 0.5 \%$ except in polar regions because of mixing with melt waters or in tropical zones because of extensive evaporation (Craig and Gordon, 1965). The maximum variation caused by glacial cycling is about $\pm 1 \sim 2 \%$, decreasing during ice melting and increasing during glaciations. Although the oxygen isotope history of seawater remains controversial despite decades of study, calculations by Muehlenbachs (1998) showed that seawater is mainly buffered by hydrothermal and weathering at mid-ocean ridges to a value of about 0\%o (SMOW).

The ${ }^{18} \mathrm{O}$ budget of seawater is controlled by several processes, such as continental weathering, submarine weathering, continental growth (recycling of sediment), hydrothermal alteration of sea floor, and water recycling by subduction. Among them continental weathering is the key process to extract ${ }^{18} \mathrm{O}$ from seawater and sea floor hydrothermal alteration is the most important process to contribute ${ }^{18} \mathrm{O}$ to the ocean (Muehlenbachs, 1998a).

In the mass balance calculations by Muehlenbachs (1998) seawater penetration depth was assumed to be $5 \mathrm{~km}$ mainly based on the data from Samail ophiolite (Gregory and Taylor, 1981). Weathering of seafloor is the major sink for ${ }^{18} \mathrm{O}$, while hydrothermal alteration by hot seawater $\left(200^{\circ} \mathrm{C}-300{ }^{\circ} \mathrm{C}\right.$ or higher $)$ is the major source of ${ }^{18} \mathrm{O}$ to the ocean. Although it has been illustrated that differences in depth of seawater penetration can not significantly affect this calculation (Muehlenbachs, 
1998), it does require a $\delta^{18} \mathrm{O}$ depleted lower ocean crust $(\sim 4.4 \%$ ) to account for the ${ }^{18} \mathrm{O}$ addition to the ocean, as the other processes tend to extract ${ }^{18} \mathrm{O}$ from sea water.

Studies on lower oceanic gabbros did show that the lower oceanic crust formed under fast-spreading ridges has an overall $\delta^{18} \mathrm{O}$ depleted value of about $\sim 4.4 \%$ o (Gregory and Taylor, 1981; Lecuyer and Reynard, 1996). However, oxygen isotope investigations of ophiolitic oceanic crust formed in slow-spreading environments revealed overall ${ }^{18} \mathrm{O}$ enrichment. The Xigaze ophiolite shows an average $\delta^{18} \mathrm{O}$ value of $+8 \%$ o (Agrinier et al., 1988) and for the Trinity ophiolite a value of $6.8 \%$ o has been found (Lecuyer and Fourcade, 1991).

Hole 735B gabbros represent nearly the whole lower oceanic crust formed under a slow-spreading ridge. The average $\delta^{18} \mathrm{O}$ composition of this gabbro section can be calculated based on $\delta^{18} \mathrm{O}$ values of component minerals and their mode composition. The oxygen isotope data in the upper part of this section are taken from the studies of Kempton et al. (1991) and Stakes et al. (1991).

Calculations show that the whole section has an average $\delta^{18} \mathrm{O}$ value of $5.5 \%$, which is indistinguishable from the average $\delta^{18} \mathrm{O}$ value for saw mud of 5.6\%o. The average $\delta^{18} \mathrm{O}$ value for pillow basalt and sheeted dikes is 9.6\% (Muehlenbachs, 1998) and its thickness is about $1.5-2 \mathrm{~km}$ for the crust formed at Hole 735B (Dick et al., 2000). Thus, the average $\delta^{18} \mathrm{O}$ value of the whole oceanic crust formed under this slow-spreading ridge is calculated to be about $7.55 \%$ o to $7.85 \%$.

These values support the idea that oceanic crust formed under slow-spreading ridges tends to have enriched $\delta^{18} \mathrm{O}$ values, while the crust formed under fast-spreading ridges may have either depleted $\delta^{18} \mathrm{O}$ values or normal MORB values. If this holds true, then one would expect an ${ }^{18} \mathrm{O}$ depleted ocean in a period when slow-spreading ridges are dominant in the ocean. However, so far, there is no evidence to show that 
the spreading rate of oceanic ridges has changed significantly with time. On the other hand, as the present day ocean shows very constant $\delta^{18} \mathrm{O}$ values, it requires roughly equal proportions of slow-spreading ridges and fast-spreading ridges on earth. Actually slow-spreading ridges $(<40 \mathrm{~mm} / \mathrm{yr}$ for full spreading rate $)$ do have a nearly identical proportion to fast-spreading ridges, which constitute $52 \%$ by length of the global mid-ocean ridge system (Baker et al., 1996). 


\section{Chapter 7 CONCLUSIONS}

ODP Hole 735B is the first and only long continuous in-situ section of lower oceanic crust ever sampled. Chemical and oxygen isotopic composition of the gabbros in the lower $1000 \mathrm{~m}$ part of this section has been investigated by a combined in-situ method.

Major and trace element data verify the known characteristics of the igneous and metamorphic evolution of the lower oceanic crust represented by Hole 735B gabbros. The crust was formed by in situ crystallization of 4 or 5 distinct olivine gabbro blocks, indicating at least two major cycles of intrusions with general upward fractionation. After initial rapid cooling and crystallization, significant amount of late stage melts were squeezed out of the crystal mush by compaction and deformation. These enriched melts then migrated upward and pervasively reacted with host olivine gabbros through solid state diffusion. Finally these melts were emplaced to higher levels in the lower crust to form evolved gabbros including ferrogabbros.

Based on the combined elemental and oxygen isotopic in-situ investigation, the following conclusions are drawn:

1. The combined in-situ method delivers meaningful, interpretable data on oceanic gabbros.

2. Trace element zoning in component minerals of gabbro, including plagioclase and clinopyroxene, is well developed and preserved in Hole 735B, which may represent a common feature in the lower ocean crust, at least for those rocks formed beneath slow-spreading ridges.

3. Petrologic modeling shows that the observed mineral zonations were not caused by primary magmatic growth process such as in-situ crystallization of trapped melt. Pervasively migrating late stage melts along grain boundaries 
resulted in the formation of trace element zoning in clinopyroxene and plagioclase by diffusive exchange between melts and gabbro.

4. Diffusion modeling of zoning profiles provides constraints to experimentally determined diffusion rates. It is shown that trace elements diffuse faster in clinopyroxene under natural conditions than under experimental conditions. In contrast to the large difference found in experimental studies, rare earth elements have been found to have quite similar diffusivities.

5. Abundant seawater penetration and circulation is limited to the upper part of the lower crust ( $\sim 600$ meters into the gabbro and $\sim 2-2.5 \mathrm{~km}$ in total into the oceanic crust from the top of pillow basalts).

6. Mass balance calculations show that the lower crust formed under this ultraslow spreading ridge (Southwest Indian Ridge) has an average $\delta^{18} \mathrm{O}$ value of $5.5 \%$, whereas the whole crust is ${ }^{18} \mathrm{O}$ enriched with $\delta^{18} \mathrm{O}$ values between $7.55 \%$ o to $7.85 \%$, depending on the possible variation of $\delta^{18} \mathrm{O}$ values of the upper pillow basalts and sheeted dykes. This enriched $\delta^{18} \mathrm{O}$ value has also been found in other oceanic crust formed under slow spreading ridges, whereas crust formed under fast-spreading ridges usually has depleted $\delta^{18} \mathrm{O}$ values caused by significant hot seawater penetrations into greater depth at temperatures above $\sim 250^{\circ} \mathrm{C}$.

7. These fundamental differences could be related to the particular magmatictectonic history and especially to broadly existing deep axial faults and shear zones that appear at an early stage during the formation of lower oceanic crust at relatively high temperatures between $600^{\circ} \mathrm{C}$ and $800^{\circ} \mathrm{C}$ at slow-spreading ridges. 


\section{REFERENCES}

Agrinier, P., Javoy, M., and Girardeau, J., 1988. Hydrothermal activity in a peculiar oceanic ridge: oxygen and hydrogen isotope evidence in the Xigaze ophiolite (Tibet, China). Chem. Geol., 71: 313-335.

Alt, J. C. and Anderson, T. F., 1991. Mineralogy and isotopic composition of sulfur in Layer 3 gabbros from the Indian Ocean, Hole 735B. Proc. ODP, Sci. Results, 118: 113-125.

Anderson, A. T. Jr., Clayton, R. N., and Mayeda, T. K., 1971. Oxygen isotope thermometry of mafic igneous rocks. J. Geol., 79: 715-729.

Bach, W., Alt, J. C., Niu, Y. L., Humphris, S. E., Erzinger, J., and Dick, H. J. B., 2001. The geochemical consequences of late-stage low-grade alteration of lower ocean crust at the SW India Ridge : Results from ODP Hole 735B (Leg 176). Geochim. Cosmochim. Acta, 65(19): 3267-3287.

Bach, W. and Humphris, S. E., 1999. Relatiosnship between the $\mathrm{Sr}$ and O isotope compositions of hydrothermal fluids and the spreading and magma-supply rates at oceanic spreading centers. Geology, 27(12): 1067-1070.

Baker, E. T., Chen, Y. J., and Morgan, J. P., 1996. The relationship between nearaxis hydrothermal cooling and the spreading rate of mid-ocean ridges. Earth. Planet. Sci. Lett., 142: 137-145.

Beattie, P., 1994. Systematics and energetics of trace-element partitioning between olivine and silicate melts: Implications for the nature of mineral/melt partitioning. Chem. Geol., 117: 57-71.

Bedard, J. H., 1994. A procedure for calculating the equilibrium distribution of trace elements among the minerals of cumulate rocks, and the concentration of trace elements in coexisting liquids. Chem. Geol., 118: 143-153.

Bideau, D., Hebert, R., Hekinian, R., and Cannat, M., 1991. Metamorphism of deep-seated rocks from the Garrett ultrafast transform (East Pacific Rise near 13²5'S). J. Geophys. Res., 96: 10079-10099.

Bloomer, S. H., Meyer, P. S., Dick, H. J. B., Ozawa, K., and Natland, J. H., 1991. Texture and mineralogic variations in gabbroic rocks from Hole 735B. In: Von Herzen, R. P. et al., (Eds.), Proc. ODP, Sci. Results Leg 118. Ocean Drilling Program, College Station, TX, pp. 21-39.

Bown, J. W. and White, R. S., 1994. Variation with spreading rate of oceanic crustal thickness and geochemistry. Earth. Planet. Sci. Lett., 121: 435-449.

Brady, J. B. and McCallister, R. H., 1983. Diffusion data for clinopyroxenes from homogenization and self-diffusion experiments. Am. Mineral., 68(1-2): 95105. 
Cann, J. R., 1970. New model for the structure of the ocean crust. Nature, 266: 928-930.

Chacko, T., Cole, D. R., and Horita, J., 2001. Equilibrium oxygen, hydrogen and carbon isotope fractionation factors applicable to geologic system. In: Valley John, W. and Cole David, R. (Eds.), Stable isotope geochemistry. Mineralogical society of America, pp. 1-83.

Chakraborty, S. and Ganguly, J., 1991. Compositional Zoning and Cation Diffusion in Garnets. In: Ganguly, J. (Ed.), Advances in Physical Geochemistry. Springer, pp. 120-175.

Cherniak, D. J., 1998a. Pb diffusion in clinopyroxene. Chem. Geol., 150(1-2): 105-117.

Cherniak, D. J., 1998b. Rare earth element and gallium diffusion in yttrium aluminium garnet. Phys. Chem. Mineral., 26: 156-163.

Cherniak, D. J., 1998c. REE diffusion in calcite. Earth. Planet. Sci. Lett., 160(34): 273-287.

Cherniak, D. J., 2000. Rare earth element diffusion in apatite. Geochim. Cosmochim. Acta, 64(22): 3871-3885.

Cherniak, D. J., 2002. REE diffusion in feldspar. Chem. Geol., 193(1-2): 25-41.

Cherniak, D. J., Hanchar, J. M., and Watson, E. B., 1997. Rare-earth diffusion in zircon. Chem. Geol., 134(4): 289-301.

Chiba, H., Chacko, T., Clayton, R. N., and Goldsmith, J. R., 1989. Oxygen isotope fractionations involving diopside, forsterite, magnetite and calcite: Application to geothermometry. Geochim. Cosmochim. Acta, 53: 2985-2995.

Clayton, R. N. and Mayeda, T. K., 1963. The use of bromine pentafluoride in the extraction of oxygen from oxides and silicates for isotopic analysis. Geochim. Cosmochim. Acta, 27: 43-52.

Cole, D. R., 2000. Isotopic exchange in mineral-fluid systems. IV. The crystal chemical controls on oxygen isotope exchange rates in carbonate- $\mathrm{H}_{2} \mathrm{O}$ and layer silicate- $\mathrm{H}_{2} \mathrm{O}$ systems. Geochim. Cosmochim. Acta, 64: 921-931.

Cole, D. R. and Chakraborty, S., 2001. Rates and Mechanisms of Isotopic Exchange. In: Valley, J. W. and Cole, D. R. (Eds.), Stable Isotope Geochemistry. The Mineralogical Society of America, pp. 83-223.

Coogan, L. A., MacLeod, C. J., Dick, H. J. B., Edwards, S. J., Kvassnes, A., Natland, J. H., Robinson, P. T., Thompson, G., and O, H. M. J., 2001. Wholerock geochemistry of gabbros from the Southwest Indian Ridge; constraints on geochemical fractionations between the upper and lower oceanic crust and magma chamber processes at (very) slow-spreading ridges. Chem. Geol., 178(1-4): 1-22. 
Coogan, L. A., Saunders, A. D., Kempton, P. D., and Norry, M. J., 2000a. Evidence from oceanic gabbros for porous melt migration within a crystal mush beneath the Mid-Atlantic Ridge. Geochem. Geophys. Geosyst., 1: paper number 2000GC000072.

Coogan, L. A., Jenkin, G. R. T., and Wilson, R. N., 2002. Constraining the cooling rate of the lower oceanic crust; a new approach applied to the Oman Ophiolite. Earth. Planet. Sci. Lett., 199(1-2): 127-146.

Coogan, L. A., Kempton, P. D., Saunders, A. D., and Norry, M. J., 2000b. Melt aggregation within the crust beneath the Mid-Atlantic Ridge; evidence from plagioclase and clinopyroxene major and trace element compositions. Earth. Planet. Sci. Lett., 176(2): 245-257.

Cooper, A. R., Eiler, J. M., Asimow, P. D., and Langmuir, C. H., 2004. Oxygen isotope evidence for the origin of enriched mantle beneath the mid atlantic ridge. Earth. Planet. Sci. Lett., 220: 297-316.

Costa, F., Chakraborty, S., and Dohmen, R., 2003. Diffusion coupling between trace and major elements and a model for calculation of magma residence times using plagioclase. Geochim. Cosmochim. Acta, 67(12): 2189-2200.

Craig, H. and Gordon, L. I., 1965. Deuterium and oxygen-18 variations in the ocean and the marine atmosphere. In: Tongiorgo, E. (Ed.), Stable isotopes in oceanographic studies and paleotemperatures. Spoleto, CNR, Lab. of Nuclear Geology, Pisa, pp. 9-130.

Crank, J., 1975. The Mathematics of Diffusion. Clarendon Press.

Criss, R., Gregory, R., and Taylor, H., 1987. Kinetic theory of oxygen isotopic exchange between minerals and water. Geochim. Cosmochim. Acta, 51(5): 1099-1108.

Dick, H. J. B., Meyer, P. S., Bloomer, S. H., Kirby, S. H., Stakes, D. S., and Mawer, C. K., 1991a. Lithostratigraphic evolution of an in-situ section of oceanic layer 3. In: Von Herzen, R. P. et al., (Eds.), Poc. ODP, Sci. Results Leg 118. pp. 439-538.

Dick, H. J. B., Natland, J. H., Alt, J. C., Bach, W., Bideau, D., Gee, J. S., Haggas, S., Hertogen, J. G. H., Hirth, G., Holm, P. M., Ildefonse, B., Iturrino, G. J., John, B. E., Kelley, D. S., Kikawa, E., Kingdon, A., LeRoux, P. J., Maeda, J., Meyer, P. S., Miller, D. J., Naslund, H. R., Niu, Y.-L., Robinson, P. T., Snow, J., Stephen, R. A., Trimby, P. W., Worm, H.-U., and Yoshinobu, A., 2000. A Long In Situ Section of the Lower Ocean Crust: Results of ODP Leg 176 Drilling at the Southwest Indian Ridge. Earth. Planet. Sci. Lett., 179: 31-51.

Dick, H. J. B., Natland, J. H., Miller, D. J., Alt, J. C., Bach, W., Bideau, D., Gee, J. S., Haggas, S., Hertogen, J. G. H., Hirth, G., Holm, P. M., Ildefonse, B., Iturrino, G. J., John, B. E., Kelley, D. S., Kikawa, E., Kingdon, A., Le, R. P. J., Maeda, J., Meyer, P. S., Naslund, H. R., Niu, Y., Robinson, P. T., Snow, J. E., Stephen, R. A., Trimby, P. W., Worm, H. U., and Yoshinobu, A., 1999. Leg 
176 summary. In: Marin, J. A. et al., (Eds.), Proc. ODP, Initial Reports Leg 176. Ocean Drilling Program, College Station, TX.

Dick, H. J. B., Ozawa, K., Meyer, P. S., Niu, Y., Robinson, P. T., Constantin, M., Herbert, R., Natland, J. H., Hirth, J. G., and Mackie, S. M., 2002. Primary silicate mineral chemistry of a $1.5-\mathrm{km}$ section of very slow spreading lower ocean crust; ODP Hole 735B, Southwest Indian Ridge. In: Natland, J. H. et al., (Eds.), Proc. ODP, Sci. Results Leg 176 (CD-Rom). Ocean Drilling Program, College Station, TX.

Dick, H. J. B., Schouten, H., Meyer, P. S., Gallo, D. G., Bergh, H., Tyce, R., Patriat, P., Johnson, K. T. M., Snow, J., and Fisher, A. T., 1991b. Tectonic evolution of the Atlantis II fracture zone. In: Von Herzen, R. P. et al., (Eds.), Poc. ODP, Sci. Results Leg 118. Ocean Drilling Program, College Station, TX, pp. 359-398.

Dimanov, A. and Jaoul, O., 1998. Calcium self-diffusion in diopside at high temperature; implications for transport properties. Phys. Chem. Mineral., 26(2): 116-127.

Dodson, M. H., 1973. Closure Temperature in Cooling Geochronological and Petrological System. Contrib. Mineral. Petrol., 40: 259-274.

Dunn, T. and Sen, C., 1994a. Mineral/matrix partition coefficients for orthopyroxene, plagioclase, and olivine in basaltic to andesitic systems: a combined analytical and experimental study. Geochim. Cosmochim. Acta, 58: 717-733.

Dunn, T. and Sen, C., 1994b. Mineral/matrix partition coefficients for orthopyroxene, plagioclase, and olivine in basaltic to andesitic systems: A combind analytical and experimental study. Geochim. Cosmochim. Acta, 58(2): 717-733.

Eiler, J. M., Farley, K. A., Valley, J. W., Hauri, E., Craig, H., Hart, S. R., and Stolper, E. M., 1997. Oxygen isotope variations in ocean island basalt phenocrystals. Geochim. Cosmochim. Acta, 61(11): 2281-2293.

Eiler, J. M., Valley, J. W., and Stolper, E. M., 1996. Oxygen isotope in olivines from the Hawaii Scientific Drilling Project. J. Geophys. Res., 101(B5): $11,807-11,813$.

Eiler, J. M., 2001. Oxygen isotope variations of basaltic lavas and upper mantle rocks. In: Valley John, W. and Cole David, R. (Eds.), Stable isotope geochemistry. Mineralogical Society of America and Geochemical Society., Washington, DC, United States., pp. 319-364.

Eiler, J. M., Mclnnes, B., Valley, J. W., Graham, C. M., and Stolper, E. M., 1998. Oxygen isotope evidence for slab-derived fluids in the sub-arc mantle. Nature (London), 393: 777-781. 
Eiler, J. M., Schiano, P., Kitchen, N., and Stolper, E. M., 2000. Oxygen-isotope evidence for recycled crust in the sources of mid-ocean-ridge basalts. Nature (London), 403: 530-534.

Eiler, J. M., Valley, J. W., and Baumgartner, L. P., 1993. A new look at stable isotope thermometry. Geochim. Cosmochim. Acta, 57: 2571-2583.

Elsenheimer, D. and Valley, J., 1993. Submillimeter scale zonation of delta (super 18) O in quartz and feldspar, Isle of Skye, Scotland. Geochim. Cosmochim. Acta, 57(15): 3669-3676.

Farver, J. R., 1989. Oxygen self-diffusion in diopside with application to cooling rate determinations. Earth. Planet. Sci. Lett., 92(3-4): 386-396.

Fiebig, J., Wiechert, W., III, D. R., and Hoefs, J., 1999. High-precision in situ oxygen isotope analysis of quartz using an ArF laser. Geochim. Cosmochim. Acta, 63(5): 687-702.

Frey, F. A., Green, D. H., and Roy, S. D., 1978. Intergrated model of basalt petrogenesis: a study of olivine melilitites to quartz tholeiites from southeastern Australia utilizing geochemical and experimental petrological data. J. Petrol., 19: 463-513.

Furman, T. H., Frey, F. H., Jakobsson, S. P., and Park, K. H., 1991. Petrogenesis of mildly alkaline lavas from Vest-mannaeyjar, Iceland: the Eldfell (1973) and Surtsey (1963-1967) eruptions. Contrib. Mineral. Petrol., 109: 19-37.

Giletti, B. J., 1985. The nature of oxygen isotope transport within minerals in the presence of hydrothermal water and the role of diffusion. Chem. Geol., 53: 197-206.

Giletti, B. J., Hickey, J. H., and Tullis, T. E., 1980. Oxygen diffusion in olivine under hydrous conditions. Eos, Transactions, American Geophysical Union, 60(18): 370.

Giletti, B. J., Semet, M. P., and Yund, R. A., 1978. Studies in diffusion, III, oxygen in feldspars: An ion microprobe determination. Geochim. Cosmochim. Acta, 42: 45-47.

Gillis, K. M., 1995. Controls on hydrothermal alteration in a section of fastspreading oceanic crust. Earth. Planet. Sci. Lett., 134: 473-489.

Gregory, R., Criss, R., and Taylor, H., 1989a. Oxygen isotope exchange kinetics of mineral pairs in closed and open systems; applications to problems of hydrothermal alteration of igneous rocks and Precambrian iron formations. Chem. Geol., 75(1-2): 1-42.

Gregory, R. T., Criss, R. E., and Taylor, H. P., Jr., 1989b. Oxygen isotope exchange kinetics of mineral pairs in closed and open systems; applications to problems of hydrothermal alteration of igneous rocks and Precambrian iron formations. Chemical Geology, 75(1-2): 1-42. 
Gregory, R. T. and Taylor, H. P., 1981a. An oxygen isotope profile in a secctin of cretaceous oceanic crust, Samail Ophiolite, Oman: Evidence for 180 buffering of the oceans by $\operatorname{deep}(>5 \mathrm{~km})$ seawater-hydrothermal circulation at MidOcean Ridges. J. Geophys. Res., 86(B4): 2737-2755.

Gregory, R. T. and Taylor, H. P., 1981b. An oxygen isotope profile in a secctin of cretaceous oceanic crust, Samail Ophiolite, Oman: Evidence for 180 buffering of the oceans by $\operatorname{deep}(>5 \mathrm{~km})$ seawater-hydrothermal circulation at MidOcean Ridges. J. Geophys. Res., 86(B4): 2737-2755.

Griffin, W. L., Smith, D., Ryan, C. G., O'Reilly, S. Y., and Win, T. T., 1996. Trace-element zoning in mantle minerals: Metasomatism and thermal events in the upper mantle. The Canada Mineralogist, 34: 1179-1193.

Harmon, R. S. and Hoefs, J., 1995. Oxygen isotope heterogeneity of the mantle deduced from global (super 18) O systematics of basalts from different geotectonic settings. Contributions to Mineralogy and Petrology, 120(1): 95114.

Hart, S. R., Blustajn, J., Dick, H., Meyer, P., and Muehlenbachs, K., 1999. The fingerprint of seawater circulation in a 500 meter section of ocean crust gabbros. Geochim. Cosmochim. Acta, 63: 4059-4080.

Hart, S. R. and Dunn, T., 1993. Experimental cpx/melt partitioning of 24 trace elements. Contrib. Mineral. Petrol., 113: 1-8.

Hattori, K. and Sato, H., 1996. Magma evolution recorded in plagioclase zoning in 1991 Pinatubo eruption products. Am. Mineral., 81(7-8): 982-994.

Hawkesworth, C., George, R., Turner, S., and Zellmer, G., 2004. Time scales of magmatic process. Earth. Planet. Sci. Lett., 218: 1-16.

Hellebrand, E., Snow, J. E., Hoppe, P., and Hofmann, A. W., 2002. Garnet-field melting and late-stage refertilization in "residual" abyssal peridotites from the Central Indian Ridge. J. Petrol., 43(12): 2305-2338.

Hess, P. C., 1993. Phase equilibria constraints on the origin of ocean floor basalts. In: Morgan, J. P. et al., (Eds.), Mantle flow and melt generation at Mid-Ocean Ridges. American Geophysical Union, Washington, pp. 67-102.

Hoefs, J., 2004. Stable Isotope Geochemistry. Springer-Verlag Berlin Heidelberg New York.

Irving, A. J., 1978. A review of experimental studies of crystal/liquid trace element partitioning. Geochim. Cosmochim. Acta, 48: 1201-1221.

Ito, E. and Clayton, R. N., 1983. Submarine metamorphism of gabbros from the Mid-Cayman Rise: an oxygen isotopic study. Geochim. Cosmochim. Acta, 47: 535-546.

Jang, Y. D. and Naslund, H. R., 2001. Major and trace element composition of Skaergaard plagioclase; geochemical evidence for changes in magma 
dynamics during the final stage of crystallization of the Skaergaard Intrusion. Contrib. Mineral. Petrol., 140(4): 441-457.

Jochum, K. P., Dingwell, D. B., Rocholl, A., Stoll, B., Hofmann, A. W., and Becker, S., 2000. The preparation and preliminary characterisation of eight geological MPI-DING standard reference glasses for in-situ microanalysis. Geostandards Newsletter, 24: 87-133.

Johnson, K. T. M. and Dick, H. J. B., 1992. Open system melting and temporal and spatial variation of peridotite and basalt at the Atlantis II fracture zone. J. Geophys. Res. (B), 97(6): 9219-9241.

Kempton, P. D., Hawkesworth, C. J., and Fowler, M., 1991. Geochemistry and Isotopic composition of gabbros from layer 3 of the india ocean crust, Hole 735B. In: Von Herzen, R. P. et al., (Eds.), Proc. ODP, Sci. Results Leg 118. Ocean Drilling Program, College Station, TX, pp. 127-143.

Klock, W. and Palme, H., 1988. Partitioning of Siderophile and Chalcophile Elements between Sulfide, Olivine, and glass in a naturally reduced Basalt from Disko Island, Greenland. Proceedings of the 18th Lunar Planetary Science Conference, 18: 471-483.

Koepke, J., Feig, S. T., Snow Jonathan, E., and Freise, M., 2003. Petrogenesis of oceanic plagiogranites by partial melting of gabbros: an experimental study. Contrib. Mineral. Petrol., 146(4): 414-432.

Korenaga, J. and Kelemen, P. B., 1997. Origin of gabbro sills in the Moho transition zone of the Oman Ophiolite; implications for magma transport in the oceanic lower crust. J. Geophys. Res. (B), 102(12): 27,729-27,749.

Korenaga, J. and Kelemen, P. B., 1998. Melt migration through the oceanic lower crust; a constraint from melt percolation modeling with finite solid diffusion. Earth. Planet. Sci. Lett., 156(1-2): 1-11.

Langmuir, C. H., Klein, E. M., and Plank, T., 1993. Petrological systematics of Mid-Ocean Ridge basalts: constraints on melt generation beneath Ocean ridges. In: Morgan, J. P. et al., (Eds.), Mantle Flow and Melt Generation at Mid-Ocean Ridges. American Geophysical Union, Washington.

Lecuyer, C. and Fourcade, S., 1991. Oxygen isotope evidence for multi-stage hydrothermal alteration at a fossil slow-spreading center: The Silurian Trinity ophiolite (California, U.S.A.). Chem. Geol., 87(13): 231-246.

Lecuyer, C. and Reynard, B., 1996. High-temperature alteration of oceanic gabbros by seawater(Hess Deep, Ocean Drilling Program Leg 147): Evidence from oxygen isotopes and elemental fluxes. J. Geophys. Res., 101(B7): $15,883-15,897$.

Lee, J. K. W., 2000. Empirical constraints on closure temperature from a single diffusion coefficient. Contrib. Mineral. Petrol., 139: 526-540. 
Loomis, T. P., 1983. Compositional zoning of crystals: A record of growth and reaction history. In: Saxena, S. K. (Ed.), Advances in Physical Geochemistry. Springer-Verlag, New York, pp. 1-60.

Macpherson, C. G., Hilton, D. R., Mattey, D. P., and Sinton, J. M., 2000. Evidence for an (super 18) O-depleted mantle plume from contrasting (super 18) $\mathrm{O} /$ (super 16) $\mathrm{O}$ ratios of back-arc lavas from the Manus Basin and Mariana Trough. Earth. Planet. Sci. Lett., 176(2): 171-183.

Maeda, J., Naslund, H. R., Jang, Y. D., Kikawa, E., Tajima, T., and Blackburn, W. H., 2002. High-temperature fluid migration within oceanic layer 3 gabbros, Hole 735B, Southwest Indian Ridge; implications for the magmatichydrothermal transition at slow-spreading mid-ocean ridges. In: Natland, J. H. et al., (Eds.), Proc. ODP, Sci. Results Leg 176 (CD-Rom). Ocean Drilling Program, College Station, TX.

Mattews, A., Goldsmith, J. R., and Clayton, R. N., 1983. Oxygen isotope fractionations involving pyroxenes: The calibration of mineral-pair geothermometers. Geochimica et Cosmochimica Acta, 47: 631-644.

Mattey, D., Lowry, D., and Macpherson, C., 1994. Oxygen isotope composition of mantle peridotite. Earth and Planetary Science Letters, 128(3-4): 231-241.

McKenzie, D. and O'Nions, R. K., 1991. Partial melt distributions from inversion of rare Earth element concentrations. J. Petrol., 32: 1021-1091.

Meyer, P. S., Dick, H. J. B., and Thompson, G., 1989. Cumulate gabbros from the Southwest Indian Ridge, 54 degrees S - 7 degrees 16' E; implications for magmatic processes at a slow spreading ridge. Contributions to Mineralogy and Petrology, 103(1): 44-63.

Muehlenbachs, K., 1998a. The oxygen isotopic composition of the oceans, sediments and the seafloor. Chemical Geology, 145: 263-273.

Muehlenbachs, K., 1998b. The oxygen isotopic composition of the oceans, sediments and the seafloor. Chem. Geol., 145: 263-273.

Muehlenbachs, K. and Clayton, R. N., 1976. Oxygen isotope composition of the oceanic crust snd its bearing on seawater. J. Geophys. Res., 81(23): 43654369.

Nakamura, E. and Kushiro, I., 1998. Trace element diffusion in jadeite and diopside melts at high pressures and its geochemical implication. Geochim. Cosmochim. Acta, 62(18): 3151-3160.

Natland, J. H., Dick Henry, J. B., Miller, D. J., Alt, J. C., Bach, W., Bideau, D., Gee Jeffrey, S., Haggas, S., Hertogen, J. G. H., Hirth, G., Holm, P. M., Ildefonse, B., Iturrino, G. J., John, B. E., Kelley, D. S., Kikawa, E., Kingdon, A., Le Roux , P. J., Maeda, J., Meyer, P. S., Naslund, H. R., Niu, Y., Robinson, P. T., Snow, J. E., Stephen, R. A., Trimby, P. W., Worm, H. U., and Yoshinobu, A., 2002. A brief narrative history of ODP Hole 735B. In: Natland, J. H. et al., (Eds.), Proc. ODP, Sci. Results Leg 176 (CD-Rom). 
Texas A\&M University, Ocean Drilling Program, College Station, TX, United States..

Natland, J. H. and Dick, H. J. B., 2001. Formation of the lower ocean crust and the crystallization of gabbroic cumulates at a very slowly spreading ridge. J. Volcanol. Geotherm. Res., 110(3-4): 191-233.

Natland, J. H. and Dick, H. J. B., 2002. Stratigraphy and composition of gabbros drilled in Ocean Drilling Program Hole 735B, Southwest Indian Ridge; a synthesis of geochemical data. In: Natland, J. H. et al., (Eds.), Proc. ODP, Sci. Results Leg 176 (CD-Rom). Ocean Drilling Program, College Station, TX.

Nikogosian, I. K. and Sobolev, A. V., 1997. Ion-microprobe analysis of melt Inclusions in olivine: experience in estimating the olivine-melt partition coefficients of trace elements. Geochem. Inter., 35: 119-126.

Niu, Y., Gilmore, T., Mackie, S. M., and Bach, W., 2002. Mineral chemistry, whole-rock compositions, and petrogenesis of Leg 176 gabbros; data and discussion. In: Natland, J. H. et al., (Eds.), Proc. ODP, Sci. Results (CD-Rom). Ocean Drilling Program, College Station, TX.

Prinzhofer, A. and Allegre, C. J., 1985. Residual peridotites and the mechanisms of partial melting. Earth. Planet. Sci. Lett., 74: 251-265.

Sneeringer, M., Hart, S. R., and Shimizu, N., 1984. Strontium and samarium diffusion in diopside. Geochim. Cosmochim. Acta, 48(8): 1589-1608.

Snow, J. E., 1995. Of Hess crust and layer cake. Nature, 374: 413-414.

Snow, J. E., 2002. Major and trace element evolution of Hole 735B gabbros. In: Natland, J. H. et al., (Eds.), Proc. ODP, Sci. Results Leg 176 (CD-Rom). Ocean Drilling Program, College Station, TX.

Stakes, D. S. and O'Neil, J. R., 1982. Mineralogy and stable isotope geochemistry of hydrothermally altered oceanic rocks. Earth. Planet. Sci. Lett., 57: 285-304.

Tracy, R. J., 1982. Compositional zoning and inclusions in metamorphic minerals. In: John, M. F. (Ed.), Characterization of metamorphism through mineral equilibria. Mineralogical Society of America, pp. 335-397.

Van Orman, J. A., Grove, T. L., and Shimizu, N., 2001. Rare earth element diffusion in diopside; influence of temperature, pressure, and ionic radius, and an elastic model for diffusion in silicates. Contrib. Mineral. Petrol., 141(6): 687-703.

Van Orman, J. A., Grove, T. L., and Shimizu, N., 2002a. Diffusive fractionation of trace elements during production and transport of melt in Earth's upper mantle. Earth. Planet. Sci. Lett., 198: 93-112.

Van Orman, J. A., Grove, T. L., Shimizu, N., and Layne, G. D., 2002b. Rare earth element diffusion in a natural pyrope single crystal at $2.8 \mathrm{GPa}$. Contrib. Mineral. Petrol., 142(4): 416-424. 
Vine, F. and Moores, E., 1972. A Model for the Gross Structure, Petrology, and Magnetic Properties of Oceanic Crust. Geol. Soc. Am. Mem., 132: 195-205.

Wiechert, U. and Hoefs, J., 1995. An excimer laser-based micro analytical preparation tecnique for in-situ oxygen isotope analysis of silicate and oxide minerals. Geochim. Cosmochim. Acta, 59: 4093-4101.

Wiechert, U., Fiebig, J., Przybilla, R., Xiao, Y., and Hoefs, J., 2002. Excimer laser isotope-ratio-monitoring mass spectrometry for in situ oxygen isotope analysis. Chem. Geol., 182(2-4): 179-194.

Wood, D. A., Joron, J. L., Treuil, M., Norry, M., and Tarney, J., 1979. Elemental and $\mathrm{Sr}$ isotope variations in basic lavas from Iceland and the surrounding ocean floor. Contrib. Mineral. Petrol., 70: 319-339. 


\section{APPENDIX}

Table AT1 Microprobe analysis results of plagioclase in Hole 735B (Leg 176) gabbros.

\begin{tabular}{|c|c|c|c|c|c|c|c|c|c|c|c|c|c|c|c|}
\hline Comment & Total & $\mathrm{SiO}_{2}$ & $\mathrm{Na}_{2} \mathrm{O}$ & $\mathrm{K}_{2} \mathrm{O}$ & $\mathrm{TiO}_{2}$ & $\mathrm{FeO}$ & $\mathrm{Al}_{2} \mathrm{O}_{3}$ & $\mathrm{MgO}$ & $\mathrm{CaO}$ & $\mathrm{Cr}_{2} \mathrm{O}_{3}$ & $\mathrm{MnO}$ & $\mathrm{NiO}$ & An & $A b$ & Or \\
\hline s126-pl-6-1 & 99.13 & 49.79 & 3.30 & 0.05 & 0.07 & 0.49 & 30.74 & 0.21 & 14.44 & 0.04 & n.d. & n.d. & 70.56 & 29.15 & 0.29 \\
\hline s126-pl-6-2 & 99.83 & 51.20 & 3.65 & 0.03 & 0.06 & 0.17 & 30.62 & 0.04 & 14.03 & n.d. & 0.02 & 0.01 & 67.83 & 31.97 & 0.19 \\
\hline s126-pl-4-1 & 99.63 & 50.72 & 3.23 & 0.05 & 0.01 & 0.25 & 31.07 & 0.04 & 14.26 & n.d. & n.d. & n.d. & 70.68 & 29.03 & 0.29 \\
\hline s126-pl-4-2 & 99.72 & 50.83 & 3.42 & 0.05 & 0.03 & 0.29 & 30.85 & 0.06 & 14.18 & n.d. & 0.01 & n.d. & 69.38 & 30.33 & 0.29 \\
\hline s126-pl-1-1 & 99.09 & 49.79 & 3.11 & 0.02 & 0.01 & 0.25 & 31.16 & 0.01 & 14.73 & n.d. & n.d. & 0.01 & 72.31 & 27.60 & 0.09 \\
\hline s126-pl-1-2 & 99.95 & 50.56 & 3.42 & 0.06 & 0.00 & 0.31 & 31.09 & 0.04 & 14.46 & n.d. & n.d. & 0.02 & 69.78 & 29.89 & 0.33 \\
\hline s126-pl-8-1 & 99.92 & 51.09 & 3.58 & 0.07 & 0.02 & 0.20 & 30.98 & n.d. & 13.97 & 0.01 & n.d. & n.d. & 68.08 & 31.53 & 0.39 \\
\hline s126-pl-8-2 & 99.82 & 51.04 & 3.47 & 0.05 & 0.01 & 0.21 & 30.86 & 0.01 & 14.17 & n.d. & n.d. & n.d. & 69.14 & 30.58 & 0.29 \\
\hline s126-pl-2-1 & 99.64 & 49.11 & 2.75 & 0.05 & 0.03 & 0.15 & 31.99 & 0.04 & 15.48 & 0.03 & 0.03 & n.d. & 75.48 & 24.26 & 0.26 \\
\hline s126-pl-2-2 & 99.94 & 49.33 & 2.82 & 0.03 & n.d. & 0.21 & 31.91 & 0.03 & 15.55 & 0.04 & n.d. & 0.01 & 75.14 & 24.66 & 0.20 \\
\hline s26-pl-11-1 & 98.49 & 49.46 & 3.38 & 0.03 & n.d. & 0.21 & 30.99 & 0.01 & 14.38 & 0.01 & n.d. & n.d. & 70.00 & 29.80 & 0.20 \\
\hline s26-pl-11-2 & 98.37 & 50.35 & 3.71 & 0.04 & 0.06 & 0.21 & 30.36 & 0.02 & 13.55 & n.d. & 0.01 & 0.07 & 66.67 & 33.07 & 0.25 \\
\hline s26-pl-14-2 & 98.31 & 51.13 & 4.22 & 0.06 & 0.06 & 0.35 & 29.53 & 0.10 & 12.86 & 0.01 & n.d. & n.d. & 62.53 & 37.15 & 0.32 \\
\hline s26-pl-14-3 & 98.23 & 51.57 & 4.43 & 0.03 & 0.08 & 0.11 & 29.28 & n.d. & 12.72 & 0.01 & n.d. & n.d. & 61.20 & 38.62 & 0.18 \\
\hline sR2-ion-p2-1 & 99.17 & 56.54 & 6.74 & 0.10 & 0.02 & 0.15 & 26.68 & n.d. & 8.88 & n.d. & 0.03 & 0.05 & 41.90 & 57.56 & 0.54 \\
\hline sR2-ion-p2-2 & 99.47 & 56.91 & 6.64 & 0.10 & 0.05 & 0.15 & 26.46 & 0.03 & 9.01 & n.d. & 0.03 & 0.09 & 42.61 & 56.84 & 0.55 \\
\hline sR2-ion-p2-3 & 100.30 & 57.26 & 6.94 & 0.07 & 0.07 & 0.13 & 26.66 & 0.02 & 9.04 & 0.01 & 0.04 & 0.06 & 41.70 & 57.89 & 0.41 \\
\hline sR2-ion-p3-1 & 99.01 & 56.66 & 6.71 & 0.06 & 0.02 & 0.21 & 26.56 & 0.02 & 8.76 & 0.01 & 0.00 & n.d. & 41.76 & 57.88 & 0.35 \\
\hline sR2-ion-p3-2 & 99.46 & 56.56 & 6.84 & 0.07 & 0.06 & 0.16 & 26.72 & 0.04 & 8.98 & n.d. & 0.03 & n.d. & 41.87 & 57.72 & 0.41 \\
\hline sR2-ion-p3-3 & 99.66 & 56.94 & 6.77 & 0.08 & 0.07 & 0.14 & 26.70 & 0.01 & 8.94 & n.d. & n.d. & n.d. & 41.99 & 57.55 & 0.47 \\
\hline sR2-ion-p1-1 & 99.65 & 56.87 & 6.92 & 0.09 & 0.02 & 0.13 & 26.64 & n.d. & 8.97 & n.d. & 0.01 & n.d. & 41.51 & 58.01 & 0.48 \\
\hline sR2-ion-p1-2 & 99.27 & 56.84 & 6.91 & 0.09 & 0.04 & 0.17 & 26.43 & 0.03 & 8.77 & n.d. & n.d. & n.d. & 40.99 & 58.52 & 0.49 \\
\hline sR2-ion-p1-3 & 99.80 & 56.84 & 6.96 & 0.09 & 0.03 & 0.14 & 26.80 & n.d. & 8.89 & 0.06 & n.d. & n.d. & 41.19 & 58.34 & 0.47 \\
\hline sR2-ion-p4-1 & 99.26 & 57.13 & 6.87 & 0.07 & 0.02 & 0.14 & 26.30 & 0.02 & 8.71 & n.d. & n.d. & n.d. & 41.03 & 58.58 & 0.38 \\
\hline sR2-ion-p4-2 & 99.43 & 57.11 & 6.90 & 0.09 & 0.09 & 0.08 & 26.52 & n.d. & 8.63 & n.d. & 0.02 & n.d. & 40.66 & 58.85 & 0.49 \\
\hline sR2-ion-p4-3 & 99.48 & 57.05 & 7.00 & 0.12 & 0.05 & 0.05 & 26.43 & 0.02 & 8.71 & 0.06 & n.d. & n.d. & 40.66 & 58.85 & 0.49 \\
\hline s65a-pl-17-1 & 99.24 & 54.14 & 5.08 & 0.08 & 0.04 & 0.22 & 28.37 & 0.03 & 11.26 & n.d. & n.d. & 0.02 & 54.78 & 44.77 & 0.46 \\
\hline s65a-pl-17-2 & 99.06 & 54.15 & 5.28 & 0.05 & 0.10 & 0.30 & 27.95 & 0.03 & 11.14 & n.d. & 0.06 & 0.01 & 53.66 & 46.05 & 0.30 \\
\hline s65a-pl-18-1 & 98.92 & 54.45 & 5.32 & 0.06 & 0.06 & 0.27 & 27.91 & 0.02 & 10.82 & n.d. & 0.01 & n.d. & 52.72 & 46.94 & 0.34 \\
\hline s65a-pl-18-2 & 99.41 & 54.65 & 5.35 & 0.11 & 0.02 & 0.29 & 28.01 & 0.11 & 10.84 & 0.00 & 0.03 & 0.01 & 52.52 & 46.88 & 0.60 \\
\hline s65a-pl-12-1 & 99.42 & 54.87 & 5.33 & 0.08 & 0.06 & 0.29 & 27.95 & 0.04 & 10.79 & n.d. & 0.02 & n.d. & 52.55 & 47.00 & 0.45 \\
\hline s65a-pl-12-2 & 99.09 & 54.51 & 5.40 & 0.07 & 0.06 & 0.22 & 27.94 & 0.01 & 10.86 & 0.01 & n.d. & 0.01 & 52.40 & 47.19 & 0.41 \\
\hline s65a-pl-16-1 & 98.66 & 54.85 & 6.13 & 0.07 & 0.04 & 0.21 & 27.97 & 0.03 & 9.31 & n.d. & 0.03 & 0.01 & 45.45 & 54.14 & 0.41 \\
\hline s65a-pl-16-2 & 99.31 & 53.83 & 5.05 & 0.06 & 0.08 & 0.28 & 28.24 & 0.03 & 11.74 & n.d. & n.d. & n.d. & 56.06 & 43.61 & 0.33 \\
\hline s65a-pl-19-1 & 99.27 & 53.51 & 5.08 & 0.06 & 0.10 & 0.29 & 28.41 & 0.05 & 11.74 & n.d. & n.d. & 0.03 & 55.91 & 43.77 & 0.32 \\
\hline s65a-pl-19-2 & 99.04 & 53.57 & 4.91 & 0.09 & 0.07 & 0.35 & 28.32 & 0.04 & 11.66 & n.d. & 0.04 & n.d. & 56.46 & 43.05 & 0.49 \\
\hline s65a-pl-20-1 & 98.96 & 53.56 & 4.88 & 0.07 & 0.10 & 0.24 & 28.32 & 0.04 & 11.70 & n.d. & 0.02 & 0.01 & 56.76 & 42.84 & 0.40 \\
\hline s65a-pl-20-2 & 99.32 & 53.41 & 4.91 & 0.09 & 0.07 & 0.64 & 28.64 & 0.05 & 11.52 & n.d. & n.d. & n.d. & 56.16 & 43.33 & 0.51 \\
\hline s65-pl-9-01 & 98.69 & 52.79 & 4.84 & 0.07 & 0.02 & 0.22 & 28.82 & 0.02 & 11.84 & 0.02 & n.d. & 0.05 & 57.26 & 42.34 & 0.40 \\
\hline s65-pl-9-02 & 99.11 & 52.84 & 4.76 & 0.05 & 0.07 & 0.28 & 28.87 & 0.02 & 12.17 & 0.06 & n.d. & n.d. & 58.39 & 41.32 & 0.29 \\
\hline s65-pl-9-3 & 98.64 & 52.51 & 4.95 & 0.07 & 0.09 & 0.23 & 28.80 & 0.02 & 11.91 & 0.00 & 0.02 & 0.04 & 56.84 & 42.76 & 0.40 \\
\hline s65-pl-9-4 & 98.76 & 54.05 & 5.19 & 0.06 & 0.05 & 0.26 & 28.16 & 0.01 & 10.95 & 0.04 & n.d. & n.d. & 53.64 & 46.03 & 0.33 \\
\hline s65-pl-9-5 & 98.27 & 53.73 & 5.17 & 0.05 & 0.04 & 0.22 & 27.96 & 0.01 & 11.01 & 0.02 & 0.03 & 0.04 & 53.86 & 45.85 & 0.29 \\
\hline s1-ion-p1-1 & 97.92 & 53.47 & 5.41 & 0.07 & 0.03 & 0.23 & 27.95 & 0.01 & 10.71 & 0.04 & n.d. & n.d. & 52.03 & 47.54 & 0.43 \\
\hline s1-ion-p1-2 & 97.47 & 52.84 & 5.32 & 0.07 & 0.01 & 0.29 & 27.99 & 0.01 & 10.91 & n.d. & 0.01 & 0.02 & 52.89 & 46.69 & 0.42 \\
\hline s1-ion-p1-3 & 97.52 & 53.12 & 5.32 & 0.03 & 0.05 & 0.19 & 27.91 & 0.02 & 10.83 & n.d. & 0.03 & 0.02 & 52.87 & 46.97 & 0.15 \\
\hline s1-ion-p2-1 & 97.42 & 52.29 & 4.96 & 0.05 & 0.00 & 0.28 & 28.64 & 0.04 & 11.12 & 0.04 & n.d. & n.d. & 55.19 & 44.52 & 0.29 \\
\hline s1-ion-p2-2 & 97.41 & 52.67 & 5.14 & 0.07 & 0.08 & 0.17 & 28.32 & 0.00 & 10.95 & 0.02 & n.d. & n.d. & 53.84 & 45.76 & 0.41 \\
\hline s1-ion-p3-1 & 97.96 & 53.02 & 4.95 & 0.07 & 0.02 & 0.23 & 28.20 & 0.04 & 11.39 & n.d. & 0.03 & n.d. & 55.74 & 43.84 & 0.41 \\
\hline s1-ion-p3-2 & 97.99 & 53.46 & 5.05 & 0.05 & 0.06 & 0.32 & 27.91 & 0.18 & 10.96 & n.d. & n.d. & n.d. & 54.35 & 45.34 & 0.30 \\
\hline s1-ion-p4-1 & 98.94 & 54.10 & 5.40 & 0.08 & 0.00 & 0.28 & 28.27 & 0.02 & 10.69 & n.d. & 0.04 & 0.07 & 52.00 & 47.56 & 0.44 \\
\hline s1-ion-p4-2 & 99.21 & 54.39 & 5.41 & 0.03 & 0.04 & 0.33 & 28.19 & 0.00 & 10.70 & 0.03 & 0.06 & 0.03 & 52.12 & 47.69 & 0.19 \\
\hline s95-pl-1-01 & 98.37 & 52.66 & 4.92 & 0.08 & 0.01 & 0.27 & 28.63 & 0.06 & 11.70 & 0.03 & 0.01 & n.d. & 56.50 & 43.03 & 0.47 \\
\hline s95-pl-1-02 & 98.95 & 54.07 & 5.40 & 0.08 & 0.07 & 0.25 & 28.01 & 0.02 & 11.02 & n.d. & 0.03 & n.d. & 52.78 & 46.75 & 0.48 \\
\hline s95-pl-1-03 & 98.98 & 53.02 & 5.03 & 0.08 & 0.05 & 0.20 & 28.71 & 0.04 & 11.80 & n.d. & 0.04 & 0.01 & 56.21 & 43.33 & 0.46 \\
\hline s28a-pl-6-1 & 99.14 & 55.67 & 6.25 & 0.12 & 0.13 & 0.81 & 26.70 & 0.03 & 9.40 & n.d. & 0.03 & n.d. & 45.10 & 54.24 & 0.66 \\
\hline s28a-pl-6-2 & 99.13 & 56.29 & 6.09 & 0.14 & 0.02 & 0.22 & 26.84 & 0.01 & 9.51 & n.d. & 0.02 & n.d. & 45.94 & 53.26 & 0.80 \\
\hline s28a-pl-6-3 & 98.71 & 55.93 & 6.21 & 0.11 & 0.07 & 0.27 & 26.63 & 0.04 & 9.39 & 0.04 & n.d. & 0.02 & 45.22 & 54.16 & 0.62 \\
\hline s28a-pl-8-1 & 98.79 & 56.14 & 6.10 & 0.12 & 0.05 & 0.20 & 26.76 & 0.01 & 9.36 & n.d. & 0.01 & 0.05 & 45.60 & 53.73 & 0.67 \\
\hline s28a-pl-8-2 & 98.90 & 55.73 & 6.24 & 0.11 & 0.03 & 0.32 & 26.76 & 0.01 & 9.64 & 0.00 & 0.07 & n.d. & 45.75 & 53.66 & 0.59 \\
\hline s28a-pl-8-3 & 98.93 & 55.79 & 6.06 & 0.10 & 0.00 & 0.21 & 27.12 & n.d. & 9.58 & 0.03 & n.d. & 0.04 & 46.35 & 53.10 & 0.56 \\
\hline s69-pl-6-1 & 98.46 & 53.49 & 5.24 & 0.12 & 0.15 & 0.35 & 28.07 & 0.04 & $\begin{array}{l}5.30 \\
10.98\end{array}$ & 0.02 & n.d. & n.d. & 53.31 & 46.02 & 0.67 \\
\hline s69-pl-6-2 & 98.23 & 53.40 & 5.33 & 0.09 & 0.12 & 0.28 & 27.88 & 0.02 & 11.04 & 0.04 & n.d. & 0.03 & 53.09 & 46.39 & 0.52 \\
\hline s69-pl-6-3 & 98.43 & 54.11 & 5.44 & 0.10 & 0.01 & 0.29 & 27.75 & 0.02 & 10.72 & n.d. & n.d. & n.d. & 51.84 & 47.61 & 0.54 \\
\hline s69-pl-6-4 & 98.52 & 54.78 & 5.67 & 0.13 & 0.00 & 0.30 & 27.38 & 0.02 & 10.24 & n.d. & n.d. & n.d. & 49.54 & 49.70 & 0.76 \\
\hline s69-pl-6-5 & 97.99 & 53.77 & 5.37 & 0.12 & 0.01 & 0.28 & 27.68 & 0.03 & 10.70 & n.d. & 0.01 & 0.01 & 52.05 & 47.25 & 0.70 \\
\hline s71-pl-02 & 98.13 & 53.08 & 5.26 & 0.05 & 0.05 & 0.23 & 28.21 & 0.03 & 11.16 & n.d. & n.d. & 0.07 & 53.85 & 45.88 & 0.28 \\
\hline s71-pl-04 & 98.93 & 53.40 & 5.25 & 0.03 & 0.08 & 0.23 & 28.53 & n.d. & 11.32 & 0.05 & n.d. & 0.06 & 54.30 & 45.55 & 0.15 \\
\hline s71-pl-05 & 98.21 & 53.16 & 5.18 & 0.03 & 0.00 & 0.24 & 28.13 & 0.01 & 11.40 & 0.06 & n.d. & n.d. & 54.79 & 45.02 & 0.19 \\
\hline s117-pl-9-01 & 98.28 & 53.69 & 5.12 & 0.09 & 0.03 & 0.33 & 27.81 & 0.02 & 11.08 & 0.11 & n.d. & n.d. & 54.17 & 45.30 & 0.53 \\
\hline s117-pl-9-02 & 98.24 & 55.07 & 5.77 & 0.11 & 0.03 & 0.17 & 27.03 & 0.00 & 10.04 & n.d. & 0.02 & n.d. & 48.71 & 50.66 & 0.63 \\
\hline s117-pl-9-03 & 99.19 & 55.82 & 5.94 & 0.09 & n.d. & 0.36 & 26.97 & 0.03 & 9.91 & 0.03 & 0.05 & n.d. & 47.74 & 51.77 & 0.49 \\
\hline s117-pl-7-01 & 98.72 & 54.25 & 5.40 & 0.10 & 0.04 & 0.3 & 27.78 & 0.0 & 10.79 & n.d. & n.d. & n.d. & 52.15 & 47.25 & 0.60 \\
\hline s117-pl-7-02 & 98. & 53.62 & 5.2 & 0.08 & 0.05 & 0.3 & 27.91 & 0. & 11.20 & n.d. & n.d. & 0.04 & 54.07 & 45.47 & 0.46 \\
\hline s117-pl-7-03 & 98.54 & 54.69 & 5.56 & 0.09 & 0.07 & 0.20 & 27.32 & 0.02 & 10.51 & 0.07 & n.d. & n.d. & 50.82 & 48.69 & 0.49 \\
\hline sR4-pl-1-1 & 99.29 & 53.59 & 4.99 & 0.05 & 0.04 & 0.18 & 28.50 & 0.02 & 11.91 & 0.02 & n.d. & n.d. & 56.72 & 43.01 & 0.27 \\
\hline sR4-pl-1-2 & 99.38 & 54.05 & 5.16 & 0.02 & 0.09 & 0.19 & 28.49 & 0.03 & 11.34 & n.d. & 0.02 & n.d. & 54.77 & 45.14 & 0.09 \\
\hline
\end{tabular}

Note : n.d. $=$ not detected, the ODP sample descriptor related to the given sample numbers are listed in Table 2.1 . 
Table AT1 (continued)

\begin{tabular}{|c|c|c|c|c|c|c|c|c|c|c|c|c|c|c|c|}
\hline Comment & Total & $\mathrm{SiO}_{2}$ & $\mathrm{Na}_{2} \mathrm{O}$ & $\mathrm{K}_{2} \mathrm{O}$ & $\mathrm{TiO}_{2}$ & $\mathrm{FeO}$ & $\mathrm{Al}_{2} \mathrm{O}_{3}$ & $\mathrm{MgO}$ & $\mathrm{CaO}$ & $\mathrm{Cr}_{2} \mathrm{O}_{3}$ & $\mathrm{MnO}$ & $\mathrm{NiO}$ & An & $A b$ & Or \\
\hline s31-pl-1-1 & 98.99 & 52.89 & 4.69 & 0.06 & 0.08 & 0.42 & 28.59 & 0.02 & 12.20 & n.d. & 0.04 & n.d. & 58.78 & 40.86 & 0.36 \\
\hline s31-pl-1-2 & 99.23 & 52.82 & 4.55 & 0.06 & 0.06 & 0.51 & 28.93 & 0.22 & 12.05 & n.d. & 0.04 & n.d. & 59.20 & 40.47 & 0.33 \\
\hline s31-pl-1-3 & 98.66 & 52.87 & 4.83 & 0.05 & 0.08 & 0.49 & 28.53 & 0.01 & 11.79 & 0.01 & n.d. & n.d. & 57.29 & 42.42 & 0.29 \\
\hline s31-pl-3-1 & 98.44 & 52.16 & 4.37 & 0.04 & 0.02 & 0.39 & 28.95 & 0.06 & 12.42 & 0.03 & n.d. & n.d. & 60.97 & 38.80 & 0.23 \\
\hline s31-pl-3-2 & 98.82 & 52.03 & 4.23 & 0.04 & 0.05 & 0.40 & 29.29 & 0.06 & 12.69 & 0.01 & n.d. & 0.02 & 62.21 & 37.58 & 0.21 \\
\hline s31-pl-3-3 & 98.76 & 52.37 & 4.41 & 0.05 & 0.08 & 0.42 & 28.82 & 0.05 & 12.45 & 0.07 & 0.02 & 0.02 & 60.76 & 38.93 & 0.31 \\
\hline s49a-pl-1-1 & 98.69 & 52.30 & 4.67 & 0.08 & 0.12 & 0.42 & 28.95 & 0.03 & 12.10 & 0.01 & 0.01 & 0.00 & 58.61 & 40.92 & 0.47 \\
\hline s49a-pl-1-2 & 97.77 & 51.88 & 4.75 & 0.09 & 0.09 & 0.33 & 28.73 & 0.02 & 11.79 & n.d. & 0.06 & 0.03 & 57.55 & 41.94 & 0.51 \\
\hline s49a-pl-1-3 & 99.23 & 54.12 & 5.14 & 0.11 & 0.06 & 0.35 & 28.21 & 0.02 & 11.15 & 0.02 & n.d. & 0.05 & 54.21 & 45.18 & 0.62 \\
\hline s49a-pl-1-4 & 98.75 & 53.64 & 5.25 & 0.10 & 0.03 & 0.26 & 28.32 & 0.03 & 11.11 & 0.01 & n.d. & n.d. & 53.61 & 45.83 & 0.56 \\
\hline s49a-pl-1-5 & 98.84 & 52.75 & 4.72 & 0.07 & n.d. & 0.30 & 29.00 & 0.03 & 11.98 & n.d. & n.d. & n.d. & 58.15 & 41.44 & 0.41 \\
\hline s16-pl-15-1 & 99.40 & 51.34 & 3.89 & 0.03 & n.d. & 0.13 & 30.54 & 0.02 & 13.44 & n.d. & 0.02 & n.d. & 65.51 & 34.33 & 0.15 \\
\hline s16-pl-15-2 & 99.34 & 51.25 & 3.94 & 0.03 & 0.04 & 0.15 & 30.31 & 0.02 & 13.59 & n.d. & n.d. & 0.02 & 65.47 & 34.37 & 0.16 \\
\hline s16-pl-16-1 & 99.03 & 49.84 & 3.43 & 0.02 & 0.09 & 0.20 & 30.80 & 0.05 & 14.59 & 0.02 & n.d. & n.d. & 70.09 & 29.78 & 0.13 \\
\hline s16-pl-16-2 & 99.30 & 50.33 & 3.38 & 0.02 & 0.02 & 0.18 & 30.98 & 0.03 & 14.33 & 0.02 & 0.01 & n.d. & 69.97 & 29.90 & 0.13 \\
\hline s16-pl-19-1 & 99.26 & 51.06 & 3.97 & 0.03 & 0.02 & 0.17 & 30.22 & 0.02 & 13.77 & n.d. & 0.01 & n.d. & 65.59 & 34.23 & 0.18 \\
\hline s16-pl-19-2 & 99.57 & 51.27 & 3.92 & 0.05 & 0.06 & 0.20 & 30.37 & 0.04 & 13.65 & 0.00 & n.d. & 0.03 & 65.64 & 34.10 & 0.26 \\
\hline s5-pl-6-01 & 98.87 & 51.94 & 4.49 & 0.06 & 0.07 & 0.40 & 29.20 & 0.01 & 12.59 & 0.04 & 0.05 & n.d. & 60.56 & 39.08 & 0.36 \\
\hline s5-pl-6-02 & 98.54 & 52.21 & 4.56 & 0.06 & 0.03 & 0.37 & 28.92 & 0.00 & 12.34 & n.d. & 0.05 & n.d. & 59.72 & 39.95 & 0.33 \\
\hline s5-pl-6-03 & 98.51 & 52.23 & 4.59 & 0.06 & 0.03 & 0.46 & 28.79 & 0.04 & 12.32 & n.d. & n.d. & n.d. & 59.56 & 40.12 & 0.32 \\
\hline s5-pl-8-01 & 98.64 & 52.50 & 4.61 & 0.07 & 0.03 & 0.42 & 28.88 & 0.00 & 12.11 & 0.03 & n.d. & n.d. & 58.97 & 40.65 & 0.38 \\
\hline s5-pl-8-02 & 98.36 & 52.64 & 4.73 & 0.06 & 0.08 & 0.31 & 28.56 & 0.02 & 11.97 & n.d. & n.d. & n.d. & 58.10 & 41.58 & 0.32 \\
\hline s5-pl-8-03 & 98.51 & 52.65 & 4.96 & 0.07 & 0.09 & 0.28 & 28.48 & 0.04 & 11.85 & 0.05 & 0.05 & n.d. & 56.67 & 42.94 & 0.39 \\
\hline s17-pl-13-1 & 99.36 & 52.72 & 4.48 & 0.07 & 0.03 & 0.54 & 29.04 & 0.21 & 12.24 & n.d. & 0.02 & n.d. & 59.91 & 39.69 & 0.40 \\
\hline s17-pl-13-2 & 100.09 & 53.08 & 4.58 & 0.05 & 0.09 & 0.40 & 29.37 & 0.04 & 12.45 & n.d. & 0.03 & n.d. & 59.83 & 39.87 & 0.30 \\
\hline s17-pl-16-1 & 99.70 & 53.13 & 4.68 & 0.05 & 0.06 & 0.28 & 29.22 & 0.04 & 12.22 & 0.02 & n.d. & n.d. & 58.92 & 40.81 & 0.27 \\
\hline s17-pl-16-2 & 99.17 & 53.29 & 4.54 & 0.07 & 0.06 & 0.28 & 28.73 & 0.02 & 12.18 & n.d. & n.d. & n.d. & 59.47 & 40.14 & 0.39 \\
\hline s17-pl-18-1 & 99.88 & 53.25 & 4.70 & 0.08 & 0.01 & 0.22 & 29.11 & 0.04 & 12.43 & 0.03 & n.d. & 0.02 & 59.10 & 40.46 & 0.44 \\
\hline s17-pl-18-2 & 99.46 & 53.06 & 4.71 & 0.06 & 0.02 & 0.24 & 29.00 & 0.05 & 12.29 & n.d. & 0.02 & 0.02 & 58.86 & 40.79 & 0.35 \\
\hline s55-pl-6-1 & 99.37 & 53.06 & 4.71 & 0.05 & 0.08 & 0.36 & 29.00 & 0.05 & 12.07 & n.d. & n.d. & n.d. & 58.46 & 41.25 & 0.28 \\
\hline s55-pl-6-2 & 99.88 & 52.87 & 4.65 & 0.06 & 0.08 & 0.37 & 29.25 & 0.07 & 12.46 & n.d. & 0.04 & 0.04 & 59.50 & 40.19 & 0.32 \\
\hline s55-pl-9-1 & 99.76 & 50.96 & 3.70 & 0.04 & n.d. & 0.47 & 30.53 & 0.07 & 13.97 & 0.03 & n.d. & n.d. & 67.44 & 32.35 & 0.21 \\
\hline s55-pl-9-2 & 99.32 & 53.32 & 4.72 & 0.05 & 0.06 & 0.63 & 28.50 & 0.41 & 11.60 & n.d. & 0.03 & n.d. & 57.39 & 42.31 & 0.30 \\
\hline s55-pl-19-1 & 99.90 & 53.09 & 4.50 & 0.04 & 0.09 & 0.42 & 29.23 & 0.06 & 12.41 & n.d. & 0.04 & 0.01 & 60.21 & 39.53 & 0.26 \\
\hline s55-pl-19-2 & 99.68 & 53.10 & 4.51 & 0.06 & 0.06 & 0.35 & 29.16 & 0.06 & 12.38 & 0.01 & 0.01 & n.d. & 60.09 & 39.57 & 0.34 \\
\hline s55-pl-20-1 & 99.76 & 53.19 & 4.58 & 0.08 & 0.10 & 0.35 & 29.10 & 0.03 & 12.28 & 0.02 & 0.04 & n.d. & 59.41 & 40.14 & 0.45 \\
\hline s55-pl-20-2 & 99.85 & 53.24 & 4.54 & 0.06 & 0.08 & 0.35 & 29.12 & 0.01 & 12.45 & n.d. & n.d. & n.d. & 60.06 & 39.61 & 0.33 \\
\hline s32-ion-p1-1 & 98.88 & 52.81 & 4.93 & 0.07 & 0.03 & 0.30 & 28.70 & 0.04 & 12.00 & n.d. & n.d. & 0.01 & 57.12 & 42.50 & 0.38 \\
\hline s32-ion-p1-2 & 98.80 & 52.37 & 4.95 & 0.07 & 0.01 & 0.28 & 28.83 & 0.04 & 12.20 & n.d. & 0.02 & n.d. & 57.40 & 42.19 & 0.41 \\
\hline s32-ion-p3-1 & 98.64 & 52.04 & 4.94 & 0.08 & 0.09 & 0.29 & 28.74 & 0.06 & 12.40 & n.d. & n.d. & n.d. & 57.86 & 41.72 & 0.43 \\
\hline s32-ion-p3-2 & 99.28 & 52.61 & 4.87 & 0.05 & n.d. & 0.28 & 29.08 & 0.05 & 12.29 & 0.04 & 0.02 & n.d. & 58.05 & 41.67 & 0.28 \\
\hline s32-ion-p2-1 & 98.76 & 52.86 & 5.07 & 0.05 & 0.07 & 0.27 & 28.44 & 0.03 & 11.96 & n.d. & n.d. & 0.01 & 56.45 & 43.28 & 0.27 \\
\hline s32-ion-p2-2 & 99.17 & 52.60 & 4.97 & 0.06 & 0.07 & 0.25 & 28.82 & 0.03 & 12.26 & 0.07 & 0.01 & 0.03 & 57.47 & 42.19 & 0.34 \\
\hline s32-ion-p4-1 & 99.06 & 52.66 & 5.19 & 0.07 & 0.01 & 0.40 & 28.69 & 0.05 & 11.96 & n.d. & 0.03 & n.d. & 55.78 & 43.83 & 0.39 \\
\hline s32-ion-p4-2 & 99.65 & 53.48 & 5.00 & 0.05 & 0.03 & 0.33 & 28.57 & 0.08 & 11.96 & 0.04 & 0.05 & 0.05 & 56.78 & 42.93 & 0.29 \\
\hline s32-ion-p5-1 & 99.10 & 52.62 & 5.19 & 0.05 & 0.10 & 0.30 & 28.71 & 0.03 & 12.05 & 0.06 & 0.00 & n.d. & 56.07 & 43.66 & 0.27 \\
\hline s32-ion-p5-2 & 99.22 & 53.15 & 5.15 & 0.04 & 0.08 & 0.47 & 28.38 & 0.05 & 11.87 & 0.01 & 0.02 & n.d. & 55.91 & 43.89 & 0.20 \\
\hline s32-ion-p7-1 & 98.94 & 53.24 & 5.16 & 0.08 & 0.07 & 0.20 & 28.52 & 0.02 & 11.58 & 0.05 & 0.03 & n.d. & 55.10 & 44.43 & 0.46 \\
\hline s32-ion-p7-2 & 99.32 & 53.49 & 5.16 & 0.08 & 0.09 & 0.24 & 28.46 & 0.03 & 11.70 & 0.06 & 0.01 & 0.00 & 55.35 & 44.22 & 0.43 \\
\hline s24-ion-p4-1 & 98.93 & 53.01 & 4.87 & 0.06 & 0.00 & 0.25 & 28.88 & 0.04 & 11.71 & 0.07 & 0.05 & n.d. & 56.86 & 42.80 & 0.34 \\
\hline s24-ion-p4-2 & 99.15 & 52.98 & 4.87 & 0.03 & 0.12 & 0.32 & 28.92 & 0.05 & 11.81 & n.d. & n.d. & 0.05 & 57.16 & 42.66 & 0.18 \\
\hline s24-ion-p4-3 & 99.01 & 53.01 & 5.02 & 0.03 & 0.08 & 0.23 & 28.82 & 0.01 & 11.76 & 0.05 & n.d. & 0.00 & 56.33 & 43.50 & 0.16 \\
\hline s24-ion-p2-1 & 99.48 & 53.39 & 5.19 & 0.03 & 0.03 & 0.24 & 28.83 & 0.02 & 11.75 & n.d. & n.d. & n.d. & 55.49 & 44.32 & 0.19 \\
\hline s24-ion-p2-2 & 98.91 & 53.19 & 5.02 & 0.04 & 0.04 & 0.30 & 28.63 & 0.03 & 11.65 & 0.01 & n.d. & n.d. & 56.07 & 43.71 & 0.22 \\
\hline s24-ion-p2-3 & 99.22 & 53.25 & 5.15 & 0.05 & 0.09 & 0.30 & 28.67 & 0.05 & 11.61 & 0.02 & 0.01 & 0.02 & 55.29 & 44.42 & 0.29 \\
\hline s24-ion-p3-1 & 99.78 & 53.77 & 5.07 & 0.07 & 0.1 & 0.31 & 28.77 & n.d. & 11.66 & 0.01 & 0.00 & n.d. & 55.74 & 43.88 & 0.38 \\
\hline s24-ion-p3-2 & 98.68 & 52.92 & 5.05 & 0.04 & 0.08 & 0.26 & 28.81 & 0.01 & 11.50 & 0.00 & 0.00 & 0.01 & 55.59 & 44.17 & 0.24 \\
\hline s24-ion-p3-3 & 99.36 & 53.33 & 5.15 & 0.07 & 0.05 & 0.29 & 28.70 & 0.02 & 11.68 & 0.02 & 0.02 & 0.04 & 55.39 & 44.20 & 0.41 \\
\hline s24-ion-p5-1 & 99.42 & 53.51 & 5.22 & 0.06 & 0.08 & 0.21 & 28.80 & 0.03 & 11.47 & 0.01 & 0.03 & 0.01 & 54.63 & 45.03 & 0.34 \\
\hline s24-ion-p5-2 & 99.12 & 52.94 & 5.08 & 0.05 & 0.11 & 0.41 & 28.76 & 0.06 & 11.68 & 0.04 & n.d. & n.d. & 55.83 & 43.90 & 0.26 \\
\hline s24-ion-p5-3 & 99.47 & 53.30 & 5.01 & 0.05 & 0.10 & 0.32 & 28.86 & 0.03 & 11.74 & 0.03 & 0.04 & n.d. & 56.28 & 43.44 & 0.28 \\
\hline s24-ion-p1-1 & 99.12 & 52.62 & 4.75 & 0.05 & 0.10 & 0.47 & 28.88 & 0.04 & 12.07 & 0.02 & 0.05 & 0.06 & 58.23 & 41.46 & 0.30 \\
\hline s24-ion-p1-2 & 99.36 & 52.70 & 4.88 & 0.06 & 0.04 & 0.35 & 29.01 & 0.06 & 12.21 & n.d. & 0.01 & 0.05 & 57.85 & 41.80 & 0.35 \\
\hline s24-ion-p1-3 & 99.18 & 53.23 & 5.01 & 0.03 & 0.10 & 0.27 & 28.71 & 0.06 & 11.72 & n.d. & 0.02 & 0.02 & 56.32 & 43.52 & 0.16 \\
\hline
\end{tabular}


Table AT2 Oxygen isotope compositions of the component minerals in Hole 735B (Leg 176) gabbros.

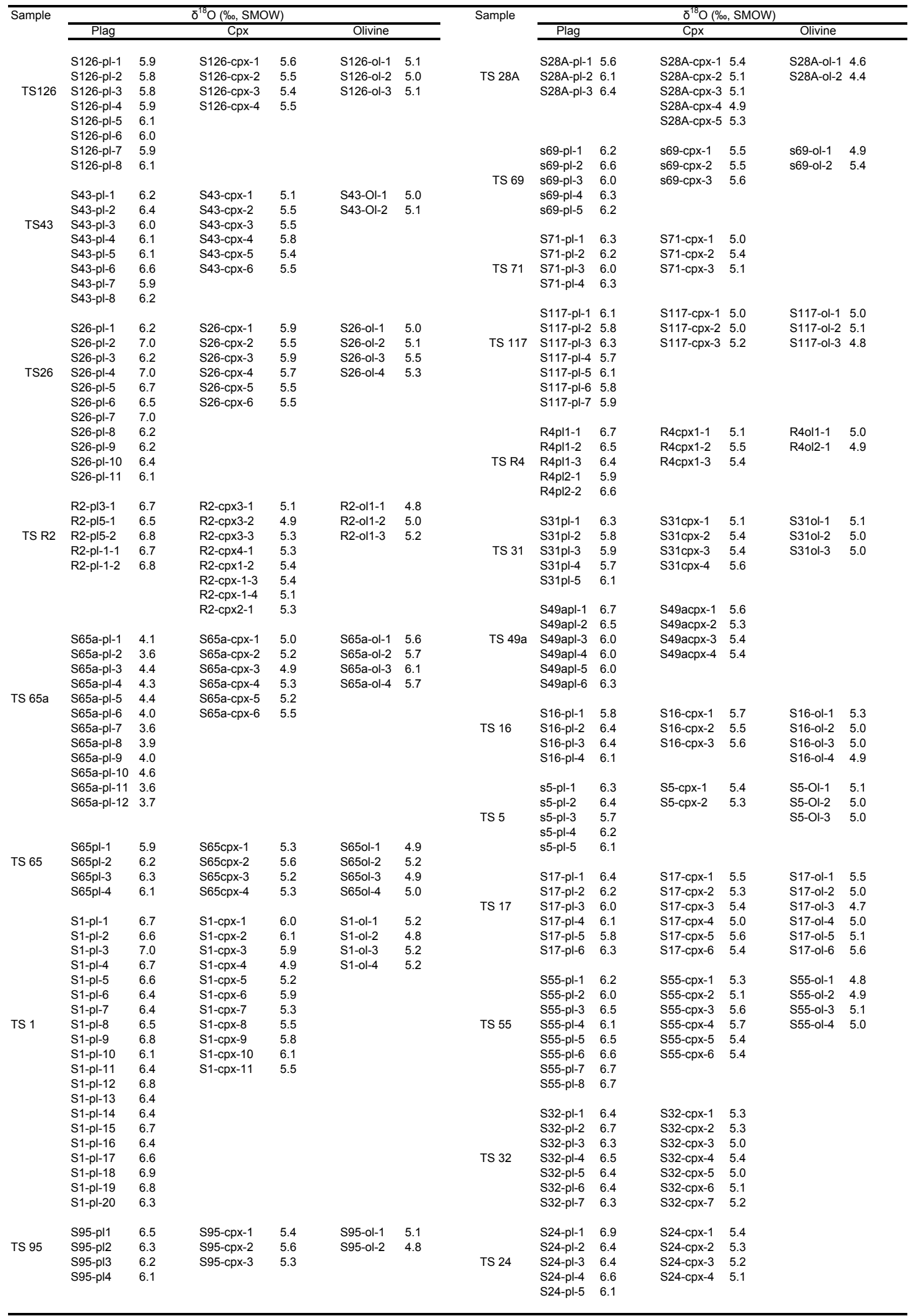

Note: ODP sample descriptors related to the TS number are given in Table 2.1. 


\section{LEBENSLAUF}

$\begin{array}{ll}\text { Name: } & \text { Yongjun Gao } \\ \text { Geburtstag: } & \text { 06. November } 1973 \\ \text { Geburtsort: } & \text { HeBei, VR China } \\ \text { Nationalität: } & \text { Chinesisch } \\ \text { Familienstand: } & \text { Verheiratet } \\ \text { Anschrift: } & \text { Petrikirchstr. 12/58 } \\ & \begin{array}{l}\text { D-37077 Göttingen } \\ \text { Tel: 0551/5036856 }\end{array}\end{array}$

Schulzeit: $\quad 1980$ bis 1985 Grundschule ZaoLin

1985 bis 1988 Mittelschule LiuJie

1988 bis 1992 HouYi Gymnasium

Studium: $\quad 1992$ bis 1996 Bachelor - Marine Geology

Ocean University of Qing Dao, Qing Dao

Diploma: June 1996

1996 bis 1999 Master- Geochemistry

Peking University, Beijing

Diploma: July, 1999

August 1999 bis Dezember 2000 Vorbereitung

Promotions-Studium

Peking University

Promotion: $\quad$ Dezember 2000 bis Juni 2004 Georg-August- Universität Göttingen Daimler-Benz Stipendium: 12/2000-12/2001

DFG Projekt im Schwerpunktprogramm International Ocean Drilling Program ,,180-in-situ Microanalysis of minerals from Hole 735B lower crustal section“"(Ho 375/21) 